Published in final edited form as:

Nat Rev Methods Primers. 2021 ; 1: . doi:10.1038/s43586-020-00002-1.

\title{
Solid-state NMR spectroscopy
}

\section{Bernd Reif ${ }^{1}$, Sharon E. Ashbrook ${ }^{2}$, Lyndon Emsley ${ }^{3}$, Mei Hong ${ }^{4}{ }^{*}$}

${ }^{1}$ Technische Universität München, Department Chemie, Lichtenbergstr. 4, D-85747 Garching, Germany ${ }^{2}$ School of Chemistry, University of St Andrews, North Haugh, St Andrews, KY16 9ST, UK ${ }^{3}$ École Polytechnique Fédérale de Lausanne (EPFL), Institut des sciences et ingénierie chimiques, $\mathrm{CH}-1015$ Lausanne, Switzerland ${ }^{4}$ Department of Chemistry and Francis Bitter Magnet Laboratory, Massachusetts Institute of Technology, 170 Albany Street, Cambridge, MA 02139

\section{Abstract}

Solid-state nuclear magnetic resonance (NMR) spectroscopy is an atomic-level method used to determine the chemical structure, three-dimensional structure, and dynamics of solids and semisolids. This Primer summarizes the basic principles of NMR as applied to the wide range of solid systems. The fundamental nuclear spin interactions and the effects of magnetic fields and radiofrequency pulses on nuclear spins are the same as in liquid-state NMR. However, because of the anisotropy of the interactions in the solid state, the majority of high-resolution solid-state NMR spectra is measured under magic-angle spinning (MAS), which has profound effects on the types of radiofrequency pulse sequences required to extract structural and dynamical information. We describe the most common MAS NMR experiments and data analysis approaches for investigating biological macromolecules, organic materials, and inorganic solids. Continuing development of sensitivity-enhancement approaches, including ${ }^{1} \mathrm{H}$-detected fast MAS experiments, dynamic nuclear polarization, and experiments tailored to ultrahigh magnetic fields, is described. We highlight recent applications of solid-state NMR to biological and materials chemistry. The Primer ends with a discussion of current limitations of NMR to study solids, and points to future avenues of development to further enhance the capabilities of this sophisticated spectroscopy for new applications.

*Corresponding email: meihong@ mit.edu.

Author contributions.

Introduction (B.R., S.E.A., L.E., and M.H.); Experimentation (B.R., S.E.A., L.E., and M.H.); Results (B.R., S.E.A., L.E., and M.H.); Applications (B.R., S.E.A., L.E., and M.H.); Reproducibility and data deposition (B.R., S.E.A., L.E., and M.H.); Limitations and optimizations (B.R., S.E.A., L.E., and M.H.); Outlook (B.R., S.E.A., L.E., and M.H.); Overview of the Primer (M.H.).

Competing Interests

There are no competing interests for all authors.

Related Links

Protein data bank (PDB): https://www.rcsb.org/

Biological Magnetic Resonance Bank (BRMB) (https://bmrb.io/)

Inorganic Crystal Structure Database (ICSD): https://icsd.products.fiz-karlsruhe.de

Cambridge Structural Database (CSD): https://www.ccdc.cam.ac.uk/solutions/csd-system/components/csd/ 


\section{Introduction}

NMR spectroscopy probes the atomic-level three-dimensional (3D) arrangement and motion of molecules and materials. Nuclear magnetic resonance is the oscillatory response of nuclei with non-zero spins in a magnetic field to resonant excitation by radiofrequency (RF) irradiation. When atoms containing non-zero nuclear spins (Table 1) are placed in an external magnetic field, the degeneracy of the nuclear spin states is lifted, with an energy difference $\Delta E$ given by equation (1).

$$
\Delta E=\gamma \hbar(1-\sigma) B_{0}
$$

Here, $\gamma$ is the gyromagnetic ratio, a fundamental property associated with each isotope; $B_{0}$ is the strength of the static magnetic field; and $\sigma$ is the chemical shielding around a nucleus. Transitions can then be induced by electromagnetic irradiation between these nuclear-spin states (Fig. 1) ${ }^{1}$. With typical magnetic fields of 5-28 Tesla used in NMR today, the transition frequencies lie in the RF regime of the electromagnetic spectrum (213-1200 MHz ${ }^{1} \mathrm{H}$ Larmor frequencies). The NMR transition frequencies are sensitive to the electron distribution around the nucleus, which shields the nucleus from the applied magnetic field. The shielding constant, $\sigma$, varies for different nuclei of a given isotope in a molecule, causing slightly different frequencies. Thus, NMR frequencies directly report on the chemical structure of the sample ${ }^{2,3}$. NMR frequencies are commonly reported as the chemical shift, $\delta$, which is the fractional difference between the frequency of a particular nucleus and a standard compound such as trimethylsilane. For a given isotope, chemical shift differences can range from 10 parts-per-million (ppm) for ${ }^{1} \mathrm{H}$ to $200 \mathrm{ppm}$ for ${ }^{13} \mathrm{C}$ to $1000 \mathrm{ppm}$ for ${ }^{17} \mathrm{O}$. In addition to chemical shifts, NMR frequencies are modified by a series of couplings: spin-spin scalar couplings, which depend on covalent bonding and which are typically in the $0-1 \mathrm{kHz}$ range; spin-spin dipolar couplings, which depend on internuclear distances and are typically in the $0-20 \mathrm{kHz}$ range; and for nuclear spins greater than $1 / 2$, quadrupolar couplings between the electric field gradient at the nucleus and the charge distribution of the nucleus, which range from $100 \mathrm{kHz}$ to tens of MHz. All these NMR interactions are anisotropic, that is they depend on the sample orientation relative to the magnetic field direction. Because of these orientation-dependent chemical shifts, internuclear couplings, and quadrupolar couplings, NMR spectra encode three-dimensional structural information. Molecular rotations partially average these anisotropic interactions, thus, measurement of motionally averaged NMR spectra and motionally induced nuclear spin relaxation reveal the geometries and rates of motion.

The RF regime of the electromagnetic spectrum is orders of magnitude lower in frequency than the microwave, infrared, and ultraviolet frequencies employed in rotational, vibrational, and electronic spectroscopies. The low NMR frequencies mean that the energy levels of nuclear spins are nearly equally populated at room temperature, according to the Boltzmann distribution in equation (2).

$$
\frac{N_{+}}{N_{-}}=e^{-\Delta E / k T}=e^{-\gamma \hbar(1-\sigma) B_{0} / k T}
$$


For example, at room temperature in a $10 \mathrm{~T}$ magnetic field, the population of the ground state $\left(N_{+}\right)$is in excess to that of the upper state $\left(N_{-}\right)$by only 1 in 10000 . This small population difference leads to intrinsically weak NMR signals and hence low signal-to-noise ratios in the spectra. These weak signals put stringent constraints on NMR sample volumes, methods of detection, and instrumentation. Much of the development of modern NMR spectroscopy has focused on increasing sensitivity. One approach is to use higher magnetic fields to increase $\Delta E$, which has been very successful, but this is limited by both technology and cost. Another approach is to record NMR spectra in the time domain following an RF pulse, and obtain the spectrum by Fourier transformation (FT) rather than by sweeping the frequency and measuring absorption or emission as in classical spectroscopy ${ }^{1,4}$. With pulsed FT NMR, one can sum the time-domain signals of many acquisitions to increase the signal-to-noise ratio of the NMR spectra. The introduction of pulsed FT NMR yielded an order of magnitude increase in sensitivity and opened the avenue to multi-dimensional NMR. Further background for these fundamental aspects of modern NMR spectroscopy is outside the scope of this article, and the reader is referred to many excellent introductory textbooks such as the texts by Keeler ${ }^{4}$ and Levitt ${ }^{1}$. The small frequencies of NMR, although causing low sensitivity, give the important advantages that NMR experiments are non-destructive, and nuclear spin coherence times can be very long (up to seconds). This long coherence time permits the study of slow molecular motions and the design of sophisticated trains of RF pulses, whose exact timing and phases can be controlled to extract highly specific structural and dynamical information.

The application of NMR to rigid or semi-rigid solid samples spans an inexhaustible variety of systems, from membrane proteins and amyloid fibrils in biochemistry, to polymers, battery materials, photovoltaic perovskites, and cements in chemistry and materials sciences. In solids, the orientation dependence of NMR frequencies causes powder patterns for each nuclear spin. In most cases, this anisotropic contribution needs to be removed to obtain siteresolved spectra. This is accomplished by magic-angle spinning (MAS), where samples are physically spun around an axis that is tilted by $54.7^{\circ}$ from the static magnetic field (Fig. 1c) 5,6 . This angle results from the fact that the anisotropy of NMR interactions is given by a second rank tensor, whose time average vanishes at $54.7^{\circ}$. Today, MAS rates of $5 \mathrm{kHz}$ to 100 $\mathrm{kHz}$ are conducted using cylindrical rotors with diameters between $7 \mathrm{~mm}$ and $0.7 \mathrm{~mm}$. Faster MAS averages out the stronger anisotropic interactions. Currently, the vast majority of solid-state NMR experiments are carried out under MAS. Because MAS averages out the information-rich anisotropic chemical shift and dipolar interactions, many RF pulse sequences have been designed to selectively reintroduce the desired spin interactions while retaining spectral resolution, Such multi-pulse and multi-dimensional experiments are the basis of many modern solid-state NMR experiments ${ }^{2,7}$.

Modern NMR spectra are obtained from Fourier transformation of the time-domain responses of the nuclear spins to RF pulses. In the simplest case, a single pulse is followed by acquisition of a time-domain signal that decays back to equilibrium in microseconds to seconds. However, multiple pulses can be applied sequentially in so-called pulse sequences, whose timings can be adapted to precisely control the dynamics of the nuclear spins (Experimentation). 1,2,7 These pulse sequences can be designed so as to average out certain 
inter-nuclear interactions, and retain only others. They can be combined and recorded in a multi-dimensional fashion through almost unlimited combinations. As a result, multidimensional NMR spectroscopy can be tailored and adapted to a given chemical system to yield precise information about inter-atomic interactions that cannot be discerned from other techniques such as diffraction and microscopy. The detailed design of multi-pulse multidimensional NMR experiments is outside the scope of this Primer, and is treated elsewhere 2,7 . By understanding the nuclei whose frequencies are being correlated and the mechanism of correlation, whether through bond(s) or through space, users can readily apply these robust multidimensional correlation NMR experiments to obtain information about chemical structure and three-dimensional structure.

The interpretation of NMR spectra can be less intuitive than microscopy or diffraction data, because structural information is encoded in frequency spectra rather than spatial density maps. The frequency peaks need to be assigned to individual atoms, which can be a significant challenge. However, the multitude of peaks in NMR spectra represents an exquisite chemical fingerprint of molecules, thus making NMR the eye of chemists. The shifts and couplings in the NMR spectra also contain three-dimensional structure and dynamics information, thus revealing the mechanisms of action of a variety of biological and chemical systems.

This Primer describes the most common solid-state NMR experiments with their accompanying pulse sequences (Experimentation). We discuss how solid-state NMR spectra and data can be interpreted (Results). We highlight recent applications of solid-state NMR to biomolecular and materials chemistry (Applications). This is followed by a description of common guidelines for data sharing, reproducibility, and reporting standards (Reproducibility and data deposition), and a discussion of the current limitations of solidstate NMR as well as areas of active advances (Limitations and optimizations). Finally, we look into the future of solid-state NMR spectroscopy and point out new and exciting areas of potential applications (Outlook).

\section{Experimentation}

In the following we discuss the key steps involved in carrying out a solid-state NMR experiment. Specifically, this involves sample preparation, setup, acquisition of NMR spectra, spectral assignment, and the choice and implementation of experiments to measure structural or dynamic parameters. The experimental choices are tailored to the systems of interest, whether they are biomolecules, inorganic solids, or if the samples are paramagnetic, and are further guided by sensitivity considerations.

\section{Sample preparation and isotopic enrichment}

Many solid-state NMR spectra are recorded on un-modified samples at natural isotopic abundance. A major advantage of NMR is the ability to analyze samples in their native states, including powders, pastes, gels, fibrils, and membranes, all of which do not have to be crystalline. 
Samples are directly packed or centrifuged into the sample holders, which for MAS experiments are usually airtight and watertight ceramic rotors, so that air-sensitive and hydrated samples can be studied. The rotors are standard sized cylinders that typically have $7,4,3.2,2.5,1.3$ or $0.7 \mathrm{~mm}$ outer diameters, which are filled with between $500 \mathrm{mg}$ (for 7 $\mathrm{mm}$ ) and $1 \mathrm{mg}$ (for $0.7 \mathrm{~mm}$ ) of sample. Small rotors are used for higher MAS speeds ( 100 $\mathrm{kHz}$ for $0.7 \mathrm{~mm})$ as compared to the larger rotors $(\sim 5 \mathrm{kHz}$ for $7 \mathrm{~mm})$.

Depending on the nature of the sample, isotopic enrichment can be paramount for obtaining high spectral sensitivity as many NMR-sensitive nuclei occur at low natural abundance (Table 1). A variety of ${ }^{13} \mathrm{C}$ and ${ }^{15} \mathrm{~N}$-enriched biological compounds such as amino acids and sugars are commercially available. Proteins can be uniformly or site-specifically ${ }^{13} \mathrm{C},{ }^{15} \mathrm{~N}$ enriched using such precursors during recombinant bacterial expression ${ }^{8-10}$. Proteins can also be perdeuterated and back-exchanged with protonated solvent to allow ${ }^{1} \mathrm{H}$-detected fast MAS experiments for studying structure and ${ }^{2} \mathrm{H}$ NMR experiments for studying dynamics. In addition to enhancing spectral sensitivity, isotopic enrichment distinguishes the molecule of interest from the unlabeled matrix. For example, ${ }^{13} \mathrm{C},{ }^{15} \mathrm{~N}$-labeled membrane proteins can be distinguished from unlabeled phospholipids, and ${ }^{13} \mathrm{C},{ }^{15} \mathrm{~N}$-labeled amyloid proteins can be distinguished from unlabeled brain tissues ${ }^{11}$.

In materials chemistry, ${ }^{29} \mathrm{Si}$ is commonly enriched using tetraethyl orthosilicate, while ${ }^{17} \mathrm{O}$ is commonly enriched using gaseous ${ }^{17} \mathrm{O}_{2}$ and liquid $\mathrm{H}_{2}{ }^{17} \mathrm{O}^{12}$. The high cost of ${ }^{17} \mathrm{O}$-enriched reagents has motivated the development of more efficient synthetic approaches such as hightemperature exchange with oxygen gas, ionothermal synthesis ${ }^{12}$, dry gel conversion reactions, small-scale hydrolysis and mechanochemistry.

\section{D and 2D correlation NMR}

NMR spectroscopists apply multiple RF pulses with specific timings, phases, and amplitudes (Fig. 2) to manipulate the nuclear magnetic moments in order to obtain the structural information of interest. The first experiment for analyzing most samples is a onedimensional MAS experiment involving either direct excitation of the nuclear spin or cross polarization (CP) from protons (CPMAS shown in Fig. 2a) ${ }^{6,13}$. CPMAS is the workhorse experiment for ${ }^{1} \mathrm{H}$-rich organic compounds because it enhances the signal sensitivity of a rare and low- $\gamma$ nucleus $\mathrm{X}$ by transferring magnetization from the abundant and high- $\gamma$ protons. ${ }^{1} \mathrm{H}$ decoupling (Box 1) is applied during X-nucleus (any nucleus other than ${ }^{1} \mathrm{H}$ ) acquisition detection to enhance spectral resolution. 1D CPMAS spectra show one peak for each chemically distinct site. At moderate MAS rates (less than $20 \mathrm{kHz}$ ), sites with large chemical shift anisotropies (CSA) exhibit spinning sidebands, whose intensities can be fitted to extract the principal values of the CSA tensor ${ }^{3,14}$. At conventional MAS rates (up to about $50 \mathrm{kHz}$ ), ${ }^{1} \mathrm{H}$ solid-state NMR spectra of organic compounds cannot be directly detected due to the line broadening caused by multi-spin ${ }^{1} \mathrm{H}-{ }^{1} \mathrm{H}$ dipolar couplings. Instead, they can be measured in the indirect dimension of $2 \mathrm{D}$ correlation spectra by applying ${ }^{1} \mathrm{H}_{-}^{1} \mathrm{H}$ homonuclear decoupling sequences ${ }^{15-18}$ At ultrafast MAS rates of $\sim 100 \mathrm{kHz}$, the ${ }^{1} \mathrm{H}$ linewidths narrow sufficiently that high-resolution ${ }^{1} \mathrm{H}$ spectra can be measured directly ${ }^{19}$.

A core strength of NMR spectroscopy is the ability to produce versatile and structurally informative multidimensional correlation spectra. In materials chemistry, the most widely 
used 2D solid-state NMR experiment is heteronuclear chemical shift correlation (HETCOR), shown in Fig. $2 \mathrm{~b}$, particularly involving ${ }^{1} \mathrm{H}$. The correlation is mediated by either throughbond $J$ coupling or through-space dipolar coupling (Box 1). ${ }^{1} \mathrm{H}$ correlation to ${ }^{13} \mathrm{C},{ }^{29} \mathrm{Si},{ }^{31} \mathrm{P}$ and other nuclei have been widely applied. HETCOR experiments can also be conducted for non-proton spins, provided that the NMR probe can be tuned to the two frequencies of interest.

Homonuclear 2D correlation NMR spectra also contain rich information. When both dimensions encode isotropic chemical shifts, which are referred to as single-quantum shifts, the spectra report conformational dynamics, chemical exchange, and spatial proximities (Fig. 2c) ${ }^{20}$. Homonuclear 2D NMR spectra can also be measured by correlating the singlequantum chemical shifts of each nucleus with the sum chemical shift of two nuclei, which are manifested by a double-quantum coherence between the two spins (Fig. 2d). This incredible-natural-abundance double-quantum transfer experiment (INADEQUATE) sequence ${ }^{21}$ adapted for spinning solids ${ }^{22}$ has been applied to many nuclei such as ${ }^{13} \mathrm{C},{ }^{31} \mathrm{P}$, and ${ }^{29} \mathrm{Si}$ to determine, for example, the structure of pharmaceutical compounds, ${ }^{23}$ network structures in phosphates ${ }^{24}$, and structure distributions in materials such as cellulose ${ }^{25}$.

A third class of 2D NMR experiments correlates an anisotropic interaction such as CSA and dipolar coupling with the isotropic chemical shift. The anisotropic interaction is usually recoupled under MAS by rotor-synchronized pulses. Dipolar recoupling (Box 1) is the basis of many modern solid-state NMR experiments ${ }^{26}$. Anisotropic interactions can also be measured by switching the rotor axis away from the magic angle ${ }^{27,28}$. This variable-angle spinning approach is now less common due to its requirement of specialized probes.

Unlike spin-1/2 nuclei, solid-state NMR spectra of quadrupolar nuclei (spin >1/2) are usually $\mathrm{MHz}$ wide because of the large size of quadrupolar interactions. ${ }^{29,30}$ This quadrupolar broadening is inversely proportional to the magnetic field strength, thus high magnetic field is advantageous for obtaining high-resolution spectra of quadrupolar nuclei ${ }^{31}$. MAS removes quadrupolar broadening to first order; but significant sidebands remain at moderate spinning rates. Moreover, when the quadrupolar interaction is large, its effect needs to be considered to second order, which cannot be averaged by MAS due to additional higher-order angular dependence. The most common method for removing the quadrupolar broadening is the multiple-quantum MAS (MQMAS) experiment ${ }^{32}$, which correlates different transitions within the spin system and yields an isotropic spectrum from the projection onto the indirect dimension, as shown in Fig. 2e. When the quadrupolar broadening is too large even for MQMAS to overcome, 1D "wideline" NMR spectra are measured for static samples (for example, with no sample rotation) as a series of sub-spectra ${ }^{33}$, each measured with different frequency offsets to yield an undistorted lineshape.

Unlike most half-integer quadrupolar nuclei, ${ }^{2} \mathrm{H}$ is a spin-1 nucleus whose NMR spectra are relatively simple to measure because of the small quadrupolar coupling constant ( $200 \mathrm{kHz})$ and the relative ease of deuteration. Both static and MAS ${ }^{2} \mathrm{H}$ NMR spectra can be measured using the two-pulse quadrupolar echo sequence. ${ }^{2} \mathrm{H}$ NMR spectra are commonly measured in specifically deuterated systems as a function of temperature to extract the geometry, rates and energetics of molecular motion. Static ${ }^{2} \mathrm{H}$ NMR has been widely applied to study 
polymer dynamics ${ }^{2,34}$ and lipid membrane dynamics. ${ }^{35}$, For the latter, acyl chain order parameters can be quantified in the absence and presence of proteins using chainperdeuterated lipids ${ }^{36,37}$. Recently, indirectly ${ }^{13} \mathrm{C}$ and ${ }^{15} \mathrm{~N}$-detected ${ }^{2} \mathrm{H}$ MAS NMR experiments have been developed to study uniformly labeled proteins and carbohydrates to determine molecular motion in a site-resolved and multiplexed manner ${ }^{38-40}$.

\section{D correlation NMR}

For ${ }^{13} \mathrm{C},{ }^{15} \mathrm{~N}$-labeled proteins, sets of $2 \mathrm{D}$ and $3 \mathrm{D}$ correlation experiments are now established for measuring the ${ }^{13} \mathrm{C}$ and ${ }^{15} \mathrm{~N}$ chemical shifts and assigning them to specific amino acid residues. For resonance assignment of small proteins $(<20 \mathrm{kDa})$ with high structural homogeneity, $2 \mathrm{D}{ }^{13} \mathrm{C}-{ }^{13} \mathrm{C}$ and ${ }^{15} \mathrm{~N}-{ }^{13} \mathrm{C}$ correlation spectra are usually measured first to serve as fingerprints of the protein conformation. Three $3 \mathrm{D}^{15} \mathrm{~N}-{ }^{13} \mathrm{C}$ correlation experiments, intra-residue NCACX, inter-residue NCOCX, and inter-residue CONCA, are then conducted to obtain sequence-specific assignment (for correlation patterns measured, see Fig. 3a). ${ }^{41}$ For larger proteins, low spectral sensitivity limits the applicability of these ${ }^{13} \mathrm{C}$-detected 3D experiments, thus ${ }^{1} \mathrm{H}$-detected $3 \mathrm{D}$ experiments are increasingly used instead. These ${ }^{1} \mathrm{H}$-detected experiments are usually conducted on perdeuterated proteins for MAS rates of less than $60 \mathrm{kHz}$ and protonated proteins for MAS rates of $100 \mathrm{kHz}$ or above. Perdeuteration reduces the ${ }^{1} \mathrm{H}$ density while $100 \mathrm{kHz}$ MAS yields highly efficient averaging of the ${ }^{1} \mathrm{H}-{ }^{1} \mathrm{H}$ dipolar couplings, both yielding high-resolution ${ }^{1} \mathrm{H}$ spectra. These ${ }^{1} \mathrm{H}$-detected NMR experiments use either $J$ couplings or dipolar couplings to achieve spin polarization transfer. ${ }^{42,4319}$ The long coherence lifetimes at the fastest MAS rates make certain $J$-based polarization transfer steps the most efficient ${ }^{44-46}$. Higher-dimensional (4D, 5D) experiments have also been proposed that employ automated projection spectroscopy ${ }^{47}$ and non-uniform sampling 48,49 to produce peak lists from lower-order spectra ${ }^{50}$, and enable semi-automated resonance assignment ${ }^{51-53}$.

\section{Distance measurement}

Inter-atomic distances (through space) can be measured in NMR through the effect of spinspin dipolar couplings. Qualitative inter-proton or inter-carbon distance restraints can be obtained from cross-peak intensities in spin-diffusion mediated multidimensional correlation spectra. Weak and strong cross peaks indicate long and short distances, respectively. ${ }^{54} \mathrm{In}$ biomolecules, ${ }^{1} \mathrm{H}-{ }^{1} \mathrm{H}$ or ${ }^{13} \mathrm{C}_{-}{ }^{13} \mathrm{C}$ distances are commonly measured via $2 \mathrm{D}{ }^{13} \mathrm{C}_{-}{ }^{13} \mathrm{C}$ or ${ }^{13} \mathrm{C}-{ }^{15} \mathrm{~N}$ planes in $3 \mathrm{D}$ correlation spectra and are used to derive short, medium and long distance restraints. ${ }^{55,5644}$ This yields distance restraints on the order of $<7 \AA$ for ${ }^{13} \mathrm{C}-{ }^{13} \mathrm{C}{ }^{55}$, $<13 \AA$ for ${ }^{1} \mathrm{H}_{-}{ }^{1} \mathrm{H}^{57}$, and $<16 \AA$ for ${ }^{19} \mathrm{~F}_{-}{ }^{19} \mathrm{~F}^{58}$ distances.

Heteronuclear distances can be measured more precisely using rotational-echo doubleresonance (REDOR) (Fig. 2f) ${ }^{59}$, which is one of the most versatile and robust techniques in solid-state NMR. The experiment uses a train of $180^{\circ}$ pulses spaced half a rotor period apart to re-introduce heteronuclear dipolar couplings that would otherwise be eliminated by MAS. There are many variants of the experiment, but usually, two experiments, with (S) and without $\left(\mathrm{S}_{0}\right) 180^{\circ}$ pulses on the unobserved channel are conducted, and the resulting intensities are divided $\left(\mathrm{S} / \mathrm{S}_{0}\right)$ to yield relaxation-free dipolar dephasing curves. These dephasing curves have a universal shape regardless of the coupling strengths, and differ only 
in the modulation time. REDOR has been applied to a large number of spin pairs ${ }^{60}$ such as ${ }^{13} \mathrm{C}-{ }^{15} \mathrm{~N},{ }^{61}{ }^{13} \mathrm{C}_{-}{ }^{31} \mathrm{P}{ }^{62}$, and ${ }^{13} \mathrm{C}-{ }^{19} \mathrm{~F}{ }^{63,64}$ in organic compounds, and ${ }^{27} \mathrm{Al}-{ }^{31} \mathrm{P},{ }^{27} \mathrm{Al}-{ }^{1} \mathrm{H}^{65}$ or ${ }^{17} \mathrm{O}-{ }^{1} \mathrm{H}^{66}$ in inorganic compounds.

Nuclear spin dipolar couplings depend not only on internuclear distances but also on the $\gamma$ of the spins. High- $\gamma$ nuclei give stronger dipolar couplings, thus their distances are easier to measure. REDOR between the high- $\gamma{ }^{19} \mathrm{~F}$ and other nuclei such as ${ }^{13} \mathrm{C}$ and ${ }^{1} \mathrm{H}$ has recently been extended to high-field fast MAS conditions, and are incorporated into 2D experiments to obtain many nanometer-range distances rapidly ${ }^{67,68}$. Similarly, $2 \mathrm{D}{ }^{19} \mathrm{~F}-{ }^{19} \mathrm{~F}$ correlation spectra under fast MAS have been developed to obtain cross peaks indicative of distances up to $\sim 2 \mathrm{~nm}{ }^{58,69-71}$.

\section{Studying molecular motion}

Solid-state NMR is ideally suited to characterize the amplitudes and rates of molecular motions ${ }^{72}$. Typically experiments will be sensitive to slow (milliseconds to seconds), intermediate (microseconds to milliseconds) or fast (picoseconds to microseconds) dynamics. The anisotropic nuclear spin interactions are averaged by intermediate to fast motion, which, in the simplest case of dipolar couplings, depends on the geometry of the motion relative to the internuclear vector. The most traditional methods for measuring geometry and rates of motion in these intermediate and fast regimes is through lineshape analysis of $1 \mathrm{D}^{2} \mathrm{H}$ or ${ }^{13} \mathrm{C}$ static or slow MAS spectra measured as a function of temperature. This typically provides very accurate information about the geometry of motion, and for intermediate motions can yield precise activation energies ${ }^{73,74}$. However, this approach is limited by low sensitivity and low throughput and requires site-specific isotopic labeling.

A robust and higher-sensitivity approach for measuring amplitudes of intermediate and fast motion in multi-site systems where selective labelling is not feasible is the 2D dipolar chemical-shift correlation (DIPSHIFT) experiment (Fig. 2g) ${ }^{75-77}$. This experiment separates heteronuclear dipolar couplings such as ${ }^{13} \mathrm{C}-{ }^{1} \mathrm{H}$ and ${ }^{15} \mathrm{~N}-{ }^{1} \mathrm{H}$ couplings by isotropic chemical shifts. Motional averaging of the dipolar couplings is manifested as reduced splittings in the frequency spectra. ${ }^{78-80}$. The motional geometry can also be measured using REDOR-recoupled ${ }^{13} \mathrm{C}-{ }^{15} \mathrm{~N}$ dipolar couplings ${ }^{81,82}$. Measurement of motional amplitudes is sensitive to RF field inhomogeneity and the presence of remote nuclei. To reduce these imperfections, off-MAS experiments, with angle offsets as small as $0.03^{\circ}$, have been proposed ${ }^{83}$. At $100 \mathrm{kHz}$ MAS, variable-contact-time $\mathrm{CP}$ can be used to measure motionally averaged dipolar couplings ${ }^{84}$. For millisecond-timescale motions, the CODEX technique 85,86 is especially robust (Fig. $2 \mathrm{~h}$ ), provided that spin diffusion, the relayed transfer of spin polarization through dipolar coupling, does not occur on the same timescale.

Fast molecular motions can be characterized using NMR relaxation measurements ${ }^{72}$. To determine dynamic models, longitudinal relaxation rates 87,88 and rotating-frame relaxation rates ${ }^{89-91}$ can be measured to probe pico- to micro-second timescale motions. Here, care has to be taken to avoid spin diffusion, which can average relaxation rates between neighboring sites, especially when fast relaxing methyl groups are present ${ }^{92,93}$. 


\section{High temperature and pressure}

Today, high-temperature (above $1600 \mathrm{~K}$ ) NMR experiments can be conducted for static samples. ${ }^{94}$ For MAS, recent approaches use laser heating, where optical fibers transport the laser to a sample in a ceramic insert within a bottomless rotor ${ }^{94}$. Commercial systems able to heat to $\sim 1000 \mathrm{~K}$ are now available for 7 or $4 \mathrm{~mm}$ MAS rotors. For high pressures, progress has been made for static samples using diamond anvil cells and Lenz lenses to overcome sensitivity limitations. Experiments up to $90 \mathrm{GPa}$ are now feasible. ${ }^{95} \mathrm{High}-$ pressure MAS experiments have been performed using sealed rotors and inserts, and a recent design has achieved pressures of $0.04 \mathrm{GPa} .{ }^{96}$

\section{Dynamic nuclear polarization experiments}

The intrinsic nuclear spin polarization in NMR is low because of the relatively small size of the nuclear $\gamma$. At magnetic fields of $9.4-18.8 \mathrm{~T}$, the ${ }^{1} \mathrm{H}$ spin polarization is less than $0.007 \%$ at ambient temperature. To increase the polarization, one approach is to transfer unpaired electron spin polarization to nuclei, since the electron $\gamma$ is 658 -fold greater than the proton $\gamma$. Dynamic nuclear polarization (DNP) is the electron-to-nuclear spin polarization transfer induced by microwave irradiation of the electron paramagnetic resonance. Proposed in the 1950s 97,98 DNP has been successfully integrated into high-field MAS NMR systems since $2008^{99,100}$. The most common microwave source for high-field DNP today is the gyrotron, a microwave oscillator that outputs 10-100 watts of power at common NMR frequencies 101. Gyrotrons are now available up to $593 \mathrm{GHz}$, corresponding to a ${ }^{1} \mathrm{H}$ Larmor frequency of $900 \mathrm{MHz}$, with MAS rates up to $65 \mathrm{kHz}$, thus covering essentially the full range of magnetic fields and MAS frequencies. DNP NMR has fueled intense research on how to increase the spectral sensitivity of samples from frozen solutions to membrane proteins. In materials research, sensitivity enhancements of two orders of magnitude are now routinely achieved for solid-state NMR spectra of a range of technologically relevant materials ${ }^{102,103}$. Samples are wetted or impregnated with a solution containing a paramagnetic polarization source, such as the biradical AMUPol dissolved in a mixture of $\mathrm{D}_{2} \mathrm{O}, \mathrm{H}_{2} \mathrm{O}$ and glycerol or dimethylsulfoxide ${ }^{104}$, or the hydrophobic biradical TEKPol dissolved in 1,1,2,2tetrachloroethane ${ }^{105}$.

\section{Paramagnetic solid-state NMR}

In compounds containing paramagnetic centers such as metalloproteins, inorganic oxides, or organometallic compounds, the hyperfine interaction between the unpaired electron(s) and the nucleus causes large shifts in the NMR frequencies called contact and pseudocontact shifts 106,107 This unpaired electron-nucleus interaction also causes paramagnetic relaxation enhancement of the nuclear spin in a distance-dependent manner ${ }^{107,108}$. Both effects report atomic-level structure around the paramagnetic center. Experiments for measuring pseudocontact shifts and contact shifts are fundamentally no different from diamagnetic NMR, except for assignment of frequency-shifted resonances. Paramagnetic relaxation enhancement can be measured using regular relaxation NMR experiments after comparing with the relaxation rates of a diamagnetic sample. Paramagnetic ions such as $\mathrm{Mn}^{2+}$ and $\mathrm{Cu}^{2+}$ can be incorporated into samples as free ions ${ }^{109,110}$, part of a chemical tag 111,112 or a metalloprotein complex ${ }^{113}$ to serve as distance probes. In addition, paramagnetic doping 
combined with fast MAS speeds up data acquisition by 1-2 orders of magnitude by reducing nuclear spin relaxation times ${ }^{114}$.

\section{Results}

\section{Peak assignment of multidimensional spectra}

Chemical shift assignment is a prerequisite for extracting structural and dynamic information from NMR spectra. Small molecules and natural abundance compounds can often be assigned from 1D spectra based on characteristic chemical shifts alone. To simplify these 1D spectra, experiments that selectively detect $\mathrm{CH}, \mathrm{CH}_{2}$ or $\mathrm{CH}_{3}$ groups (sometimes called spectral editing experiments) are often used to aid assignment ${ }^{115-117}$. For proteins and other biopolymers, the large number of peaks can usually only be resolved and assigned in multidimensional correlation spectra. This assignment is based on connecting peaks that share a common chemical shift in a particular dimension of a $2 \mathrm{D}$ or $3 \mathrm{D}$ spectrum. For example, a $\mathrm{Ca}-\mathrm{C} \beta$ correlation peak and a $\mathrm{C} \gamma-\mathrm{C} \beta$ peak in a $2 \mathrm{D}^{13} \mathrm{C}-{ }^{13} \mathrm{C}$ spectrum will manifest the same $\mathrm{C} \beta$ chemical shift in the $\mathrm{F} 2$ dimension of the spectrum. For proteins, the NCACX spectrum correlates $\mathrm{N}, \mathrm{Ca}$ and $\mathrm{CO}$ chemical shifts within the same residue, while the NCOCX spectrum correlates the $\mathrm{N}$ chemical shift of a residue with the $\mathrm{CO}$ and $\mathrm{Ca}$ chemical shifts of the preceding residue ${ }^{118-120}$ (Fig. 3a). For ${ }^{1} \mathrm{H}$-detected 2D and 3D experiments such as the hNH experiment (Fig. 2i), the ${ }^{1} \mathrm{H}$ and ${ }^{15} \mathrm{~N}$ chemical shifts serve as the readout of the $\mathrm{Ca}$ and $\mathrm{CO}$ chemical shifts of two sequential residues ${ }^{19}$. A representative strip of ${ }^{1} \mathrm{H}$-detected 3D spectra of the Alzheimer's A $\beta$ peptide is shown in Fig. 3c.

\section{Distance measurements}

Qualitative distance restraints can be extracted from 2D and 3D correlation spectra based on the shortest mixing times when a peak appears. These restraints are typically reported as upper bounds, because peak intensities also depend on experimental conditions: cross peak intensities generally decrease with increasing $\mathrm{B}_{0}$, MAS rate, and spin diffusion mixing times. The upper-bound distance is usually calibrated using model compounds with known distances. For uniformly ${ }^{13} \mathrm{C}$-labeled proteins, on an $800 \mathrm{MHz}$ spectrometer under $10 \mathrm{kHz}$ MAS, cross peaks that appear after $100 \mathrm{~ms}, 250 \mathrm{~ms}$, and $500 \mathrm{~ms}$ spin diffusion have been estimated to correspond to ${ }^{13} \mathrm{C}-{ }^{13} \mathrm{C}$ distance upper limits of $6.0 \AA$, 7.0 $\AA$ and $8.0 \AA$, respectively ${ }^{55}$. Longer ${ }^{13} \mathrm{C}_{-}{ }^{13} \mathrm{C}$ distances can be probed qualitatively using ${ }^{1} \mathrm{H}$-mediated recoupling experiments such as phase-alternated rotation of magnetization (PAR) and pulsed proton-assisted recoupling (PULSAR) ${ }^{121,122}$. More quantitative ${ }^{13} \mathrm{C}-{ }^{13} \mathrm{C}$ distances can be measured using recoupling techniques such as finite-pulse radio-frequency-driven recoupling (fpRFDR) ${ }^{123}$.

Quantitative heteronuclear distances can be extracted from REDOR dipolar dephasing as a function of mixing time (Fig. 3d). The shape of the REDOR dephasing curve is invariant to the product of the dipolar coupling strength and mixing time. Thus short and long distances have the same universal curve ${ }^{59}$, which significantly facilitates distance analysis. Even at fast MAS rates of $\sim 40 \mathrm{kHz}$, where the $180^{\circ}$ pulses occupy a sizeable fraction of the rotor period, REDOR dephasing is still relatively quantitative, and the finite pulse-length effect can be treated analytically ${ }^{124}$. When the spins have large CSA and the $180^{\circ}$ pulses cause 
incomplete inversion, the imperfection can be accounted for in numerical simulations. This approach has been used to analyze ${ }^{13} \mathrm{C}-{ }^{19} \mathrm{~F}$ REDOR at moderately high magnetic fields where the ${ }^{19} \mathrm{~F} \mathrm{CSA}$ is large ${ }^{67}$.

Semi-quantitative long distances to $\sim 2 \mathrm{~nm}$ can also be measured effectively using paramagnetic relaxation enhancement NMR. ${ }^{15} \mathrm{~N}$ and ${ }^{1} \mathrm{H}$ relaxation experiments on $\mathrm{Cu}^{2+}$ and $\mathrm{Gd}^{3+}$ tagged proteins have been used to measure solvent accessibility to proteins ${ }^{112}$, $\mathrm{Cu}^{2+}$ binding sites in influenza M2 ${ }^{125}$, A $\beta 40$ fibrils ${ }^{110}$ and human prion protein fibrils ${ }^{126}$. Paramagnetic $\mathrm{Mn}^{2+}$ introduced to lipid bilayer surfaces have been used to measure the depth of insertion of membrane protein in lipid bilayers ${ }^{109,127}$.

\section{Motional amplitudes and rates}

Measurement of motionally averaged couplings and nuclear spin relaxation rates provide rich information about motional geometry and rates. For characterizing motional amplitudes, the DIPSHIFT class of experiments has been used extensively to obtain order parameters in membrane-bound helical bundles ${ }^{128,129}$, dynamically disordered polymers in biomaterials ${ }^{130}$, and functionally important sidechain motions in ion channels ${ }^{131}$. Longitudinal, rotating frame, cross relaxation rates and order parameters can be analyzed using a so-called "extended model-free" formalism, which yields correlation for fast and slow internal motions of the protein ${ }^{89,132,133}$. In the absence of overall tumbling, these relaxation data have allowed the studies of protein rocking motions in crystals 134135 . Temperaturedependent NMR relaxation data provide information about the energetics of molecular motion and have been used to demonstrate coupling between protein dynamics and solvent dynamics ${ }^{136}$. Relaxation data can also be analyzed in conjunction with molecular dynamics (MD) simulations to quantify motion, as shown for heterokaryon incompatibility proteins (HETs) amyloid fibrils ${ }^{137}$. Microsecond to millisecond peptide backbone dynamics can be observed through ${ }^{15} \mathrm{~N}$ rotating-frame relaxation dispersion experiments ${ }^{89}$, as shown for a variant of the human prion protein, Y145Stop ${ }^{138}$. Finally, ${ }^{1} \mathrm{H}$-detected fast MAS experiments combined with tailored isotopic labeling has allowed high-resolution characterization of both the amplitudes and rates of phenylalanine ring flips in the large $(\sim 0.5 \mathrm{MDa})$ enzyme complex, dodecameric aminopeptidase TET2 ${ }^{139}$.

In semi-crystalline polymers, the mobility of polymer chains in the crystalline region is directly related to the bulk mechanical properties of the materials. For example, poly(4methyl-1-pentene)(P4M1P), has a helical $7_{2}$ structure in crystallites in which chain defects travel by discrete rotation and translation around the helical axis that reproduce the original structure. The jump angles and activation energies can be determined quantitatively by NMR using CODEX experiments (Fig 3d ${ }^{85}$. These experiments revealed jump angles of $\sim 103^{\circ}$ and jump rates with correlation times between $10 \mathrm{~s}$ and $15 \mathrm{~ms}$ at 305 and $360 \mathrm{~K}$, respectively.

\section{Quadrupolar NMR spectra of solids}

The NMR spectra of quadrupolar nuclei display broad lineshapes and spinning sideband manifolds due to the large anisotropy. ${ }^{29,30,140}$ Fitting programs that minimize the difference between simulated and experimental spectra can be used to extract the magnitude, 
asymmetry and isotropic shift of the quadrupolar tensor. ${ }^{141,142}$ If a spin is affected by more than one interaction, the lineshape will also depend on the relative orientation of the interaction tensors. In some cases, the NMR parameters can be directly related to structure, while in others, chemical information is obtained by comparison to similar materials or to NMR parameters predicted by first-principle calculations.

The different dependence of the quadrupolar interaction and CSA on the magnetic field means that multi-field measurements are vital to structural analysis. ${ }^{33}$ MQMAS experiments resolve the signals of all species in the sample and the individual lineshapes of each species, as shown in Fig. 3f for ${ }^{17} \mathrm{O}$ NMR of a silicate mineral. ${ }^{143-146}$ The relative amounts of each species have to be corrected for the different excitation efficiencies by comparison to numerical simulations. From each MAS lineshape, the magnitude and asymmetry of the quadrupolar interaction and isotropic chemical shift can be extracted and used as starting points for multi-parameter fits of the complete spectrum. The position of the spectral lineshape in an MQMAS spectrum provide an alternative source of information on the quadrupolar and chemical shift parameters. For disordered materials such as glasses, information about structural distributions can be obtained from MAS or MQMAS spectra. 146 As the magnitude and asymmetry are both related to the principal components of the quadrupolar tensor, it is often assumed that a joint distribution of these parameters can be described using the Czjzek model. ${ }^{147}$ This is an area where isotropic-anisotropic correlation approaches such as dynamic-angle spinning ${ }^{28}$ can be highly informative, and have been used to extract correlations between quadrupolar parameters in densified silica glasses to gain insight into bond-length and bond-angle distributions ${ }^{148}$.

\section{Computation of NMR parameters}

Computational methods are increasingly used to support interpreting, assigning, and predicting the solid-state NMR spectra of materials. ${ }^{149,150}$ Density functional theory (DFT) is the method of choice, owing to its balance of efficiency and accuracy, with many studies carried out using periodic planewave codes ${ }^{151}$ to exploit the inherent translational symmetry of solids. Calculations determine the electronic structure for particular arrangement of atoms, and from this the shielding, quadrupolar and $J$ coupling tensors for any nucleus can be calculated. In the simplest cases, NMR parameters are predicted from structural models obtained from diffraction and matched to the experimental data. Calculations allow the assignment of signals in NMR spectra to specific sites (Fig. 3f), and can help identify overlapped or missing signals, helping the experimentalist to decide the best next experiments to try. The joint use of NMR and computation for structural analysis is often referred to as NMR crystallography. ${ }^{149,150}$

If less is known about the atomic structure of the solid, generating structural models is more challenging. When partial structures are available, possible structural models can be produced using automated algorithms, structure searching approaches or Monte Carlo methods, as demonstrated on proteins, ceramics, microporous materials, pharmaceuticals and glasses. ${ }^{150}$ Comparison of predicted and experimental parameters can then be used to refine the atomic coordinates ${ }^{152}$. When no prior information is available, powder 
crystallography of molecular solids involves the combination of de novo structure prediction, DFT calculation and measured chemical shifts ${ }^{153}$.

For disordered materials, calculations of manually modified models of ordered analogues predict the magnitude and direction of changes in the quadrupolar and/or shielding NMR parameters. These changes include variations in the type of atoms present (compositional disorder) or variations of the exact atomic arrangements (positional disorder). Multiple models can then be compared in terms of their energies and agreement with the measured NMR parameters. ${ }^{149,154}$ For amorphous materials such as glasses, the most successful approaches exploit MD simulations, with initial configurations generated using a random distribution of the specified number of atoms. ${ }^{155}$

\section{Applications}

\section{Protein structural biology}

X-ray crystallography and cryo-electron microscopy (cryoEM) can both provide atomic structures of large proteins and protein complexes. However, dynamically disordered or heterogeneous systems are not easily amenable to these approaches. As a result, membrane proteins that contain large soluble domains, polymorphic amyloid fibrils, or polydisperse protein complexes that are conformationally plastic for function, are uniquely suited to solid-state NMR analyses.

Membrane proteins-Multidimensional correlation ${ }^{13} \mathrm{C},{ }^{15} \mathrm{~N}$ and ${ }^{1} \mathrm{H}$ NMR has been applied to many membrane proteins to elucidate their structure, dynamics, and mechanism of action. These membrane proteins include proton channels ${ }^{128,156,157}$, potassium channels ${ }^{158-160}$, transporters ${ }^{161,162}$, seven-transmembrane-helix proteins ${ }^{163,164}, \beta$-barrel proteins ${ }^{165}$, and antibiotic membrane peptides ${ }^{166}$. Assignment of ${ }^{13} \mathrm{C}$ and ${ }^{15} \mathrm{~N}$ chemical shifts provided the first line of information about backbone conformation. Chemical shifts reveal the positions of disordered segments in predominantly a-helical membrane proteins ${ }^{128}$ and report protein conformational changes ${ }^{167}$. Chemical shift changes have been used to detect $\mathrm{pH}$-induced conformational changes of the influenza M2 protein (Fig. 4a) ${ }^{168}$, coupled structural changes between the $\mathrm{pH}$ gate and selectivity filter of potassium channels ${ }^{167}$, conformational changes of an $\mathrm{ABC}$ transporter upon binding to nucleotides ${ }^{169}$, and lightinduced conformational changes of subunit interfaces in proteorhodopsin (Fig. 4b) ${ }^{170}$. To detect conformational changes of large membrane proteins, pairwise amino-acid labeling combined with DNP is an effective approach ${ }^{171}$. With sensitivity enhancement, protonation and structural changes of key residues in bacteriorhodopsin are observed that reveal the proton transfer mechanism of this light-induced ion pump ${ }^{172} .{ }^{1} \mathrm{H}$-detected NMR experiments have enabled high-resolution characterization of $\beta$-barrel membrane proteins ${ }^{165} .{ }^{15} \mathrm{~N}$ longitudinal and rotating-frame relaxation experiments have been used to measure the amplitudes and rates of slow motions in the seven-transmembrane-helix sensory rhodopsin ${ }^{173}$. Finally, studies of water interactions with membrane proteins have given insights into the mechanism of ion conduction by channel proteins 160 .

Ligand binding and dynamics are critical to the function of many membrane proteins. ${ }^{19} \mathrm{~F}$ NMR is well suited to measure ligand-binding sites in proteins, by orthogonal labeling of the 
ligand and the protein. Fluorinated cholesterol has been used to identify the cholesterolbinding site in influenza M2 ${ }^{64}$. This binding is important for M2-mediated virus budding and membrane scission. Mixed fluorinated and ${ }^{13} \mathrm{C}$-labeled proteins have been used to determine the tetrameric structure of the influenza BM2 protein ${ }^{128}$.

Amyloid proteins-Solid-state NMR is well suited to the characterization of amyloid proteins ${ }^{174}$, many of which proteins form as a result of protein misfolding in diseases. These proteins form extended cross- $\beta$ fibrils with high one-dimensional order, which gives rise to well resolved NMR spectra. Recent examples of NMR-characterized amyloid proteins include: Alzheimer's A $\beta$ peptide ${ }^{175-177}$; a-synuclein ${ }^{178,179}$; transthyretin ${ }^{180} ; \beta_{2-}$ microglobulin ${ }^{181}$; fused in sarcoma (FUS) ${ }^{182}$; tau ${ }^{183}$; and immunoglobulin light chains 184,185. In addition to the fibril structure itself, solid-state NMR has been used to investigate small-molecule binding to these fibrils. For example, the binding of sulindac sulfide, a nonsteroidal anti-inflammatory drug, to A $\beta 40$ fibrils was studied using REDOR NMR 186 (Fig. 4c). Epigallocatechin gallate, a compound found in green-tea, binds $A \beta 40$ monomers to induce the formation of non-toxic spherical aggregates ${ }^{187}$. Amyloid intermediates and oligomers, which are too dynamically disordered to be studied by cryoEM, have been studied by observing chemical shift distribution in NMR spectra ${ }^{188}$. The data indicate the presence of significant $\beta$-strand segments before the formation of mature fibrils. The interaction of $\mathrm{A} \beta, a$-synuclein and human islet amyloid protein with lipid membranes have been studied to understand the mechanisms of neurotoxicity and fibril transmission between cells ${ }^{189,190}$. Finally, measurement of the interactions of amyloid proteins with water ${ }^{191-193}$ provides insight into the stability and water-accessibility of these fibrils.

While many amyloid proteins are involved in disease, other amyloid proteins carry out biological function and occur during pharmaceutical formulation. For example, the Het-S protein of filamentous fungi forms a $\beta$-solenoid structure ${ }^{194}$. Amyloid fibrils formed by the peptide hormones glucagon ${ }^{195}$ and $\beta$-endorphin ${ }^{196}$ have been structurally characterized. While most amyloid fibrils exhibit parallel-in-register $\beta$-strand structures, glucagon forms a novel antiparallel hydrogen-bonded $\beta$-sheet structure containing two coexisting molecular conformations (Fig. 4d). ${ }^{195}$ This showcases the structural diversity of amyloid proteins and suggests approaches to design fibrillization-resistant glucagon analogs to improve the solution stability of this anti-hypoglycemia drug.

Protein complexes-Solid-state NMR is increasingly applied to heterogeneous and dynamic protein complexes. These complexes can be sedimented from solution into MAS rotors or directly spun into the rotor to collect the solid ${ }^{197}$. This sedimentation NMR approach, together with other methods, has been used to characterize microtubule-bound motor proteins ${ }^{198}$, HIV capsid protein ${ }^{199}$, the $20 \mathrm{~S}$ proteasome ${ }^{200}$, the $50 \mathrm{~S}$ ribosome ${ }^{201}$, and protein-protein interactions between GB1 and immunoglobulin ${ }^{112}$. These studies have given insights into the structural stability and activation of these assemblies. For example, $\mathrm{aB}$ crystallin, which assembles into a polydisperse and dynamic complex, was found to interact with amorphous client proteins and fibril-forming proteins at different interfaces ${ }^{202}$. ${ }^{1} \mathrm{H}$-detected NMR experiments on the 14-subunit complex of caseinolytic protease ${ }^{203}$ revealed the binding site of an inhibitor, bortezomib. Site-specific measurement of the 
motional amplitudes of the HIV capsid protein revealed the flexibility of a loop domain and its rigidification upon binding to a host protein, cyclophilin $\mathrm{A}^{199}$. For metalloproteins such as superoxide dismutase and matrix metalloproteinase-12 (MMP12), pseudocontact shifts and paramagnetic relaxation enhancement measurements 204,205 allowed structure determination. Other dynamic assemblies involving hydrogels and phase-separated biomolecules such as membrane-less cellular organelles are also being investigated ${ }^{206}$. Fast MAS is instrumental for studying these paramagnetic proteins, by averaging the dipolarcoupling contribution to the resonance linewidth, especially near the paramagnetic center, thus revealing the structure of the metal coordination sphere with high precision ${ }^{207}$.

\section{Cell walls and extracellular matrices}

The glycan-rich matrix on the cell surfaces of plants, bacteria, and fungi is well suited to solid-state NMR studies. Cell walls and extracellular matrices contain carbohydrates, proteins, lignin, and other biopolymers. These biomaterials can be investigated using ${ }^{13} \mathrm{C}$, ${ }^{15} \mathrm{~N}$ and ${ }^{1} \mathrm{H}$ NMR experiments ${ }^{208}$. Both isotopically enriched and natural-abundance samples can be studied, the latter often requiring DNP ${ }^{209}$. For plants, the primary cell walls of both dicots and monocots have been extensively studied using ${ }^{13}$ C NMR (Fig. 4f) ${ }^{210}$. The refocused INADEQUATE experiment is particularly effective for identifying dynamic polysaccharides such as homogalacturonan. $3 \mathrm{D}{ }^{13} \mathrm{C}$ correlation NMR experiments further resolve the signals ${ }^{211}$, and enable the detection of intermolecular contacts. These data have revised the conventional model of primary cell wall structures, indicating that cellulose, hemicellulose, and pectins exist in a single network rather than two separate networks. Highfield 2D ${ }^{13}$ C MAS NMR spectra resolved multiple conformations of cellulose 212 and xylan 213 , and distinguished the conformation of the chemically reactive hydroxymethyl groups in cellulose ${ }^{214}$. DNP-enhanced NMR has been used to determine the site of protein binding to cellulose microfibrils to loosen the cell wall for plant growth ${ }^{215}$. DNP NMR has also been used to investigate lignin interaction with xylan and cellulose in plant secondary cell walls ${ }^{216} .2 \mathrm{D}{ }^{13} \mathrm{C}$ NMR has been applied to fungal cell walls ${ }^{217}$ to show a layered structure composed of chitin and diverse glucans ${ }^{217}$. For bacterial cell walls, DNP ${ }^{209}$ and ${ }^{1} \mathrm{H}$ detected NMR experiments ${ }^{218}$ have been used to study peptidoglycan structure. Finally, bacterial extracellular matrix has been studied using quantitative ${ }^{13} \mathrm{C}$ NMR to determine the composition of polysaccharides and proteins ${ }^{219}$, and to discover a new form of cellulose, covalently linked to phosphoethanolamine, in E. coli biofilm ${ }^{220}$.

\section{Organic and molecular solids}

One of the main applications of solid-state NMR is the characterization of powdered molecular solids. Chemical shifts can be readily measured and compared with those of known compounds or calculated shifts to test structural hypothesis. ${ }^{13} \mathrm{C}$ and ${ }^{1} \mathrm{H}$ chemical shifts can be measured from $1 \mathrm{D}^{13} \mathrm{C}$ CPMAS, $2 \mathrm{D}^{1} \mathrm{H}_{-}{ }^{13} \mathrm{C}$ HETCOR or ${ }^{1} \mathrm{H}$ fast MAS spectra. They can be assigned with $2 \mathrm{D}^{1} \mathrm{H}_{-}{ }^{13} \mathrm{C}$ HETCOR or ${ }^{13} \mathrm{C}$ INADEQUATE spectra enhanced with DNP ${ }^{221}$. This approach has been widely applied to crystalline polymorphs of pharmaceutical compounds $23,222,223$. For example, it was used to elucidate the stabilization mechanism of an amorphous form of tenapanor hydrochloride ${ }^{224}$. More sophisticated approaches for de novo structure determination combine computational structure prediction with experimental chemical shifts or distance restraints. This has led to complete 3D 
structures of microcrystalline drugs and organic $\mathrm{CO}_{2}$ capture materials ${ }^{225,226}$. These structures can be quantified in terms of probability and precision ${ }^{227}$, with average displacement parameters of $0.01 \AA^{2}$ for a recent structure of ampicillin ${ }^{226}$. With fast MAS and DNP NMR, sensitivity is now sufficient to characterize pharmaceutical polymorphs in situ, as embedded in formulations 102,228 . These methods can be used to identify interactions between the different components of the formulation, leading to better understanding of drug release. Because solid-state NMR does not require long-range order to produce highresolution spectra, characterizing mixtures and observing impurities is straightforward. With sensitivity enhancements by DNP, the detection limit for MAS NMR has improved to $\sim 80$ pmol. For example, the ${ }^{31} \mathrm{P}$ signal of a single phosphodiester in DNA oligomers attached to a glass plate has been observed. ${ }^{229}$

To characterize supramolecular systems, high-resolution ${ }^{1} \mathrm{H}$ spectra have allowed the measurement of inter-atomic distances, often to hydrogen-bonded protons. This approach has been used for example to study the structures of self-assembled G quartets, ${ }^{230}$ or to reveal intermolecular H-bonding and dynamics in a deep eutectic pharmaceutical. ${ }^{231}$ Molecular mobility plays an important role in the properties of these supramolecular systems. In addition to ${ }^{2} \mathrm{H}$ NMR lineshapes, isotropic and anisotropic chemical shifts and other approaches have been employed to study dynamic processes such as thermally activated rotational dynamics of H-bonded and charge-transferred diazabicyclo [2.2.2]octane molecular rotors 232 .

Domain structures in molecular solids can be characterized using spin diffusion NMR. ${ }^{233}$ Spin diffusion of DNP-hyperpolarized magnetization has been used to characterize API distributions within lipid nanoparticles ${ }^{234}$, and to identify core-shell structures in organic crystalline nanoparticles. ${ }^{235}$

Solid-state NMR is currently the best available method for quantitative characterization of the chemical composition of complex organic materials and other carbon-rich materials. Relative peak areas in multi-cross-polarization spectra ${ }^{236}$ or fully relaxed direct-polarization NMR spectra provide the relative concentrations of functional groups, unlike in Raman and IR spectroscopies. In carbon X-ray photoelectron spectroscopy, the number of resolved peaks is usually ten times smaller than in NMR spectra that selectively detect the signals of quaternary carbons, $\mathrm{CH}, \mathrm{CH}_{2}$, sp ${ }^{3}$-hybridized $\mathrm{C}$, and $\mathrm{N}$-bonded $\mathrm{C}^{237}$. Solid-state NMR can quantitatively determine functional groups and aromaticity in carbon materials such as char residues ${ }^{238}$, while the aromatic cluster size can be estimated based on recoupled dipolar dephasing. In addition, using dipolar couplings and spin diffusion, proximity between different components and domain thicknesses can be determined on the $1-40 \mathrm{~nm}$ scale, for instance in complex materials such as polymer-molecular organic framework (MOF) composites 239 or the organic-inorganic nanocomposite in bone 240241 .

\section{Inorganic and hybrid materials}

Solid-state NMR is a key tool for the structural characterization of oxides, whose chemical flexibility allows tuning of physical and chemical properties for a wide range of applications such as electronics, ceramics, energy materials, and catalysis. ${ }^{146}$ Compositional disorder is often studied by combining NMR and DFT calculations, as described above, with recent 
applications to pyrochlores, ${ }^{242}$ fluorites, ${ }^{243}$ and oxide catalysts. ${ }^{244-246}$ Due to the significant interest in hybrid perovskite structures, they have recently been the subject of intense NMR studies to determine the composition, phase segregation or layer structures in 2D materials. 247-249. Variable-temperature measurements are used to study the dynamics in oxides such as $\mathrm{ZrW}_{2} \mathrm{O}_{8},{ }^{250}$ where $2 \mathrm{D}$ exchange NMR was used to show that negative thermal expansion resulted from a "ratchet-like" mechanism where all O species interconvert. The sensitivity of solid-state NMR to dynamics has also allowed extensive studies of lithium-ion batteries. $146,251,252 \mathrm{In}$ situ and in operando ${ }^{6} \mathrm{Li} /{ }^{7} \mathrm{Li},{ }^{31} \mathrm{P},{ }^{17} \mathrm{O}$ and ${ }^{23} \mathrm{Na} N \mathrm{NM}$ experiments ${ }^{251}$ have used plastic cell capsules to create a working device, allowing the determination of the phases formed as batteries are cycled, and tracking dendrite formation and battery failure. ${ }^{251}$ Recently, the study of oxides has been extended to nanoparticles and the importance of the surface chemistry in processes such as catalysis 253 .

Solid-state NMR has found considerable application in the study of silicate minerals and clays, with ${ }^{29} \mathrm{Si}$ chemical shifts sensitive to the number and type of coordinating atoms, next-nearest neighboring nuclei and chain polymerization. ${ }^{146,254,255}$ Multinuclear NMR studies have explored cation and anion disorder, ${ }^{256,257}$ the substitution of paramagnetic impurities 146,258 and radiation damage in natural minerals. ${ }^{146}$ For mantle minerals, ${ }^{255}$ the high pressure required for synthesis using multi-anvil presses limits the sample volume. Thus, approaches to improve sensitivity such as composite pulses (where multiple pulses are used in place of a single pulse to increase efficiency ${ }^{29}$, satellite-transition MAS (STMAS) 259,260 , and isotopic enrichment ${ }^{12,261}$ are required. Computation augments these experiments, as shown in recent work of the hydration of deep Earth silicates using random structure searching and ${ }^{1} \mathrm{H},{ }^{29} \mathrm{Si}$ and ${ }^{17} \mathrm{O}$ NMR (Fig. 5a). ${ }^{261,262}$

Microporous and mesoporous materials, including zeolites, phosphate-based and MOFs (Fig. 5b, c) are important in gas storage, drug delivery, and catalysis. ${ }^{146,263}$ The combination of compositional, positional and dynamic disorder in these systems makes NMR ideal for studying their structure and reactivity. Solid-state NMR is widely used to understand the number, distribution and strength of acid sites in zeolites ${ }^{146}$ using probe molecules. Recent work has exploited ${ }^{17} \mathrm{O}$ enrichment to demonstrate the unexpected lability of the framework bonds. ${ }^{264}$ In situ experiments have been used to probe the reactivity and hydrolytic disassembly of zeolites. ${ }^{146,265}$ For aluminophosphates, ${ }^{27} \mathrm{Al}$ MAS and MQMAS and ${ }^{27} \mathrm{Al} /{ }^{31} \mathrm{P}$ heteronuclear multiple quantum coherence (HMQC) experiments have been combined with DFT calculations to study cation disorder, anion disorder and dynamics of guest molecules within the pores. ${ }^{146,266,267}$ The chemical flexibility of MOFs allows fine tuning of the pore size and chemical properties, ${ }^{268,269}$ and NMR can be used to study the nodes, organic linkers and guest molecules. Recent work on mixed-linker MOFs ${ }^{270}$ used ${ }^{13} \mathrm{C} /{ }^{15} \mathrm{~N}$ REDOR experiments to measure internuclear distances. Comparison to MD calculations showed alternation of the three different linkers present. The binding of guest molecules to open metal sites (particularly $\mathrm{CO}_{2}$ ) has also been studied using NMR. ${ }^{269}$

Disordered and amorphous materials such as many ceramics (Fig. 5d), glasses (Fig. 5e) and cements, as well as the chemically and structurally heterogeneous inorganic-organic hybrid materials ${ }^{271}$, pose considerable challenges for structural analysis, and NMR is the method of choice for studying these materials. The distribution of structural environments leads to a 
range of NMR parameters and overlapped spectral lineshapes. ${ }^{146,272}$ The relation between NMR parameters and local geometry has been probed by MD simulations ${ }^{155}$ that generate a suite of possible structures for which DFT calculations can predict the NMR parameters. For example, ${ }^{89} \mathrm{Y}$ NMR of oxide ceramics ${ }^{242}$ used an ensemble-based modeling approach, considering every possible arrangement of atoms, and simulated the NMR spectra to compare with experiment. For cements, ${ }^{1} \mathrm{H},{ }^{27} \mathrm{Al}$, and ${ }^{29} \mathrm{Si}$ NMR experiments are widely used to probe local structure, and ${ }^{43} \mathrm{Ca}$ NMR is becoming increasingly more viable as magnetic field strengths increase, overcoming the dual challenges of low $\gamma$ and quadrupolar broadening. Detailed atomic-level information on the role of water and retardants such as sucrose were obtained using 2D correlation NMR. ${ }^{273}$ DNP has enabled the measurement of correlations between $\mathrm{Si}$ atoms and between $\mathrm{Si}$ and $\mathrm{Al}$ with high sensitivity. By combining these results with simulations and DFT chemical shift calculations, the full threedimensional atomic structures of cementitious calcium silicate hydrate and calcium aluminate silicate hydrate can be determined ${ }^{274}$. Also, hybrid materials containing calcium phosphate have been of interest, owing to the role they play in biomaterials such as bone, bioglasses and synthetic apatites. While most studies exploit ${ }^{1} \mathrm{H},{ }^{13} \mathrm{C}$ and ${ }^{31} \mathrm{P} \mathrm{NMR},{ }^{43} \mathrm{Ca}$ and ${ }^{17} \mathrm{O}$ NMR are becoming increasingly used ${ }^{241}$. Recent work performing ex vivo, microimaging of an intact mouse tooth under MAS was able to selectively identify and locate the mineral and organic components with high spatial resolution $(\sim 100 \mu \mathrm{m}){ }^{275}$.

For inorganic semiconductor and metal nanoparticles (NPs), ${ }^{13} \mathrm{C}$ and ${ }^{31} \mathrm{P}$ NMR give detailed information on the composition of the organic capping groups on the surface of NPs that govern their size and shape ${ }^{276}$. Solid-state ${ }^{77} \mathrm{Se},{ }^{31} \mathrm{P},{ }^{113} \mathrm{Cd}$ or ${ }^{119} \mathrm{Sn}$ NMR of InP, GaP, $\mathrm{CdSe}, \mathrm{CdS}$, and $\mathrm{SnO}_{2}$ NPs show clear differences between the surface and bulk. The reactivity of metal NPs has been widely studied using surface probe molecules to understand the state of metal atoms at surfaces. Gold NPs have been extensively studied, leading to the determination of the complete structures of surface capping groups. ${ }^{277}$ Also, the mode of ligands binding to the surface of NPs has been determined using 2D NMR. In CdSe NPs, detailed analysis of the interactions between hexadecylamine and thiophenol capping ligands and the surface $\mathrm{Cd}$ and $\mathrm{Se}$ atoms using ${ }^{1} \mathrm{H}_{-}{ }^{113} \mathrm{Cd}$ and ${ }^{1} \mathrm{H}_{-}{ }^{77} \mathrm{Se}$ CPMAS HETCOR indicated that thiophenol binds to NPs by occupying a selenium vacancy site. ${ }^{278}$

Some of the most interesting features of materials occur on surfaces or at interfaces, which have traditionally been studied by $\mathrm{CP}$ experiments to exploit the presence of protons only on the surface of a material. For example, ${ }^{1} \mathrm{H}$ NMR used in combination with extended X-ray absorption fine structure measurements revealed the dissociation mechanism of $\mathrm{N}_{2}$ on tantalum surface sites supported on silica surfaces ${ }^{279} \cdot{ }^{1} \mathrm{H}-{ }^{13} \mathrm{C}$ and ${ }^{1} \mathrm{H}-{ }^{29} \mathrm{Si}$ HETCOR NMR was also used with fast MAS to provide insight into the conformation of allyl groups covalently anchored to the surface of MCM-41 silica surfaces ${ }^{280}$. Oxygen-17 experiments in combination with surface selective isotopic labelling were used to show that ${ }^{17} \mathrm{O}$ resonances arising from the first to third surface layers, hydroxyl sites, and oxygen atoms near vacancies can be distinguished from the bulk. ${ }^{281}$ However, low sensitivity has severely restricted such applications. The introduction of DNP surface-enhanced NMR (DNP SENS) has largely solved this problem in the past decade ${ }^{103}$. DNP SENS has been used to determine the structures of organometallic ligands on surfaces ${ }^{282}$ and the Brønsted acidity of surface hydroxyls in silica and silica-alumina materials. ${ }^{283,284}$ 
In summary, for biological chemistry, solid-state NMR spectroscopy is well equipped to elucidate small-molecule binding to biomacromolecules, functionally important protein and ligand dynamics, and chemical processes such as protonation reactions. These applications are highly complementary to X-ray and cryoEM approaches. For materials chemistry, the sensitivity of NMR to the atomic-scale environment allows elucidation of the types and levels of static and dynamic disorder, which are vital to understanding chemical reactivity.

\section{Reproducibility and data deposition}

\section{Reproducibility of solid-state NMR data}

Solid-state NMR spectra are largely reproducible because they are averaged over multiple scans and reflect ensemble averages of nuclear spin properties. Thus, if the same experiment is run with the same acquisition parameters, on the same sample, and using the same NMR probe, then spectra should be reproducible to within their signal-to-noise ratio. However, differences in sample preparation can cause variations in NMR spectra, since NMR chemical shifts reflect the environment around each nucleus and are thus sensitive to conformational heterogeneity. Second, phase transients and RF inhomogeneity vary between probes, which influence pulse sequence performance ${ }^{285}$. This probe-specific variation can affect the reproducibility of spectral intensities. Similarly, experiments that require precise choice of $\mathrm{RF}$ fields such as the proton-assisted insensitive nuclei (PAIN)-CP experiment may make it difficult to obtain reproducible spectral intensities ${ }^{286}$. To achieve high spectral reproducibility, it is thus important to report the full sample preparation conditions and experimental acquisition and processing parameters when publishing experimental data.

\section{Deposition of solid-state NMR data}

It is recommended that all raw NMR data associated with publications are deposited for open access. This is a rapidly evolving area, with several initiatives underway, although currently there is no centralized database to deposit raw NMR data. The Biological Magnetic Resonance Data Bank (BMRB) accepts chemical shifts, distance and orientational restraints for biological NMR data. Similar centralized resources will likely become available for small molecule and materials NMR data. In the meantime, data can be conveniently deposited with services such as Zenodo. At present, we recommend that raw data be deposited in the JCAMP-DX version 6.0 standard, together with the original commercial format (for example, TopSpin) data, and that data be made available under the CC-BY-4.0 (Creative Commons Attribution-ShareAlike 4.0 International) license.

\section{Deposition of structural data}

NMR-derived structures can be deposited in several databases (Table 2), including the Protein Data Bank (PDB) (> 15,000 entries) and the BMRB for biological molecules, the Cambridge Structural Database (CSD) (>1,000,000 entries) for organic and metal-organic solids, the Inorganic Crystal Structure Database (ICSD) (>200 000 entries) for purely inorganic solids. 


\section{Limitations and optimizations}

\section{NMR sensitivity and resolution}

The main challenge of NMR spectroscopy is its low sensitivity. Significant advances in this area include the development of DNP and ${ }^{1} \mathrm{H}$-detected experiments under fast MAS (up to $\sim 170 \mathrm{kHz}){ }^{287}$. Compared to ${ }^{13} \mathrm{C}$-detected experiments, ${ }^{1} \mathrm{H}$ detection can increase the experimental sensitivity by 8 -fold, which enables the measurement of high-resolution and high-sensitivity ${ }^{1} \mathrm{H}$ NMR spectra of undeuterated systems with high sensitivity 44,288 . Nevertheless, various challenges remain. ${ }^{1} \mathrm{H}$ spectral resolution of solids is still a factor 10 100 worse than in solution NMR spectra. Most DNP experiments achieve their maximum sensitivity enhancements at cryogenic temperatures of $20-110 \mathrm{~K}$ where the electron relaxation time is sufficiently long for polarization transfer to nuclei ${ }^{99}$. At these cryogenic temperatures, disordered systems manifest much broader linewidths than at room temperature, thus causing spectral overlap unless the number of chemically distinct sites is low. Moreover, the efficiency of polarization in continuous-wave cross-effect DNP experiments scales unfavourably with $\mathrm{B}_{0}$, making high-field DNP $(>9.4 \mathrm{~T})$ a current challenge. As a result, DNP NMR has so far been more readily applicable to materials research ${ }^{102}$ than to biological systems.

\section{Spectral interpretation and refinement}

For many solid-state NMR spectra, spectral resolution limits the amount of structural information obtainable. This is particularly true for disordered materials and for quadrupolar nuclei, where spectral overlap is common. ${ }^{140}$ Spectral fitting can ameliorate this problem, but there are limitations to the accuracy of multi-parameter multi-site fits unless variable field measurements or prior information is available. In many cases, particularly for anisotropically broadened lineshapes, ideal lineshapes are not relevant and simulation programs that include the exact effect of RF pulses on the density matrix (and ultimately on the spectrum) need to be used. ${ }^{142}$ For quadrupolar nuclei, the complex spin dynamics mean that many experiments produce qualitative rather than quantitative information, for example, giving relative proximities rather than exact distances.

Similarly, spectral overlap in protein samples complicates structural analysis. Overlap of ${ }^{15} \mathrm{~N}$ chemical shifts limits the reliability of chemical shift assignment, in particular for assignment strategies that rely on NCACX and NCACX experiments. Semi-automated assignment programs have been developed to ameliorate this assignment ambiguity ${ }^{289-292}$.

DFT calculations can greatly aid in the interpretation of the NMR spectra of materials, through the prediction of both quadrupolar and shielding parameters, but the accuracy of these calculations are limited by the methods and the functional used. Typically, generalized gradient approximation approaches are the method of choice for condensed matter simulations. ${ }^{149,150293}$ In principle, hybrid functionals offer improved accuracy, and some (for example, B3LYP) are widely used in molecular systems and have been shown to improve predicted ${ }^{13} \mathrm{C}$ NMR spectra of molecular crystals ${ }^{294}$. Although these functionals come with considerable computational costs, particularly in a periodic approach, recent developments in fragment-based techniques have demonstrated a route to exploit the benefits 
of hybrid functionals in solids while ensuring a reasonable computational cost ${ }^{294}$. More generally, the biggest limitation of using predicted NMR spectra to solve or refine structures is the time and cost of the calculation, which poses challenges to a real-time automated solution. To address this problem, machine learning approaches have been introduced to calculate chemical shifts in molecular solids that reduce computational cost by orders of magnitude while maintaining the accuracy of DFT 295.

\section{Outlook}

\section{Higher magnetic fields and faster MAS}

Higher magnetic fields and faster MAS have consistently opened up new doors in solid-state NMR in the past, and we expect they will continue to do so in the future. Ultra-high magnetic fields that are equivalent to 1.2 to $1.5 \mathrm{GHz}$ in ${ }^{1} \mathrm{H}$ Larmor frequency are becoming available through the construction of hybrid low- and high-temperature superconducting magnets 296 and series connected hybrid magnets ${ }^{297}$. These ultra-high magnetic fields simultaneously enhance spectral sensitivity and resolution (Fig. 6). Spectral sensitivity scales with $B_{0}{ }^{3 / 2}$ and spectral linewidths scale with $1 / \mathrm{B}_{0}$ for homogeneously broadened resonances. For protons, sensitivity gains beyond the $B_{0}^{3 / 2}$ factor are expected when the isotropic chemical shift difference exceeds the ${ }^{1} \mathrm{H}^{1}{ }^{1} \mathrm{H}$ dipolar coupling strength ${ }^{298}$. Quadrupolar nuclei further benefit from high magnetic fields as a result of the resolution enhancement due to the scaling of second-order quadrupolar interactions inversely with with $\mathrm{B}_{0} \cdot{ }^{33,140,263,299}$ Even when the magnetic field is not high enough to reduce the quadrupolar broadening to fully resolve all sites, multi-field experiments are advantageous for extracting structurally informative NMR parameters.

Similar to higher magnetic fields, faster MAS has historically led to higher-resolution and more informative solid-state NMR spectra. The maximum achievable MAS frequencies are currently limited by the speed of sound at the rotor surface ${ }^{300}$, and thus higher rates can be achieved only for ever smaller-diameter rotors. This appears to lead to a severe reduction in sensitivity, with a $0.7 \mathrm{~mm}$ for example only containing $\sim 1 \mathrm{mg}$ of sample ${ }^{301}$. However, since the detection efficiency, the relaxation times that are effective during the insensitive nuclei enhanced by polarization transfer (INEPT) experiment and cross polarization all increase in smaller rotors, ${ }^{50}$ experimentally, small fast-spinning samples give rise to similar sensitivities as large slower-spinning samples. ${ }^{44}$ It has been predicted that this trend will hold up to MAS rates of $\sim 300 \mathrm{kHz}$ (Fig. 6) ${ }^{302}$. Faster MAS may also be achieved by exploring rotors with non-cylindrical geometries ${ }^{303}$. Recently, fast MAS has been shown to enhance the sensitivity of DNP NMR experiments. ${ }^{288,304}$ : for example, results from $0.7 \mathrm{~mm}$ rotors spinning at $65 \mathrm{kHz}$ show 2-fold higher DNP enhancements simply due to higher spinning rates, yielding sensitivity enhancements of 200 at high field (21.1 T). The combination of fast MAS and DNP thus opens up the possibility of ${ }^{1} \mathrm{H}$-detected MAS DNP.

\section{Further development in DNP NMR}

Most current continuous-wave DNP experiments are conducted at cryogenic temperatures and moderate magnetic fields to obtain high sensitivity enhancements. Key future directions include the development of pulsed DNP techniques ${ }^{305}$ to increase the sensitivity gains at 
high fields, with the concomitant improvement of spectral resolution ${ }^{306}$, and development of new polarizing strategies suitable for ambient temperatures.

\section{New NMR methods}

Continued advances of solid-state NMR will benefit from the discovery of conceptually novel experimental methods, as observed since the introduction of pulsed NMR in the 1970s. Many of these new pulse sequences are expected to capitalize on the increased resolution and coherence lifetimes enabled by faster MAS, higher magnetic fields, and the increased polarization available from DNP. New methods to measure distances and largeamplitude motions under these high-field and fast-MAS conditions will be especially desirable ${ }^{39,40}$.

For quadrupolar nuclei, future challenges lie in the measurement of high-resolution and high-sensitivity spectra and the extraction of more quantitative information. ${ }^{30,140} \mathrm{Here}$, we expect to see completely new approaches to provide the step change in sensitivity. For extracting quantitative structural information from NMR experiments, we expect that the rapid advances in computational methods will enable large-scale calculations of NMR parameters and artificial intelligence-based spectral interpretation for direct output of molecular or materials properties.

Solid-state NMR is particularly dependent on the development of probe technology. In addition to faster MAS, multi-channel NMR probes that allow simultaneous decoupling of multiple quadrupolar nuclei will be beneficial for enhancing the spectral resolution of inorganic materials. This instrumentation will also facilitate correlation experiments between different quadrupolar nuclei. Such experiments will require the development of more efficient polarization transfer pulse sequences, which can be aided by efficient simulation of larger spin systems. ${ }^{307}$

\section{In situ, in operando and in vivo experiments}

As chemistry, biology and materials sciences move away from studying pure systems towards complex systems on living or operational objects, in situ, in operando and in vivo NMR become more and more attractive. We expect to see rapid development of experiments and technology in this area tailored to new applications in materials research such as catalysis, electrochemistry, and solar conversion, as well as in biological chemistry research. In parallel, we expect to see an increased interest in trapping methods for $e x$-situ NMR analysis, such as $\mathrm{pH}$ jump, rapid mixing, and freeze quenching ${ }^{308}$. Some of these trapping protocols will be combined with DNP NMR ${ }^{309}$. In vivo biological studies by NMR ${ }^{310}$ benefit from the non-perturbing nature of NMR and its capability to detect both immobilized and dynamic molecules in cells quantitatively. Emerging topics include bacterial and mammalian extracellular matrices 219,311 , protein folding and misfolding in mammalian cells ${ }^{312}$, and membrane proteins in native membranes 313,314 .

\section{High pressure and temperature experiments}

Measurements at temperatures and pressures that are higher than currently available are imperative for many applications in catalysis and materials science. Further miniaturization 
will be required to enable experiments in smaller and faster-spinning rotors. ${ }^{94}$ Performing solid-state NMR experiments at higher pressure will require significant development of new instrumentation such as possibly integrating miniature diamond anvil cells within a MAS rotor.

\section{Miniaturization}

Another direction that could enable new applications is related to miniaturization of solidstate NMR systems. This potentially includes micron-sized rotors arising from new geometries for MAS ${ }^{300}$ and the reduction in size of NMR magnets and probes from the current $1 \mathrm{~m}$ scale to the $\mathrm{cm}$ range ${ }^{315}$. Such developments could transform the ability to carry out in situ measurements. The possibility to conduct solid-state NMR experiments in open faced systems with spinning magnets 316,317 instead of spinning samples is also being explored to enable NMR measurements in many industrial and operando settings.

\section{New horizons}

The methodological advances discussed above will expand the applications of solid-state NMR spectroscopy to many emerging fields where atomic-level characterization is vital but where few other analytical methods are available. For example, in chemical biology, increasing interest in mapping brain functions invites the application of solid-state NMR for studying protein-RNA interactions; the structurally poorly understood yet disease-significant glycan layers of pathogens and cancer cells calls for comprehensive studies of carbohydrateprotein interactions; the central role of the proteostasis network in diseases suggests that solid-state NMR studies of the time course of protein folding and misfolding will likely be of interest; and challenges in drug delivery compels solid-state NMR studies of systems such as lipid nanoparticles. In these applications, we expect solid-state NMR to be increasingly integrated with biochemical techniques, and to complement other methods by providing atomic-scale structural, dynamical, and chemical information. In materials science, we envision solid-state NMR to play an increasing role in discovering new materials, in addition to characterizing materials. Such discovery processes require atomic probes of complex multi-scale heterogeneous architectures, which NMR is well positioned to provide. We expect conventional solid-state NMR to operate in parallel with new approaches for in situ and in operando online analysis, for example combining miniaturized solid-state NMR systems with artificial intelligence controlled discovery labs.

\section{Conclusions}

We have highlighted the major practices of contemporary solid-state NMR experiments and data analysis, and illustrated how these experiments are applied to biological and materials chemistry research. The exquisite control of nuclear spin coherence available to researchers, through an unlimited number of RF pulse sequences, allows scientists to extract multifaceted information from NMR data, including not only static three-dimensional structure, but also dynamics, chemical composition, intermolecular interactions, structural disorder, and the relation of these atomic and molecular properties to function. 


\section{Acknowledgements}

M.H. acknowledges support by NIH grant GM066976.

\section{Glossary}

\section{non-zero nuclear spins}

nuclear isotopes with a non-zero spin angular momentum

gyromagnetic ratio

the ratio of the magnetic moment of a particle to its angular momentum

anisotropic

orientation dependent

\section{Fourier transformation}

A mathematical transformation that decomposes a function (usually of time) into its constituent frequencies

\section{paramagnetic}

Weakly attracted by an externally applied magnetic field, typically as a result of the presence of unpaired electrons

ionothermal synthesis

the use of ionic liquids as both the solvent and potential template in the formation of solids

chemical shift anisotropies

The orientation-dependent component of the chemical shielding interaction

\section{molecular dynamics}

Computer simulated method used for characterising the dynamics of atoms and molecules, providing an overview of how they move over a set period of time

\section{Density functional theory}

Computational quantum-mechanical modelling approach used to investigate electronic structure in many-body systems

\section{cryo-electron microscopy}

an electron microscopy technique used to determine the three-dimensional structure of samples frozen at cryogenic temperatures, which are not in a crystalline form

\section{extended X-ray absorption fine structure}

a X-ray absorption spectroscopy technique that is amenable for non-uniform crystalline samples

\section{generalized gradient approximation}

A type of exchange correlation functional used in DFT that considers the density and the gradient of the density 


\section{References}

1. Levitt MH Spin Dynamics Basic of Nuclear Magnetic Resonance, (Wiley, 2008).

2. Schmidt-Rohr K \& Spiess HW Multidimensional Solid-State NMR and Polymers, 478 (Academic Press, San Diego, 1994).

3. Facelli JC Chemical shift tensors: theory and application to molecular structural problems. Prog. Nucl. Magn. Reson. Spectrosc. 58, 176-201 (2011). [PubMed: 21397119]

4. Keeler J Understanding NMR Spectroscopy, (Wiley, 2011).

5. Andrew ER, Bradbury A \& Eades RG Nuclear magnetic resonance spectra from a crystal rotated at high speed. Nature 182, 1659-1659 (1958).

6. Schaefer J \& Stejskal EO C13 nuclear magnetic resonance of polymers spinning at magic angle. J. Am. Chem. Soc. 98, 1031-1032 (1976).

7. Duer MJ Introduction to Solid-State NMR Spectroscopy, (Blackwell Science, 2004).

8. Hong M \& Jakes K Selective and Extensive 13C Labeling of a Membrane Protein for Solid-State NMR Investigation. J. Biomol. NMR 14, 71-74 (1999). [PubMed: 10382307]

9. Tugarinov V, Kanelis V \& Kay LE Isotope labeling strategies for the study of high-molecularweight proteins by solution NMR spectroscopy. Nat. Protoc. 1, 749-754 (2006). [PubMed: 17406304]

10. Kainosho M, Torizawa T, Iwashita Y, Terauchi T, Mei Ono A \& Güntert P Optimal isotope labelling for NMR protein structure determinations. Nature 440, 52-57 (2006). [PubMed: 16511487]

11. Lu J, Qiang W, Yau W, Schwieters C, Meredith S \& Tycko R Molecular Structure of b-Amyloid Fibrils in Alzheimer's Disease Brain Tissue. Cell 154, 1257-1268 (2013). [PubMed: 24034249]

12. Ashbrook SE \& Smith ME Solid state O-17 NMR - an introduction to the background principles and applications to inorganic materials. Chem. Soc. Reviews 35, 718-735 (2006).

13. Pines A, Gibby MG \& Waugh JS Proton-enhanced NMR of dilute spins in solids. J. Chem. Phys. 59, 569-590 (1973). This paper describes the first structure determination of brain-derived Alzheimer's $\beta$-amyloid fibrils using NMR and brain-seeded fibrils.

14. Herzfeld J \& Berger AE Sideband intensities in NMR spectra of samples spinning at the magic angle. J. Chem. Phys. 73, 6021 (1980).

15. Bielecki A, Kolbert AC \& Levitt MH Frequency-switched pulse sequences: homonuclear decoupling and dilute spin NMR in solids. Chem. Phys. Lett. 155, 341-346 (1989).

16. Mote KR, Agarwal V \& Madhu PK Five decades of homonuclear dipolar decoupling in solid-state NMR: Status and outlook. Prog. Nucl. Magn. Reson. Spectrosc. 97, 1-39 (2016). [PubMed: 27888838]

17. Paruzzo FM \& Emsley L High-resolution (1)H NMR of powdered solids by homonuclear dipolar decoupling. J. Magn. Reson. 309, 106598 (2019). [PubMed: 31586820]

18. Perras FA, Goh TW, Wang LL, Huang W \& Pruski M Enhanced (1)H-X D-HMQC performance through improved (1)H homonuclear decoupling. Solid State Nucl. Magn. Reson. 98, 12-18 (2019). [PubMed: 30669006]

19. Barbet-Massin E et al. Rapid proton-detected NMR assignment for proteins with fast magic angle spinning. J. Am. Chem. Soc. 136, 12489-12497 (2014). [PubMed: 25102442]

20. Takegoshi K, Nakamura S \& Terao T C-13-H-1 dipolar-assisted rotational resonance in magicangle spinning NMR. Chem. Phys. Lett. 344, 631-637 (2001).

21. Bax A, Freeman R \& Kempsell SP Natural-abundance 13C-13C coupling observed via doublequantum coherence. J. Am. Chem. Soc. 102, 4849-4851 (1980).

22. Lesage A, Bardet M \& Emsley L Through-bond carbon-carbon connectivities in disordered solids by NMR J. Am. Chem. Soc. 121, 10987-10993 (1999).

23. Harris RK Applications of solid-state NMR to pharmaceutical polymorphism and related matters. J. Pharm. Pharmacol. 59, 225-39 (2007). [PubMed: 17270076]

24. King IJ, Fayon F, Massiot D, Harris RK \& Evans JSO A space group assignment of ZrP2O7 obtained by P-31 solid state NMR. Chem. Commun. 18, 1766-1767 (2001). 
25. Cadars S, Lesage A \& Emsley L Chemical shift correlations in disordered solids. J. Am. Chem. Soc. 127, 4466-76 (2005). [PubMed: 15783229]

26. De Paëpe G Dipolar recoupling in magic angle spinning solid-state nuclear magnetic resonance. Annu. Rev. Phys. Chem. 63, 661-684 (2012). [PubMed: 22404583]

27. Terao T, Miura H \& Saika A I-S Dipolar Switching-Angle Spinning 2D NMR (SLF). J. Chem. Phys. 85, 3816-3826 (1986).

28. Mueller KT, Samoson A, Sun BQ, Chingas GC, Zwanziger JW, Terao T \& Pines A Dynamic-angle spinning of quadrupolar nuclei. J. Magn. Reson. 86, 470 (1990).

29. Apperley DC, Harris RK \& Hodgkinson P Solid-state NMR: Basic principles and practice, (Momentum Press, 2012).

30. Ashbrook SE \& Sneddon S New Methods and Applications in Solid-State NMR Spectroscopy of Quadrupolar Nuclei. J. Am. Chem. Soc. 136, 15440-15456 (2014). [PubMed: 25296129]

31. Gan Z, Gor'kov P, Cross TA, Samoson A \& Massiot D Seeking higher resolution and sensitivity for NMR of quadrupolar nuclei at ultrahigh magnetic fields. J. Am. Chem. Soc. 124, 5634-5 (2002). [PubMed: 12010025]

32. Frydman L \& Harwood JS Isotropic spectra of half-integer quadrupolar spins from bidimensional magic-angle-spinning NMR. J. Am. Chem. Soc. 117, 5367-5368 (1995).

33. Schurko RW Ultra-Wideline Solid-State NMR Spectroscopy. Acc. Chem. Res. 46, 1985-1995 (2013). [PubMed: 23745683]

34. Spiess HW 2H NMR for studying mobility and orientation in polymers. Adv. Polym. Sci. 66, 2356 (1985). This paper revolutionized the structural study of quadrupolar nuclei in many materials by removing the line broadening that affects the solid-state NMR spectra.

35. Davis JH The description of membrane lipid conformation, order and dynamics by 2H-NMR. Biochim. Biophys. Acta. 737, 117-171 (1983). [PubMed: 6337629]

36. Petrache HI, Dodd SW \& Brown MF Area per lipid and acyl length distributions in fluid phosphatidylcholines determined by H-2 NMR spectroscopy. Biophys. J. 79, 3172-3192 (2000). [PubMed: 11106622]

37. Kamp F, Scheidt HA, Winkler E, Basset G, Heinel H, Hutchison JM, LaPointe LM, Sanders CR, Steiner H \& Huster D Bexarotene Binds to the Amyloid Precursor Protein Transmembrane Domain, Alters Its alpha-Helical Conformation, and Inhibits gamma-Secretase Nonselectively in Liposomes. ACS Chem. Neurosci. 9, 1702-1713 (2018). [PubMed: 29717863]

38. Hologne M, Faelber K, Diehl A \& Reif B Characterization of dynamics of perdeuterated proteins by MAS solid-state NMR. J. Am. Chem. Soc. 127, 11208-9 (2005). [PubMed: 16089426]

39. Shi XY \& Rienstra CM Site-Specific Internal Motions in GB1 Protein Microcrystals Revealed by 3D H-2-C-13-C-13 Solid-State NMR Spectroscopy. J. Am. Chem. Soc. 138, 4105-4119 (2016). [PubMed: 26849428]

40. Gelenter MD, Wang T, Liao SY, O’Neill H \& Hong M 2H-13C correlation solid-state NMR for investigating dynamics and water accessibilities of proteins and carbohydrates. J. Biomol. NMR 68, 257-270 (2017). [PubMed: 28674916]

41. Comellas G \& Rienstra CM Protein structure determination by magic-angle spinning solid-state NMR, and insights into the formation, structure, and stability of amyloid fibrils. Annu. Rev. Biophys. 42, 515-536 (2013). [PubMed: 23527778]

42. Chevelkov V, Rehbein K, Diehl A \& Reif B Ultra-high resolution in proton solid-state NMR at high levels of deuteration. Angew. Chem. Int. Ed. 45, 3878-3881 (2006).

43. Penzel S, Smith AA, Agarwal V, Hunkeler A, Org ML, Samoson A, Böckmann A, Ernst M \& Meier BH Protein resonance assignment at MAS frequencies approaching $100 \mathrm{kHz}$ : a quantitative comparison of J-coupling and dipolar-coupling-based transfer methods. J. Biomol. NMR 63, 165 186 (2015). [PubMed: 26267840]

44. Andreas LB et al. Structure of fully protonated proteins by proton-detected magic-angle spinning NMR. Proc. Natl. Acad. Sci. U. S. A. 113, 9187-9192 (2016). [PubMed: 27489348] This reports the first demonstration of high-resolution $1 \mathrm{H}$ correlation solid-state NMR spectra.

45. Xiang S, Grohe K, Rovó P, Vasa SK, Giller K, Becker S \& Linser R Sequential backbone assignment based on dipolar amide-to-amide correlation experiments. J. Biomol. NMR 62, 303 311 (2015). [PubMed: 25975745] 
46. Schanda P, Huber M, Verel R, Ernst M \& Meier BH Direct detection of (3h)J(NC') hydrogen-bond scalar couplings in proteins by solid-state NMR spectroscopy. Angew. Chem. Int. Ed. 48, 9322-5 (2009). This paper describes the first de novo structure obtained from 1 H-detected solid-state NMR experiments.

47. Hiller S, Wasmer C, Wider G \& Wuthrich K Sequence-specific resonance assignment of soluble nonglobular proteins by 7D APSY-NMR Spectroscopy. J. Am. Chem. Soc. 129, 10823-10828 (2007). [PubMed: 17691781]

48. Mobli M \& Hoch JC Nonuniform sampling and non-Fourier signal processing methods in multidimensional NMR. Prog. Nucl. Magn. Reson. Spectrosc. 83, 21-41 (2014). [PubMed: 25456315]

49. Paramasivam S, Suiter CL, Hou G, Sun S, Palmer M, Hoch JC, Rovnyak D \& Polenova T Enhanced sensitivity by nonuniform sampling enables multidimensional MAS NMR spectroscopy of protein assemblies. J. Phys. Chem. B 116, 7416-27 (2012). [PubMed: 22667827]

50. Orton HW et al. Protein NMR Resonance Assignment without Spectral Analysis: 5D SOlid-State Automated Projection SpectroscopY (SO-APSY). Angew. Chem. Int. Ed. 59, 2380-2384 (2020).

51. Schmidt E \& Guntert P A new algorithm for reliable and general NMR resonance assignment. J. Am. Chem. Soc. 134, 12817-29 (2012). [PubMed: 22794163]

52. Tycko R On the problem of resonance assignments in solid state NMR of uniformly N-15, C-13labeled proteins. J. Magn. Reson. 253, 166-172 (2015). [PubMed: 25797013]

53. Stanek J, Schubeis T, Paluch P, Güntert P, Andreas LB \& Pintacuda G Automated Backbone NMR Resonance Assignment of Large Proteins Using Redundant Linking from a Single Simultaneous Acquisition. J. Am. Chem. Soc. 142, 5793-5799 (2020). [PubMed: 32129995]

54. Hong M \& Schmidt-Rohr K Magic-angle-spinning NMR techniques for measuring long-range distances in biological macromolecules. Acc. Chem. Res. 46, 2154-2163 (2013). [PubMed: 23387532]

55. Castellani F, vanRossum B, Diehl A, Schubert M, Rehbein K \& Oschkinat H Structure of a protein determined by solid-state magic-angle spinning NMR spectroscopy. Nature 420, 98-102 (2002). [PubMed: 12422222]

56. Grommek A, Meier BH \& Ernst M Distance information from proton-driven spin diffusion under MAS. Chem. Phys. Lett. 427, 404-409 (2006).

57. Linser R, Bardiaux B, Higman V, Fink U \& Reif B Structure calculation from unambiguous longrange amide and methyl $1 \mathrm{H}-1 \mathrm{H}$ distance restraints for a microcrystalline protein with MAS solidstate NMR spectroscopy. J. Am. Chem. Soc. 133, 5905-12 (2011). [PubMed: 21434634] This report demonstrates the first complete protein structure determined by solid-state NMR.

58. Roos M, Wang T, Shcherbakov AA \& Hong M Fast Magic-Angle-Spinning ${ }^{19}$ F Spin Exchange NMR for Determining Nanometer ${ }^{19} \mathrm{~F}-{ }^{19} \mathrm{~F}$ Distances in Proteins and Phamaceutical Compounds. J. Phys. Chem. B 122, 2900-2911 (2018). [PubMed: 29486126]

59. Gullion T \& Schaefer J Rotational echo double resonance NMR. J. Magn. Reson. 81, 196-200 (1989).

60. Cegelski L REDOR NMR for drug discovery. Bioorg. Med. Chem. Lett. 23, 5767-5775 (2013). [PubMed: 24035486]

61. Jaroniec CP, Filip C \& Griffin RG 3D TEDOR NMR experiments for the simultaneous measurement of multiple carbon-nitrogen distances in uniformly C-13, N-15-labeled solids. J. Am. Chem. Soc. 124, 10728-10742 (2002). [PubMed: 12207528]

62. Tang M, Waring AJ \& Hong M Phosphate-Mediated Arginine Insertion Into Lipid Membranes and Pore Formation by a Cationic Membrane Peptide from Solid-State NMR. J. Am. Chem. Soc. 129, 11438-11446 (2007). [PubMed: 17705480]

63. Yang H, Staveness D, Ryckbosch SM, Axtman AD, Loy BA, Barnes AB, Pande VS, Schaefer J, Wender PA \& Cegelski L REDOR NMR Reveals Multiple Conformers for a Protein Kinase C Ligand in a Membrane Environment. ACS Cent. Sci. 4, 89-96 (2018). [PubMed: 29392180]

64. Elkins MR, Williams JK, Gelenter MD, Dai P, Kwon B, Sergeyev IV, Pentelute BL \& Hong M Cholesterol-binding site of the influenza M2 protein in lipid bilayers from solid-state NMR. Proc. Natl. Acad. Sci. U. S. A. 114, 12946-12951 (2017). [PubMed: 29158386] 
65. Brus J, Kobera L, Schoefberger W, Urbanová M, Klein P, Sazama P, Tabor E, Sklenak S, Fishchuk AV \& Dědeček J Structure of framework aluminum Lewis sites and perturbed aluminum atoms in zeolites as determined by $27 \mathrm{Al}\{1 \mathrm{H}\}$ REDOR (3Q) MAS NMR spectroscopy and DFT/molecular mechanics. Angew. Chem. Int. Ed. Engl. 54, 541-5 (2015). [PubMed: 25393612]

66. Peng L, Liu Y, Kim N, Readman JE \& Grey CP Detection of Brønsted acid sites in zeolite HY with high-field 17O-MAS-NMR techniques. Nat. Mater. 4, 216-9 (2005). [PubMed: 15711551]

67. Shcherbakov AA \& Hong M Rapid Measurement of Long-Range Distances in Proteins by Multidimensional 13C-19F REDOR NMR under Fast Magic-Angle Spinning. J. Biomol. NMR 71, 31-43 (2018). [PubMed: 29785460]

68. Shcherbakov AA, Mandala VS \& Hong M High-Sensitivity Detection of Nanometer 1H-19F Distances for Protein Structure Determination by 1H-Detected Fast MAS NMR. J. Phys. Chem. B. 123, 4387-4391 (2019). [PubMed: 31034230]

69. Wang M, Lu M, Fritz M, Quinn C, Byeon IJ, Byeon CH, Struppe J, Maas W, Gronenborn AM \& Polenova T Fast Magic Angle Spinning ${ }^{19}$ F NMR of HIV-1 Capsid Protein Assemblies. Angew. Chem. Int. Ed. 57, 16375-16379 (2018).

70. Ruiz-Preciado MA, Kubicki DJ, Hofstetter A, McGovern L, Futscher MH, Ummadisingu A, Gershoni-Poranne R, Zakeeruddin SM, Ehrler B, Emsley L, Milić JV \& Grätzel M Supramolecular Modulation of Hybrid Perovskite Solar Cells via Bifunctional Halogen Bonding Revealed by TwoDimensional (19)F Solid-State NMR Spectroscopy. J. Am. Chem. Soc. 142, 1645-1654 (2020). [PubMed: 31913617]

71. Gilchrist ML Jr, Monde K, Tomita Y, Iwashita T, Nakanishi K \& McDermott AE Measurement of interfluorine distances in solids. J. Magn. Reson. 152, 1-6 (2001). [PubMed: 11531358]

72. Steigel A \& Spiess HW Dynamic NMR Spectroscopy, (Springer Verlag, Berlin, Heidelberg, New York, 1978).

73. Geahigan KB, Meints GA, Hatcher ME, Orban J \& Drobny GP The dynamic impact of CpG methylation in DNA. Biochemistry 39, 4939-46 (2000). [PubMed: 10769153]

74. Copié V, McDermott AE, Beshah K, Williams JC, Spijker-Assink M, Gebhard R, Lugtenburg J, Herzfeld J \& Griffin RG Deuterium solid-state nuclear magnetic resonance studies of methyl group dynamics in bacteriorhodopsin and retinal model compounds: evidence for a 6-s-trans chromophore in the protein. Biochemistry 33, 3280-6 (1994). [PubMed: 8136363]

75. Munowitz MG, Griffin RG, Bodenhausen G \& Huang TH Two-dimensional rotational spin-echo NMR in solids: correlation of chemical shift and dipolar interactions. J. Am. Chem. Soc. 103, 2529-2533 (1981).

76. Hong M, Gross JD, Rienstra CM, Griffin RG, Kumashiro KK \& Schmidt-Rohr K Coupling Amplification in 2D MAS NMR and Its Application to Torsion Angle Determination in Peptides. J. Magn. Reson. 129, 85-92 (1997). [PubMed: 9405219]

77. deAzevedo ER, Saalwachter K, Pascui O, de Souza AA, Bonagamba TJ \& Reichert D Intermediate motions as studied by solid-state separated local field NMR experiments. J. Chem. Phys. 128, 104505 (2008). [PubMed: 18345904]

78. Hohwy M, Jaroniec CP, Reif B, Rienstra CM \& Griffin RG Determination of local structure and relaxation properties in solid-state NMR: Accurate measurement of amide N-H bond lengths and H-N-H bond angles. J. Am. Chem. Soc. 122, 3218-3219 (2000).

79. Hou GJ, Lu XY, Vega AJ \& Polenova T Accurate measurement of heteronuclear dipolar couplings by phase-alternating R-symmetry (PARS) sequences in magic angle spinning NMR spectroscopy. J. Chem. Phys. 141, e104202 (2014).

80. van Rossum B-J, de Groot CP, Ladizhansky V, Vega S \& de Groot HJM A Method for Measuring Heteronuclear (1H-13C) Distances in High Speed MAS NMR. J. Am. Chem. Soc. 122, 3465-3472 (2000).

81. Schanda P, Huber M, Boisbouvier J, Meier BH \& Ernst M Solid-State NMR Measurements of Asymmetric Dipolar Couplings Provide Insight into Protein Side-Chain Motion. Angew. Chem. Int. Ed. 50, 11005-11009 (2011).

82. Asami S \& Reif B Comparative Study of REDOR and CPPI Derived Order Parameters by 1 HDetected MAS NMR and MD Simulations. J. Phys. Chem. B 121, 8719-8730 (2017). [PubMed: 28841025] 
83. Xue K, Mühlbauer M, Mamone S, Sarkar R \& Reif B Accurate Determination of 1H-15N Dipolar Couplings Using Inaccurate Settings of the Magic Angle in Solid-State NMR Spectroscopy. Angew. Chem. Int. Ed. 58, 4286-4290 (2019).

84. Paluch P, Trebosc J, Nishiyama Y, Potrzebowski MJ, Malon M \& Amoureux JP Theoretical study of CP-VC: A simple, robust and accurate MAS NMR method for analysis of dipolar C-H interactions under rotation speeds faster than ca. $60 \mathrm{kHz}$. J. Magn. Res. 252, 67-77 (2015).

85. deAzevedo ER, Bonagamba TJ, Hu W \& Schmidt-Rohr K Centerband-only detection of exchange: efficient analysis of dynamics in solids by NMR. J. Am. Chem. Soc. 121, 8411-8412 (1999).

86. Krushelnitsky A, deAzevedo E, Linser R, Reif B, Saalwächter K \& Reichert D Direct observation of millisecond to second motions in proteins by dipolar CODEX NMR spectroscopy. J. Am. Chem. Soc. 131, 12097-12099 (2009). [PubMed: 19673476]

87. Giraud N, Blackledge M, Goldman M, Böckmann A, Lesage A, Penin F \& Emsley L Quantitative Analysis of Backbone Dynamics in a Crystalline Protein from Nitrogen-15 Spin-Lattice Relaxation. J. Am. Chem. Soc. 127, 18190-18201 (2005). [PubMed: 16366572]

88. Chevelkov V, Diehl A \& Reif B Measurement of ${ }^{15} \mathrm{~N}-\mathrm{T}_{1}$ Relaxation Rates in a Perdeuterated Protein by MAS Solid-State NMR Spectroscopy. J. Chem. Phys. 128, 052316 (2008). [PubMed: 18266433]

89. Lewandowski JR, Sass HJ, Grzesiek S, Blackledge M \& Emsley L Site-specific measurement of slow motions in proteins. J. Am. Chem. Soc. 133, 16762-16765 (2011). [PubMed: 21923156]

90. Rovo P \& Linser R Microsecond Timescale Protein Dynamics: a Combined Solid-State NMR Approach. Chemphyschem. 19, 34-39 (2018). [PubMed: 29149466]

91. Marion D, Gauto DF, Ayala I, Giandoreggio-Barranco K \& Schanda P Microsecond Protein Dynamics from Combined Bloch-McConnell and Near-Rotary-Resonance R-1p RelaxationDispersion MAS NMR. Chemphyschem 20, 276-284 (2019). [PubMed: 30444575]

92. Giraud N, Blackledge M, Böckmann A \& Emsley L The influence of nitrogen-15 proton-driven spin diffusion on the measurement of nitrogen-15 longitudinal relaxation times. J. Magn. Reson. 184, 51-61 (2007). [PubMed: 17030133]

93. Phan V, Fry EA \& Zilm KW Accounting for the temperature dependence of C-13 spin-lattice relaxation of methyl groups in the glycyl-alanyl-leucine model system under MAS with spin diffusion. J. Biomol. NMR 73, 411-421 (2019). [PubMed: 31407207]

94. Kirchhain H \& van Wullen L Solid state NMR at very high temperatures. Prog. Nucl. Magn. Reson. Spectrosc. 114, 71-85 (2019). [PubMed: 31779886]

95. Meier T, Khandarkhaeva S, Petitgirard S, Korber T, Lauerer A, Rossler E \& Dubrovinsky L NMR at pressures up to $90 \mathrm{GPa}$. J. Magn. Res. 292, 44-47 (2018).

96. Chamas A, Qi L, Mehta HS, Sears JA, Scott SL, Walter ED \& Hoyt DW High temperature/ pressure MAS-NMR for the study of dynamic processes in mixed phase systems. Magn. Reson. Imaging 56, 37-44 (2019). [PubMed: 30482639]

97. Overhauser AW Polarization of nuclei in metals. Phys. Rev. 92, 411-415 (1953).

98. Carver TR \& Slichter CP Polarization of nuclear spins in metals. Phys. Rev. 92, 212-213 (1953).

99. Ni QZ, Daviso E, Can TV, Markhasin E, Jawla SK, Swager TM, Temkin RJ, Herzfeld J \& Griffin RG High Frequency Dynamic Nuclear Polarization. Acc. Chem. Res. 46, 1933-1941 (2013). [PubMed: 23597038]

100. Lilly Thankamony AS, Wittmann JJ, Kaushik M \& Corzilius B Dynamic nuclear polarization for sensitivity enhancement in modern solid-state NMR. Prog. Nucl. Magn. Reson. Spectrosc. 102103, 120-195 (2017).

101. Bajaj VS, Farrar CT, Hornstein MK, Mastovsky I, Vieregg J, Bryant J, Elena B, Kreischer KE, Temkin RJ \& Griffin RG Dynamic nuclear polarization at 9T using a novel $250 \mathrm{GHz}$ gyrotron microwave source. J. Magn. Reson. 160, 85-90 (2003). [PubMed: 12615147]

102. Rossini AJ, Zagdoun A, Lelli M, Lesage A, Copéret C \& Emsley L Dynamic nuclear polarization surface enhanced NMR spectroscopy. Acc. Chem. Res. 46, 1942-1951 (2013). [PubMed: 23517009]

103. Lesage A et al. Surface enhanced NMR spectroscopy by dynamic nuclear polarization. J. Am. Chem. Soc. 132, 15459-61 (2010). [PubMed: 20831165] This is the first paper introducing 
impregnation DNP and showing how it can enable the study of surface structures of materials, using nanoporous silica material as an example.

104. Sauvée C, Rosay M, Casano G, Aussenac F, Weber RT, Ouari O \& Tordo P Highly efficient, water-soluble polarizing agents for dynamic nuclear polarization at high frequency. Angew. Chem. Int. Ed. Engl. 52, 10858-61 (2013). [PubMed: 23956072]

105. Zagdoun A, Casano G, Ouari O, Schwarzwälder M, Rossini AJ, Aussenac F, Yulikov M, Jeschke G, Copéret C, Lesage A, Tordo P \& Emsley L Large molecular weight nitroxide biradicals providing efficient dynamic nuclear polarization at temperatures up to $200 \mathrm{~K}$. J. Am. Chem. Soc. 135, 12790-7 (2013). [PubMed: 23961876]

106. Bertini I, Luchinat C, Parigi G \& Ravera E NMR of Paramagnetic Molecules: Applications to Metallobiomolecules and Models, 2nd Edition, (ELSEVIER SCIENCE BV, SARA BURGERHARTSTRAAT 25, PO BOX 211, 1000 AE AMSTERDAM, NETHERLANDS, 2017).

107. Pell AJ, Pintacuda G \& Grey CP Paramagnetic NMR in solution and the solid state. Prog. Nucl. Magn. Reson. Spectrosc. 111, 1-271 (2019). [PubMed: 31146806]

108. Solomon I Relaxation processes in a system of two spins. Phys. Rev. 99, 559-565 (1955).

109. Buffy JJ, Hong T, Yamaguchi S, Waring A, Lehrer RI \& Hong M Solid-State NMR Investigation of the Depth of Insertion of Protegin-1 in Lipid Bilayers Using Paramagnetic Mn2+. Biophys. J. 85, 2363-2373 (2003). [PubMed: 14507700]

110. Parthasarathy S, Long F, Miller Y, Xiao Y, McElheny D, Thurber K, Ma B, Nussinov R \& Ishii Y Molecular-level examination of $\mathrm{Cu} 2+$ binding structure for amyloid fibrils of 40-residue Alzheimer's $\beta$ by solid-state NMR spectroscopy. J. Am. Chem. Soc. 133, 3390-3400 (2011). [PubMed: 21341665]

111. Nadaud PS, Helmus JJ, Sengupta I \& Jaroniec CP Rapid Acquisition of Multidimensional SolidState NMR Spectra of Proteins Facilitated by Covalently Bound Paramagnetic Tags J. Am. Chem. Soc. 132, 9561-9563 (2010). [PubMed: 20583834]

112. Öster C, Kosol S, Hartlmüller C, Lamley JM, Iuga D, Oss A, Org ML, Vanatalu K, Samoson A, Madl T \& Lewandowski JR Characterization of Protein-Protein Interfaces in Large Complexes by Solid-State NMR Solvent Paramagnetic Relaxation Enhancements. J. Am. Chem. Soc. 139, 12165-12174 (2017). [PubMed: 28780861]

113. Knight MJ, Pell AJ, Bertini I, Felli IC, Gonnelli L, Pierattelli R, Herrmann T, Emsley L \& Pintacuda G Structure and backbone dynamics of a microcrystalline metalloprotein by solid-state NMR. Proc. Natl. Acad. Sci. U. S. A. 109, 11095-100 (2012). [PubMed: 22723345]

114. Wickramasinghe NP, Parthasarathy S, Jones CR, Bhardwaj C, Long F, Kotecha M, Mehboob S, Fung LW, Past J, Samoson A \& Ishii Y Nanomole-scale protein solid-state NMR by breaking intrinsic 1HT1 boundaries. Nat. Methods 6, 215-218 (2009). [PubMed: 19198596]

115. Wu XL \& Zilm KW Complete spectral editing in CPMAS NMR. J. Magn. Reson. A 102, 205213 (1993).

116. Schmidt-Rohr K \& Mao JD Efficient CH-group selection and identification in C-13 solid-state NMR by dipolar DEPT and H-1 chemical-shift filtering. J. Am. Chem. Soc. 124, 13938-13948 (2002). [PubMed: 12431126]

117. Mao JD \& Schmidt-Rohr K Methylene spectral editing in solid-state C-13 NMR by three-spin coherence selection. J. Magn. Reson. 176, 1-6 (2005). [PubMed: 15941664]

118. Rienstra CM, Hohwy M, Hong M \& Griffin RG 2D and 3D 15N-13C-13C NMR chemical shift correlation spectroscopy of solids: assignment of MAS spectra of peptides. J. Am. Chem. Soc. 122, 10979-10990 (2000).

119. Baldus M, Petkova AT, Herzfeld J \& Griffin RG Cross polarization in the tilted frame: assignment and spectral simplification in heteronuclear spin systems. Mol. Phys. 95, 1197-1207 (1998).

120. Pauli J, Baldus M, vanRossum B, Groot H.d. \& Oschkinat H Backbone and side-chain 13C and $15 \mathrm{~N}$ signal assignments of the alpha-spectrin $\mathrm{SH} 3$ domain by magic-angle spinning solid-state NMR at 17.6 Tesla. ChemBioChem 2, 272-281 (2001). [PubMed: 11828455]

121. De Paëpe G, Lewandowski JR, Loquet A, Böckmann A \& Griffin RG Proton assisted recoupling and protein structure determination. J. Chem. Phys. 129, 245101 (2008). [PubMed: 19123534] 
122. Gelenter MD \& Hong M Efficient 15 N-13C Polarization Transfer by Third-Spin-Assisted Pulsed Cross-Polarization Magic-Angle-Spinning NMR for Protein Structure Determination. J. Phys. Chem. B 122, 8367-8379 (2018). [PubMed: 30106585]

123. Ishii Y C-13-C-13 dipolar recoupling under very fast magic angle spinning in solid-state nuclear magnetic resonance: Applications to distance measurements, spectral assignments, and highthroughput secondary-structure determination. J. Chem. Phys. 114, 8473-8483 (2001).

124. Jaroniec CP, Tounge BA, Rienstra CM, Herzfeld J \& Griffin RG Recoupling of heteronuclear dipolar interactions with rotational-echo double-resonance at high magic-angle spinning frequencies. J. Magn. Reson. 146, 132-139 (2000). [PubMed: 10968966]

125. Su Y, Hu F \& Hong M Paramagnetic Cu(II) for Probing Membrane Protein Structure and Function: Inhibition Mechanism of the Influenza M2 Proton Channel. J. Am. Chem. Soc. 134, 8693-8702 (2012). [PubMed: 22519936]

126. Theint T, Xia Y, Nadaud PS, Mukhopadhyay D, Schwieters CD, Surewicz K, Surewicz WK \& Jaroniec CP Structural Studies of Amyloid Fibrils by Paramagnetic Solid-State Nuclear Magnetic Resonance Spectroscopy. J. Am. Chem. Soc. 140, 13161-13166 (2018). [PubMed: 30295029]

127. Su Y, Mani R \& Hong M Asymmetric Insertion of Membrane Proteins in Lipid Bilayers by SolidState NMR Paramagnetic Relaxation Enhancement: a Cell-Penetrating Peptide Example. J. Am. Chem. Soc. 130, 8856-8864 (2008). [PubMed: 18597439]

128. Mandala VS, Loftis AR, Shcherbakov AA, Pentelute BL \& Hong M Atomic Structures of Closed and Open Influenza B M2 Proton Channel Reveal the Conduction Mechanism. Nat. Struc. Mol. Biol. 27, 160-167 (2020).

129. Das BB, Nothnagel HJ, Lu GJ, Son WS, Tian Y, Marassi FM \& Opella SJ Structure determination of a membrane protein in proteoliposomes. J. Am. Chem. Soc. 134, 2047-2056 (2012). [PubMed: 22217388]

130. Phyo P, Wang T, Kiemle SN, O’Neill H, Pingali SV, Hong M \& Cosgrove DJ Gradients in Wall Mechanics and Polysaccharides along Growing Inflorescence Stems. Plant Physiol. 175, 15931607 (2017). [PubMed: 29084904]

131. Williams JK, Zhang Y, Schmidt-Rohr K \& Hong M pH-Dependent Conformation, Dynamics, and Aromatic Interaction of the Gating Tryptophan Residue of the Influenza M2 Proton Channel from Solid-State NMR. Biophys. J. 104, 1698-1708 (2013). [PubMed: 23601317]

132. Chevelkov V, Fink U \& Reif B Accurate determination of order parameters from $1 \mathrm{H}, 15 \mathrm{~N}$ dipolar couplings in MAS solid-state NMR experiments. J. Am. Chem. Soc. 131, 14018-22 (2009). [PubMed: 19743845]

133. Schanda P, Meier BH \& Ernst M Quantitative Analysis of Protein Backbone Dynamics in Microcrystalline Ubiquitin by Solid-State NMR Spectroscopy. J. Am. Chem. Soc. 132, 1595715967 (2010). [PubMed: 20977205]

134. Ma PX, Xue Y, Coquelle N, Haller JD, Yuwen TR, Ayala I, Mikhailovskii O, Willbold D, Colletier JP, Skrynnikov NR \& Schanda P Observing the overall rocking motion of a protein in a crystal. Nature Commun. 6, e8361 (2015).

135. Lewandowski JR, Sein J, Blackledge M \& Emsley L Anisotropic Collective Motion Contributes to Nuclear Spin Relaxation in Crystalline Proteins. J. Am. Chem. Soc. 132, 1246-+ (2010). [PubMed: 19916496]

136. Lewandowski JR, Halse ME, Blackledge M \& Emsley L Protein dynamics. Direct observation of hierarchical protein dynamics. Science 348, 578-581 (2015). [PubMed: 25931561]

137. Smith AA, Ernst M, Riniker S \& Meier BH Localized and Collective Motions in HET-s(218-289) Fibrils from Combined NMR Relaxation and MD Simulation. Angew. Chem. Int. Ed. 58, 93839388 (2019).

138. Shannon MD, Theint T, Mukhopadhyay D, Surewicz K, Surewicz WK, Marion D, Schanda P \& Jaroniec CP Conformational Dynamics in the Core of Human Y145Stop Prion Protein Amyloid Probed by Relaxation Dispersion NMR. Chemphyschem 20, 311-317 (2019). [PubMed: 30276945]

139. Gauto DF, Macek P, Barducci A, Fraga H, Hessel A, Terauchi T, Gajan D, Miyanoiri Y, Boisbouvier J, Lichtenecker R, Kainosho M \& Schanda P Aromatic Ring Dynamics, Thermal Activation, and Transient Conformations of a 468 kDa Enzyme by Specific H-1-C-13 Labeling 
and Fast Magic-Angle Spinning NMR. J. Am. Chem. Soc. 141, 11183-11195 (2019). [PubMed: 31199882] This study provides a quantitative analysis of the coupling of protein and solvent dynamics using relaxation NMR.

140. Wasylishen RE, Ashbrook SE \& Wimperis S NMR of quadrupolar nuclei in solid materials, (John Wiley \& Sons, 2012).

141. Massiot D, Fayon F, Capron M, King I, Le Calve S, Alonso B, Durand JO, Bujoli B, Gan ZH \& Hoatson G Modelling one- and two-dimensional solid-state NMR spectra. Magn. Reson. Chem. 40, 70-76 (2002).

142. Bak M, Rasmussen JT \& Nielsen NC SIMPSON: A general simulation program for solid-state NMR spectroscopy. J. Magn. Res. 147, 296-330 (2000).

143. Ashbrook SE, Berry AJ \& Wimperis S O-17 multiple-quantum MAS NMR study of pyroxenes. J. Phys. Chem. B. 106, 773-778 (2002).

144. Frydman L \& Harwood JS ISOTROPIC SPECTRA OF HALF-INTEGER QUADRUPOLAR SPINS FROM BIDIMENSIONAL MAGIC-ANGLE-SPINNING NMR. J. Am. Chem. Soc. 117, 5367-5368 (1995).

145. Goldbourt A \& Madhu PK Multiple-quantum magic-angle spinning: High-resolution solid-state NMR of half-integer spin quadrupolar nuclei. Annu. Reports on NMR Spec. 54, 81-153 (2005).

146. Moran RF, Dawson DM \& Ashbrook SE Exploiting NMR spectroscopy for the study of disorder in solids. Int. Rev. Phys. Chem. 36, 39-115 (2017).

147. Le Caer G, Bureau B \& Massiot D An extension of the Czjzek model for the distributions of electric field gradients in disordered solids and an application to NMR spectra of Ga-71 in chalcogenide glasses. J. Phys. Condensed Matter 22(2010).

148. Trease NM, Clark TM, Grandinetti PJ, Stebbins JF \& Sen S Bond length-bond angle correlation in densified silica-Results from O-17 NMR spectroscopy. J. Chem. Phys. 146, 184505 (2017).

149. Ashbrook SE \& McKay D Combining solid-state NMR spectroscopy with first-principles calculations - a guide to NMR crystallography. Chem. Commun. 52, 7186-7204 (2016).

150. Bonhomme C, Gervais C, Babonneau F, Coelho C, Pourpoint F, Azais T, Ashbrook SE, Griffin JM, Yates JR, Mauri F \& Pickard CJ First-Principles Calculation of NMR Parameters Using the Gauge Including Projector Augmented Wave Method: A Chemist's Point of View. Chem. Rev. 112, 5733-5779 (2012). [PubMed: 23113537]

151. Pickard CJ \& Mauri F All-electron magnetic response with pseudopotentials: NMR chemical shifts. Phys. Rev. B 63, 245101 (2001). This review describes how to use computational prediction of NMR interactions and NMR parameters alongside experiments to help interpret and assign complex spectral signals, thereby gaining more detailed structural insight.

152. Caulkins BG, Young RP, Kudla RA, Yang C, Bittbauer TJ, Bastin B, Hilario E, Fan L, Marsella MJ, Dunn MF \& Mueller LJ NMR Crystallography of a Carbanionic Intermediate in Tryptophan Synthase: Chemical Structure, Tautomerization, and Reaction Specificity. J. Am. Chem. Soc. 138, 15214-15226 (2016). [PubMed: 27779384]

153. Baias M, Dumez JN, Svensson PH, Schantz S, Day GM \& Emsley L De novo determination of the crystal structure of a large drug molecule by crystal structure prediction-based powder NMR crystallography. J. Am. Chem. Soc. 135, 17501-7 (2013). [PubMed: 24168679] This paper established the framework for accurate calculation of chemical shifts in periodic solids.

154. Cadars S, Allix M, Brouwer DH, Shayib R, Suchomel M, Garaga MN, Rakhmatullin A, Burton AW, Zones SI, Massiot D \& Chmelka BF Long- and Short-Range Constraints for the Structure Determination of Layered Silicates with Stacking Disorder. Chem. Materials 26, 6994-7008 (2014).

155. Charpentier T, Menziani MC \& Pedone A Computational simulations of solid state NMR spectra: a new era in structure determination of oxide glasses. Rsc Advances 3, 10550-10578 (2013).

156. Cady SD, Schmidt-Rohr K, Wang J, Soto CS, DeGrado WF \& Hong M Structure of the amantadine binding site of influenza M2 proton channels in lipid bilayers. Nature 463, 689-692 (2010). [PubMed: 20130653]

157. Sharma M, Yi M, Dong H, Qin H, Peterson E, Busath D, Zhou HX \& Cross TA Insight into the mechanism of the influenza A proton channel from a structure in a lipid bilayer. Science 330, 509-512 (2010). [PubMed: 20966252] 
158. Lange A, Giller K, Hornig S, Martin-Eauclaire MF, Pongs O, Becker S \& Baldus M Toxininduced conformational changes in a potassium channel revealed by solid-state NMR. Nature 440, 959-962 (2006). [PubMed: 16612389] This study demonstrates the first determination of the structure and dynamics of a pharmaceutical drug bound to a membrane protein.

159. Wylie BJ, Bhate MP \& McDermott AE Transmembrane allosteric coupling of the gates in a potassium channel. Proc. Natl. Acad. Sci. U. S. A. 111, 185-190 (2014). [PubMed: 24344306]

160. Öster C, Hendriks K, Kopec W, Chevelkov V, Shi C, Michl D, Lange S, Sun H, de Groot BL \& Lange A The conduction pathway of potassium channels is water free under physiological conditions. Sci. Adv. 5, eaaw6756 (2019). [PubMed: 31392272] This study shows how highaffinity binding of the scorpion toxin to a chimeric $\mathrm{K}+$ channel is associated with significant structural rearrangements in both molecules, which explains the high specificity of toxin-K+ channel interactions.

161. Gayen A, Leninger M \& Traaseth NJ Protonation of a glutamate residue modulates the dynamics of the drug transporter EmrE. Nat. Chem. Biol. 12, 141-145 (2016). [PubMed: 26751516]

162. Lehnert E, Mao JF, Mehdipour AR, Hummers G, Abele R, Glaubitz C \& Tampe R Antigenic Peptide Recognition on the Human ABC Transporter TAP Resolved by DNP-Enhanced SolidState NMR Spectroscopy. J. Am. Chem. Soc. 138, 13967-13974 (2016). [PubMed: 27659210]

163. Lalli D, Idso MN, Andreas LB, Hussain S, Baxter N, Han S, Chmelka BF \& Pintacuda G ProtonBased Structural Analysis of a Heptahelical Transmembrane Protein in Lipid Bilayers. J. Am. Chem. Soc. 139, 13006-13012 (2017). [PubMed: 28724288]

164. Wang SL, Munro RA, Shi LC, Kawamura I, Okitsu T, Wada A, Kim SY, Jung KH, Brown LS \& Ladizhansky V Solid-state NMR spectroscopy structure determination of a lipid-embedded heptahelical membrane protein. Nature Methods 10, 1007-+ (2013). [PubMed: 24013819]

165. Retel JS et al. Structure of outer membrane protein G in lipid bilayers. Nat. Commun. 8(2017).

166. Medeiros-Silva J, Jekhmane S, Paioni AL, Gawarecka K, Baldus M, Swiezewska E, Breukink E \& Weingarth M High-resolution NMR studies of antibiotics in cellular membranes. Nat. Commun. 9, 3963 (2018). [PubMed: 30262913]

167. Amani R, Borcik CG, Khan NH, Versteeg DB, Yekefallah M, Do HQ, Coats HR \& Wylie BJ Conformational changes upon gating of KirBac1.1 into an open-activated state revealed by solidstate NMR and functional assays. Proc. Natl. Acad. Sci. U. S. A. 117, 2938-2947 (2020). [PubMed: 31980523]

168. Mandala VS, Gelenter MD \& Hong M Transport-Relevant Protein Conformational Dynamics and Water Dynamics on Multiple Time Scales in an Archetypal Proton Channel: Insights from SolidState NMR. J. Am. Chem. Soc. 140, 1514-1524 (2018). [PubMed: 29303574]

169. Spadaccini R, Kaur H, Becker-Baldus J \& Glaubitz C The effect of drug binding on specific sites in transmembrane helices 4 and 6 of the ABC exporter MsbA studied by DNP-enhanced solidstate NMR. Biochim. Biophys. Acta 1860, 833-840 (2018).

170. Maciejko J, Kaur J, Becker-Baldus J \& Glaubitz C Photocycle-dependent conformational changes in the proteorhodopsin cross-protomer Asp-His-Trp triad revealed by DNP-enhanced MASNMR. Proc. Natl. Acad. Sci. U. S. A. 116, 8342-8349 (2019). [PubMed: 30948633]

171. Becker-Baldus J, Bamann C, Saxena K, Gustmann H, Brown LJ, Brown RC, Reiter C, Bamberg E, Wachtveitl J, Schwalbe H \& Glaubitz C Enlightening the photoactive site of channelrhodopsin-2 by DNP-enhanced solid-state NMR spectroscopy. Proc. Natl. Acad. Sci. U.S.A. 112, 9896-901 (2015). [PubMed: 26216996]

172. Ni QZ, Can TV, Daviso E, Belenky M, Griffin RG \& Herzfeld J Primary Transfer Step in the Light-Driven Ion Pump Bacteriorhodopsin: An Irreversible U-Turn Revealed by Dynamic Nuclear Polarization-Enhanced Magic Angle Spinning NMR. J. Am. Chem. Soc. 140, 40854091 (2018). [PubMed: 29489362]

173. Good D, Pham C, Jagas J, Lewandowski JR \& Ladizhansky V Solid-State NMR Provides Evidence for Small-Amplitude Slow Domain Motions in a Multispanning Transmembrane aHelical Protein. J. Am. Chem. Soc. 139, 9246-9258 (2017). [PubMed: 28613900]

174. Tycko R Amyloid polymorphism: structural basis and neurobiological relevance. Neuron 86,632 45 (2015). [PubMed: 25950632] 
175. Xiao YL, Ma BY, McElheny D, Parthasarathy S, Long F, Hoshi M, Nussinov R \& Ishii Y A beta(1-42) fibril structure illuminates self-recognition and replication of amyloid in Alzheimer's disease. Nature Struct. Mol. Biol. 22, 499-505 (2015). [PubMed: 25938662]

176. Colvin MT, Silvers R, Ni QZ, Can TV, Sergeyev I, Rosay M, Donovan KJ, Michael B, Wall J, Linse S \& Griffin RG Atomic Resolution Structure of Monomorphic A beta(42) Amyloid Fibrils. J. Am. Chem. Soc. 138, 9663-9674 (2016). [PubMed: 27355699]

177. Wälti MA, Ravotti F, Arai H, Glabe CG, Wall JS, Böckmann A, Güntert P, Meier BH \& Riek R Atomic-resolution structure of a disease-relevant $A \beta(1-42)$ amyloid fibril. Proc. Natl Acad. Sci. U.S.A. 113, E4976-4984 (2016). [PubMed: 27469165]

178. Bousset L, Pieri L, Ruiz-Arlandis G, Gath J, Jensen PH, Habenstein B, Madiona K, Olieric V, Bockmann A, Meier BH \& Melki R Structural and functional characterization of two alphasynuclein strains. Nature Commun. 4(2013). This paper determines an atomic resolution structure of a monomorphic form of A 342 amyloid fibrils, which is essential to the etiology of AD.

179. Tuttle MD et al. Solid-state NMR structure of a pathogenic fibril of full-length human alphasynuclein. Nature Struct. Mol. Biol. 23, 409-415 (2016). [PubMed: 27018801]

180. Fitzpatrick AW et al. Atomic structure and hierarchical assembly of a cross- $\beta$ amyloid fibril. Proc. Natl Acad. Sci. U.S.A. 110, 5468-5473 (2013). [PubMed: 23513222]

181. Iadanza MG, Silvers R, Boardman J, Smith HI, Karamanos TK, Debelouchina GT, Su YC, Griffin RG, Ranson NA \& Radford SE The structure of a beta(2)-microglobulin fibril suggests a molecular basis for its amyloid polymorphism. Nature Commun. 9(2018).

182. Murray DT, Kato M, Lin Y, Thurber KR, Hung I, McKnight SL \& Tycko R Structure of FUS Protein Fibrils and Its Relevance to Self-Assembly and Phase Separation of Low-Complexity Domains. Cell 171, 615-627 (2017). [PubMed: 28942918]

183. Dregni AJ, Mandala VS, Wu H, Elkins MR, Wang HK, Hung I, DeGrado WF \& Hong M In vitro ON4R tau fibrils contain a monomorphic b-sheet core enclosed by dynamically heterogeneous fuzzy coat segments. Proc. Natl. Acad. Sci. U.S.A 116, 16357-16366 (2019). [PubMed: 31358628]

184. Piehl DW, Blancas-Mejía LM, Wall JS, Kennel SJ, Ramirez-Alvarado M \& Rienstra CM Immunoglobulin Light Chains Form an Extensive and Highly Ordered Fibril Involving the Nand C-Termini. ACS Omega 2, 712-720 (2017). [PubMed: 28261692]

185. Hora M, Sarkar R, Morris V, Xue K, Prade E, Harding E, Buchner J \& Reif B Antibody light chain fibrils are similar to oligomeric precursors. PloS ONE 12, e0181799 (2017). [PubMed: 28746363]

186. Prade E, Bittner HJ, Sarkar R, Lopez del Amo JM, Althoff-Ospelt G, Multhaup G, Hildebrand PW \& Reif B Structural mechanism of the interaction of Alzheimer's disease A $\beta$ fibrils with the NSAID sulindac sulfide. J. Biol. Chem. 290, 28737-28745 (2015). [PubMed: 26416887]

187. Lopez del Amo J-M, Dasari M, Fink U, Grelle G, Wanker EE, Bieschke J \& Reif B Structural Properties of EGCG induced, non-toxic Alzheimer's disease A $\beta$ oligomers J. Mol. Biol. 421, 517-524 (2012). [PubMed: 22300765]

188. Chimon S, Shaibat MA, Jones CR, Calero DC, Aizezi B \& Ishii Y Evidence of fibril-like betasheet structures in a neurotoxic amyloid intermediate of Alzheimer's beta-amyloid. Nat. Struct. Mol. Biol. 14, 1157-1164 (2007). [PubMed: 18059284]

189. Qiang W, Yau WM \& Schulte J Fibrillation of $\beta$ amyloid peptides in the presence of phospholipid bilayers and the consequent membrane disruption. Biochim. Biophys. Acta 1848, 266-76 (2015). [PubMed: 24769158]

190. Fusco G, De Simone A, Gopinath T, Vostrikov V, Vendruscolo M, Dobson CM \& Veglia G Direct observation of the three regions in a-synuclein that determine its membrane-bound behaviour. Nat. Commun. 5, 3827 (2014). [PubMed: 24871041]

191. Wang T, Jo H, DeGrado WF \& Hong M Water Distribution, Dynamics, and Interactions with Alzheimer's $\beta$-Amyloid Fibrils Investigated by Solid-State NMR. J. Am. Chem. Soc. 139, 62426252 (2017). [PubMed: 28406028]

192. Murray DT \& Tycko R Side Chain Hydrogen-Bonding Interactions within Amyloid-like Fibrils Formed by the Low-Complexity Domain of FUS: Evidence from Solid State Nuclear Magnetic Resonance Spectroscopy. Biochemistry 59, 364-378 (2020). [PubMed: 31895552] 
193. Dregni AJ, Duan P \& Hong M Hydration and Dynamics of Full-Length Tau Amyloid Fibrils Investigated by Solid-State Nuclear Magnetic Resonance. Biochemistry 59, 2237-2248 (2020). [PubMed: 32453948]

194. Wasmer C, Lange A, Van Melckebeke H, Siemer AB, Riek R \& Meier BH Amyloid fibrils of the HET-s(218-289) prion form a beta solenoid with a triangular hydrophobic core. Science 319, 1523-1526 (2008). [PubMed: 18339938]

195. Gelenter MD, Smith KJ, Liao SY, Mandala VS, Dregni AJ, Lamm MS, Tian Y, Xu W, Pochan DJ, Tucker TJ, Su YC \& Hong M The peptide hormone glucagon forms amyloid fibrils with two coexisting beta-strand conformations. Nat. Struct. Mol. Biol. 26, 592-598 (2019). [PubMed: 31235909]

196. Nespovitaya N, Gath J, Barylyuk K, Seuring C, Meier BH \& Riek R Dynamic Assembly and Disassembly of Functional beta-Endorphin Amyloid Fibrils. J. Am. Chem. Soc. 138, 846-856 (2016). [PubMed: 26699104]

197. Bertini I, Luchinat C, Parigi G, Ravera E, Reif B \& Turano P Solid-state NMR of proteins sedimented by ultracentrifugation. Proc. Nat. Acad. Sci. U.S.A 108, 10396-9 (2011).

198. Yan S, Guo C, Hou G, Zhang H, Lu X, Williams JC \& Polenova T Atomic-resolution structure of the CAP-Gly domain of dynactin on polymeric microtubules determined by magic angle spinning NMR spectroscopy. Proc. Natl. Acad. Sci. U. S. A. 112, 14611-14616 (2015). [PubMed: 26604305]

199. Lu M et al. Dynamic allostery governs cyclophilin A-HIV capsid interplay. Proc. Natl. Acad. Sci. U.S.A. 112, 14617-22 (2015). [PubMed: 26553990]

200. Mainz A, Religa TL, Sprangers R, Linser R, Kay LE \& Reif B NMR spectroscopy of soluble protein complexes at one mega-dalton and beyond. Angew. Chem. Int. Ed. 52, 8746-51 (2013).

201. Kurauskas V, Crublet E, Macek P, Kerfah R, Gauto DF, Boisbouvier J \& Schanda P Sensitive proton-detected solid-state NMR spectroscopy of large proteins with selective CH3 labelling: application to the 50S ribosome subunit. Chem. Commun. 52, 9558-61 (2016).

202. Mainz A, Peschek J, Stavropoulou M, Back KC, Bardiaux B, Asami S, Prade E, Peters C, Weinkauf S, Buchner J \& Reif B The chaperone aB-crystallin uses different interfaces to capture an amorphous and an amyloid client. Nat. Struct. Mol. Biol. 22, 898-905 (2015). [PubMed: 26458046]

203. Felix J, Weinhäupl K, Chipot C, Dehez F, Hessel A, Gauto DF, Morlot C, Abian O, Gutsche I, Velazquez-Campoy A, Schanda P \& Fraga H Mechanism of the allosteric activation of the ClpP protease machinery by substrates and active-site inhibitors. Sci. Adv. 5, eaaw3818 (2019). [PubMed: 31517045]

204. Knight MJ, Felli IC, Pierattelli R, Bertini I, Emsley L, Herrmann T \& Pintacuda G Rapid measurement of pseudocontact shifts in metalloproteins by proton-detected solid-state NMR spectroscopy. J. Am. Chem. Soc. 134, 14730-14733 (2012). [PubMed: 22916960]

205. Bertini I, Bhaumik A, De Paëpe G, Griffin RG, Lelli M, Lewandowski JR \& Luchinat C Highresolution solid-state NMR structure of a $17.6 \mathrm{kDa}$ protein. J. Am. Chem. Soc. 132, 1032-40 (2010). [PubMed: 20041641]

206. Damman R, Schütz S, Luo Y, Weingarth M, Sprangers R \& Baldus M Atomic-level insight into mRNA processing bodies by combining solid and solution-state NMR spectroscopy. Nat. Commun. 10, 4536 (2019). [PubMed: 31586050]

207. Bertarello A, Benda L, Sanders KJ, Pell AJ, Knight MJ, Pelmenschikov V, Gonnelli L, Felli IC, Kaupp M, Emsley L, Pierattelli R \& Pintacuda G Picometer Resolution Structure of the Coordination Sphere in the Metal-Binding Site in a Metalloprotein by NMR. J. Am. Chem. Soc. 142, 16757-16765 (2020). [PubMed: 32871082]

208. Wang T, Phyo P \& Hong M Multidimensional solid-state NMR spectroscopy of plant cell walls. Solid State Nucl. Magn. Reson. 78, 56-63 (2016). [PubMed: 27552739]

209. Takahashi H, Ayala I, Bardet M, De Paëpe G, Simorre JP \& Hediger S Solid-State NMR on Bacterial Cells: Selective Cell Wall Signal Enhancement and Resolution Improvement using Dynamic Nuclear Polarization. J. Am. Chem. Soc. 135, 5105-5110 (2013). [PubMed: 23362837] 
210. Wang T \& Hong M Solid-state NMR investigations of cellulose structure and interactions with matrix polysaccharides in plant primary cell walls. J. Exp. Botany 67, 503-514 (2016). [PubMed: 26355148]

211. Dick-Pérez M, Zhang Y, Hayes J, Salazar A, Zabotina OA \& Hong M Structure and interactions of plant cell-wall polysaccharides by two- and three-dimensional magic-angle-spinning solidstate NMR. Biochemistry 50, 989-1000 (2011). [PubMed: 21204530]

212. Wang T, Yang H, Kubicki JD \& Hong M Cellulose Structural Polymorphism in Plant Primary Cell Walls Investigated by High-Field 2D Solid-State NMR Spectroscopy and Density Functional Theory Calculations. Biomacromolecules 17, 2210-22 (2016). [PubMed: 27192562]

213. Simmons TJ, Mortimer JC, Bernardinelli OD, Pöppler AC, Brown SP, deAzevedo ER, Dupree R \& Dupree P Folding of xylan onto cellulose fibrils in plant cell walls revealed by solid-state NMR. Nat. Commun. 7, 13902 (2016). [PubMed: 28000667]

214. Phyo P, Wang T, Yang Y, O’Neill H \& Hong M Direct Determination of Hydroxymethyl Conformations of Plant Cell Wall Cellulose Using 1H Polarization Transfer Solid-State NMR. Biomacromolecules 19, 1485-1497 (2018). [PubMed: 29562125]

215. Wang T, Park YB, Caporini MA, Rosay M, Zhong L, Cosgrove DJ \& Hong M Sensitivityenhanced solid-state NMR detection of expansin's target in plant cell walls. Proc. Natl. Acad. Sci. U. S. A. 110, 16444-16449 (2013). [PubMed: 24065828]

216. Kang X, Kirui A, Dickwella Widanage MC, Mentink-Vigier F, Cosgrove DJ \& Wang T Ligninpolysaccharide interactions in plant secondary cell walls revealed by solid-state NMR. Nat. Commun. 10, 347 (2019). [PubMed: 30664653]

217. Kang X, Kirui A, Muszyński A, Widanage MCD, Chen A, Azadi P, Wang P, Mentink-Vigier F \& Wang T Molecular architecture of fungal cell walls revealed by solid-state NMR. Nat. Commun. 9, 2747 (2018). [PubMed: 30013106]

218. Bougault C, Ayala I, Vollmer W, Simorre JP \& Schanda P Studying intact bacterial peptidoglycan by proton-detected NMR spectroscopy at $100 \mathrm{kHz}$ MAS frequency. J. Struct. Biol. 206, 66-72 (2019). [PubMed: 30031884]

219. McCrate OA, Zhou X, Reichhardt C \& Cegelski L Sum of the parts: composition and architecture of the bacterial extracellular matrix. J. Mol. Biol. 425, 4286-4294 (2013). [PubMed: 23827139] This solid-state NMR study provided the first comprehensive molecular-level structural insights into lignin-polysaccharide interactions in plant secondary cell walls.

220. Thongsomboon W, Serra DO, Possling A, Hadjineophytou C, Hengge R \& Cegelski L Phosphoethanolamine cellulose: A naturally produced chemically modified cellulose. Science 359, 334-338 (2018). [PubMed: 29348238]

221. Rossini AJ, Zagdoun A, Hegner F, Schwarzwalder M, Gajan D, Coperet C, Lesage A \& Emsley L Dynamic Nuclear Polarization NMR Spectroscopy of Microcrystalline Solids. J. Am. Chem. Soc. 134, 16899-16908 (2012). [PubMed: 22967206]

222. Hartman JD, Day GM \& Beran GJ Enhanced NMR Discrimination of Pharmaceutically Relevant Molecular Crystal Forms through Fragment-Based Ab Initio Chemical Shift Predictions. Cryst. Growth Des. 16, 6479-6493 (2016).

223. Lu X, Huang C, Lowinger MB, Yang F, Xu W, Brown CD, Hesk D, Koynov A, Schenck L \& Su Y Molecular Interactions in Posaconazole Amorphous Solid Dispersions from Two-Dimensional Solid-State NMR Spectroscopy. Mol. Pharm. 16, 2579-2589 (2019). [PubMed: 31021639]

224. Nilsson Lill SO, Widdifield CM, Pettersen A, Svensk Ankarberg A, Lindkvist M, Aldred P, Gracin S, Shankland N, Shankland K, Schantz S \& Emsley L Elucidating an Amorphous Form Stabilization Mechanism for Tenapanor Hydrochloride: Crystal Structure Analysis Using X-ray Diffraction, NMR Crystallography, and Molecular Modeling. Mol. Pharm. 15, 1476-1487 (2018). [PubMed: 29490140]

225. Leclaire J, Poisson G, Ziarelli F, Pepe G, Fotiadu F, Paruzzo FM, Rossini AJ, Dumez JN, ElenaHerrmann B \& Emsley L Structure elucidation of a complex CO2-based organic framework material by NMR crystallography. Chem. Sci 7, 4379-4390 (2016). [PubMed: 30155085]

226. Hofstetter A, Balodis M, Paruzzo FM, Widdifield CM, Steyanato G, Pinon AC, Bygrave PJ, Day GM \& Emsley L Rapid Structure Determination of Molecular Solids Using Chemical Shifts 
Directed by Unambiguous Prior Constraints. J. Am. Chem. Soc. 141, 16624-16634 (2019). [PubMed: 31117663]

227. Engel EA, Anelli A, Hofstetter A, Paruzzo F, Emsley L \& Ceriotti M A Bayesian approach to NMR crystal structure determination. Phys. Chem. Chem. Phys. 21, 23385-23400 (2019). [PubMed: 31631196]

228. Ni QZ et al. In Situ Characterization of Pharmaceutical Formulations by Dynamic Nuclear Polarization Enhanced MAS NMR. J. Phys. Chem. B 121, 8132-8141 (2017). [PubMed: 28762740]

229. Walder BJ, Berk C, Liao WC, Rossini AJ, Schwarzwalder M, Pradere U, Hall J, Lesage A, Coperet C \& Emsley L One- and Two-Dimensional High-Resolution NMR from Flat Surfaces. ACS Central Sci. 5, 515-523 (2019).

230. Webber AL, Masiero S, Pieraccini S, Burey JC, Tatton AS, Iuga D, Pham TN, Spada GP \& Brown SP Identifying Guanosine Self Assembly at Natural Isotopic Abundance by HighResolution H-1 and C-13 Solid-State NMR Spectroscopy. J. Am. Chem. Soc. 133, 19777-19795 (2011). [PubMed: 22034827]

231. Mann SK, Pham TN, McQueen LL, Lewandowski JR \& Brown SP Revealing Intermolecular Hydrogen Bonding Structure and Dynamics in a Deep Eutectic Pharmaceutical by Magic-Angle Spinning NMR Spectroscopy. Mol. Pharm. 17, 622-631 (2020). [PubMed: 31887061]

232. Jiang X, Duan HB, Jellen MJ, Chen Y, Chung TS, Liang Y \& Garcia-Garibay MA Thermally Activated Transient Dipoles and Rotational Dynamics of Hydrogen-Bonded and ChargeTransferred Diazabicyclo 2.2.2 Octane Molecular Rotors. J. Am. Chem. Soc. 141, 16802-16809 (2019). [PubMed: 31547646]

233. Tracht U, Wilhelm M, Heuer A, Feng H, Schmidt-Rohr K \& Spiess HW Length scale of dynamic heterogeneities at the glass transition determined by multidimensional nuclear magnetic resonance. Phys. Rev. Lett. 81, 2727-2730 (1998).

234. Viger-Gravel J, Schantz A, Pinon AC, Rossini AJ, Schantz S \& Emsley L Structure of Lipid Nanoparticles Containing siRNA or mRNA by Dynamic Nuclear Polarization-Enhanced NMR Spectroscopy. J. Phys. Chem. B 122, 2073-2081 (2018). [PubMed: 29332384]

235. Pinon AC, Skantze U, Viger-Gravel J, Schantz S \& Emsley L Core-Shell Structure of Organic Crystalline Nanoparticles Determined by Relayed Dynamic Nuclear Polarization NMR. J. Phys. Chem. A 122, 8802-8807 (2018). [PubMed: 30336028]

236. Johnson RL \& Schmidt-Rohr K Quantitative solid-state 13C NMR with signal enhancement by multiple cross polarization. J. Magn. Reson. 239, 44-49 (2014). [PubMed: 24374751]

237. Mao JD, Cao XY, Olk DC, Chu WY \& Schmidt-Rohr K Advanced solid-state NMR spectroscopy of natural organic matter. Prog. Nuc. Magn. Reson. Spect. 100, 17-51 (2017).

238. Mao JD, Johnson RL, Lehmann J, Olk DC, Neves EG, Thompson ML \& Schmidt-Rohr K Abundant and Stable Char Residues in Soils: Implications for Soil Fertility and Carbon Sequestration. Environ. Sci. Technol. 46, 9571-9576 (2012). [PubMed: 22834642]

239. Duan P, Li X, Wang T, Chen B, Juhl SJ, Koeplinger D, Crespi VH, Badding JV \& Schmidt-Rohr K The Chemical Structure of Carbon Nanothreads Analyzed by Advanced Solid-State NMR. J. Am. Chem. Soc. 140, 7658-7666 (2018). [PubMed: 29808673]

240. Hu YY, Rawal A \& Schmidt-Rohr K Strongly bound citrate stabilizes the apatite nanocrystals in bone. Proc. Natl. Acad. Sci. U. S. A. 107, 22425-22429 (2010). [PubMed: 21127269]

241. Davies E, Müller KH, Wong WC, Pickard CJ, Reid DG, Skepper JN \& Duer MJ Citrate bridges between mineral platelets in bone. Proc. Natl. Acad. Sci. U. S. A. 111, E1354-63 (2014). [PubMed: 24706850] This study employed ${ }^{13} \mathrm{C}$ chemical shifts and ${ }^{13} \mathrm{C}-{ }^{31} \mathrm{P}$ distance NMR experiments to show that the calcium phosphate surfaces in bone are studded with citrate molecules, which stabilize the apatite nanocrystals in bone.

242. Moran RF, McKay D, Tornstrom PC, Aziz A, Fernandes A, Grau-Crespo R \& Ashbrook SE Ensemble-Based Modeling of the NMR Spectra of Solid Solutions: Cation Disorder in Y2(Sn,Ti)2O7. J. Am. Chem. Soc. 141, 17838-17846 (2019). [PubMed: 31591883]

243. Ashbrook SE, Mitchell MR, Sneddon S, Moran RF, de los Reyes M, Lumpkin GR \& Whittle KR New insights into phase distribution, phase composition and disorder in $\mathrm{Y} 2(\mathrm{Zr}, \mathrm{Sn}) 2 \mathrm{O} 7$ ceramics from NMR spectroscopy. Phys. Chem. Chem. Phys. 17, 9049-9059 (2015). [PubMed: 25754713] 
244. Valla M, Rossini AJ, Caillot M, Chizallet C, Raybaud P, Digne M, Chaumonnot A, Lesage A, Emsley L, van Bokhoven JA \& Coperet C Atomic Description of the Interface between Silica and Alumina in Aluminosilicates through Dynamic Nuclear Polarization Surface-Enhanced NMR Spectroscopy and First-Principles Calculations. J. Am. Chem. Soc. 137, 10710-10719 (2015). [PubMed: 26244620] This paper showed how solid-state nuclear magnetic resonance combined with molecular simulations can map the spatial distributions of linkers in multivariate metalorganic framework materials as random, well-mixed, or clustered.

245. Playford HY, Hannon AC, Tucker MG, Dawson DM, Ashbrook SE, Kastiban RJ, Sloan J \& Walton RI Characterization of Structural Disorder in gamma-Ga2O3. J. Phys. Chem. C 118, 16188-16198 (2014).

246. Jaegers NR, Mueller KT, Wang Y \& Hu JZ Variable Temperature and Pressure Operando MAS NMR for Catalysis Science and Related Materials. Acc. Chem. Res. 53, 611-619 (2020). [PubMed: 31927984]

247. Buannic L, Blanc F, Middlemiss DS \& Grey CP Probing Cation and Vacancy Ordering in the Dry and Hydrated Yttrium-Substituted BaSnO3 Perovskite by NMR Spectroscopy and First Principles Calculations: Implications for Proton Mobility. J. Am. Chem. Soc. 134, 14483-14498 (2012). [PubMed: 22691062]

248. Alharbi EA et al. Atomic-level passivation mechanism of ammonium salts enabling highly efficient perovskite solar cells. Nat. Commun. 10, 3008 (2019). [PubMed: 31285432]

249. Kubicki DJ, Prochowicz D, Hofstetter A, Zakeeruddin SM, Gratzel M \& Emsley L Phase Segregation in Cs-, Rb- and K-Doped Mixed-Cation (MA)(x)(FA)(1-x)Pbl(3) Hybrid Perovskites from Solid-State NMR. J. Am. Chem. Soc. 139, 14173-14180 (2017). [PubMed: 28892374]

250. Soleilhavoup A, Hampson MR, Clark SJ, Evans JSO \& Hodgkinson P Using O-17 solid-state NMR and first principles calculation to characterise structure and dynamics in inorganic framework materials. Magn. Reson. Chem. 45, S144-S155 (2007). [PubMed: 18157838]

251. Pecher O, Carretero-Gonzalez J, Griffith KJ \& Grey CP Materials' Methods: NMR in Battery Research. Chem. Materials 29, 213-242 (2017).

252. Liu T, Leskes M, Yu WJ, Moore AJ, Zhou LN, Bayley PM, Kim G \& Grey CP Cycling Li-O-2 batteries via LiOH formation and decomposition. Science 350, 530-533 (2015). [PubMed: 26516278]

253. Chen $\mathrm{J}$ et al. Polar surface structure of oxide nanocrystals revealed with solid-state NMR spectroscopy. Nat. Commun. 10, 5420 (2019). [PubMed: 31780658]

254. Stebbins JF \& Xue XY NMR Spectroscopy of Inorganic Earth Materials. in Spectroscopic Methods in Mineralology and Materials Sciences, Vol. 78 (eds. Henderson GS, Neuville DR \& Downs RT) 605-653 (2014).

255. Griffin JM \& Ashbrook SE Solid-State NMR of High-Pressure Silicates in the Earth's Mantle. Annu. Reports on NMR Spec. 79, 241-332 (2013).

256. Langner R, Fechtelkord M, Garcia A, Palin EJ \& Lopez-Solano J Aluminum ordering and clustering in Al-rich synthetic phlogopite: $\{\mathrm{H}-1\}->$ Si-29 CPMAS HETCOR spectroscopy and atomistic calculations. American Mineralogist 97, 341-352 (2012).

257. Florian P, Veron E, Green TFG, Yates JR \& Massiot D Elucidation of the Al/Si Ordering in Gehlenite Ca2A12SiO7 by Combined Si-29 and Al-27 NMR Spectroscopy/Quantum Chemical Calculations. Chem. Materials 24, 4068-4079 (2012). This paper describes how to overcome key challenges in engineering of $\mathrm{Li}$-air batteries and the use of ${ }^{7} \mathrm{Li}$ and ${ }^{1} \mathrm{H}$ NMR to determine the discharge products and elucidate the origin of protons in the formed $\mathrm{LiOH}$.

258. Palke AC, Stebbins JF, Geiger CA \& Tippelt G Cation order-disorder in Fe-bearing pyrope and grossular garnets: A Al-27 and Si-29 MAS NMR and Fe-57 Mossbauer spectroscopy study. American Mineralogist 100, 536-547 (2015).

259. Gan ZH Isotropic NMR spectra of half-integer quadrupolar nuclei using satellite transitions and magic-angle spinning. J. Am. Chem. Soc. 122, 3242-3243 (2000).

260. Ashbrook SE \& Wimperis S High-resolution NMR of quadrupolar nuclei in solids: the satellitetransition magic angle spinning (STMAS) experiment. Prog. Nucl. Magn. Reson. Spectrosc. 45, 53-108 (2004). 
261. McKay D, Moran RF, Dawson DM, Griffin JM, Sturniolo S, Pickard CJ, Berry AJ \& Ashbrook SE A Picture of Disorder in Hydrous Wadsleyite-Under the Combined Microscope of Solid-State NMR Spectroscopy and Ab Initio Random Structure Searching. J. Am. Chem. Soc. 141, 30243036 (2019). [PubMed: 30676032]

262. Griffin JM, Berry AJ, Frost DJ, Wimperis S \& Ashbrook SE Water in the Earth's mantle: a solidstate NMR study of hydrous wadsleyite. Chem. Sci. 4, 1523-1538 (2013).

263. Ashbrook SE, Dawson DM \& Seymour VR Recent developments in solid-state NMR spectroscopy of crystalline microporous materials. Phys. Chem. Chem. Phys. 16, 8223-8242 (2014). [PubMed: 24675798]

264. Pugh SM, Wright PA, Law DJ, Thompson N \& Ashbrook SE Facile, Room-Temperature O-17 Enrichment of Zeolite Frameworks Revealed by Solid-State NMR Spectroscopy. J. Am. Chem. Soc. 142, 900-906 (2020). [PubMed: 31875398]

265. Bignami GPM, Dawson DM, Seymour VR, Wheatley PS, Morris RE \& Ashbrook SE Synthesis, Isotopic Enrichment, and Solid-State NMR Characterization of Zeolites Derived from the Assembly, Disassembly, Organization, Reassembly Process. J. Am. Chem. Soc. 139, 5140-5148 (2017). [PubMed: 28319391]

266. Nagashima H, Martineau-Corcos C, Tricot G, Trebosc J, Pourpoint F, Amoureux JP \& Lafon O Recent Developments in NMR Studies of Aluminophosphates. 94, 113-185 (2018).

267. Dawson DM, Griffin JM, Seymour VR, Wheatley PS, Amri M, Kurkiewicz T, Guillou N, Wimperis S, Walton RI \& Ashbrook SE A Multinuclear NMR Study of Six Forms of AlPO-34: Structure and Motional Broadening. J. Phys. Chem. C 121, 1781-1793 (2017).

268. Lucier BEG, Chen SS \& Huang YN Characterization of Metal-Organic Frameworks: Unlocking the Potential of Solid-State NMR. Acc. Chem. Res. 51, 319-330 (2018). [PubMed: 29251909]

269. Witherspoon VJ, Xu J \& Reimer JA Solid-State NMR Investigations of Carbon Dioxide Gas in Metal-Organic Frameworks: Insights into Molecular Motion and Adsorptive Behavior. Chem. Rev. 118, 10033-10048 (2018). [PubMed: 30288971]

270. Kong XQ, Deng HX, Yan FY, Kim J, Swisher JA, Smit B, Yaghi OM \& Reimer JA Mapping of Functional Groups in Metal-Organic Frameworks. Science 341, 882-885 (2013). [PubMed: 23887875]

271. Bonhomme C, Gervais C \& Laurencin D Recent NMR developments applied to organic-inorganic materials. Prog. Nucl. Magn. Reson. Spectrosc. 77, 1-48 (2014). [PubMed: 24411829]

272. Eden M Al-27 NMR Studies of Aluminosilicate Glasses. 86, 237-331 (2015).

273. Pustovgar E, Sangodkar RP, Andreev AS, Palacios M, Chmelka BF, Flatt RJ \& de Lacaillerie JBD Understanding silicate hydration from quantitative analyses of hydrating tricalcium silicates. Nature Commun. 7(2016).

274. Kunhi Mohamed A, Moutzouri P, Berruyer P, Walder BJ, Siramanont J, Harris M, Negroni M, Galmarini SC, Parker SC, Scrivener KL, Emsley L \& Bowen P The Atomic-Level Structure of Cementitious Calcium Aluminate Silicate Hydrate. J. Am. Chem. Soc. 142, 11060-11071 (2020). [PubMed: 32406680]

275. Gervais C, Bonhomme C \& Laurencin D Recent directions in the solid-state NMR study of synthetic and natural calcium phosphates. Solid State Nucl. Magn. Reson. 107, 101663 (2020). [PubMed: 32325374]

276. Casabianca LB Solid-state nuclear magnetic resonance studies of nanoparticles. Solid State Nucl. Magn. Reson. 107, 101664 (2020). [PubMed: 32361159]

277. Al-Johani $\mathrm{H}$ et al. The structure and binding mode of citrate in the stabilization of gold nanoparticles. Nature Chem. 9, 890-895 (2017). [PubMed: 28837175]

278. Berrettini MG, Braun G, Hu JG \& Strouse GF NMR analysis of surfaces and interfaces in 2-nm CdSe. J. Am. Chem. Soc. 126, 7063-7070 (2004). [PubMed: 15174877]

279. Avenier P, Taoufik M, Lesage A, Solans-Monfort X, Baudouin A, de Mallmann A, Veyre L, Basset JM, Eisenstein O, Emsley L \& Quadrelli EA Dinitrogen dissociation on an isolated surface tantalum atom. Science 317, 1056-1060 (2007). [PubMed: 17717179]

280. Trebosc J, Wiench JW, Huh S, Lin VSY \& Pruski M Studies of organically functionalized mesoporous silicas using heteronuclear solid-state correlation NMR spectroscopy under fast magic angle spinning. J. Am. Chem. Soc. 127, 7587-7593 (2005). [PubMed: 15898810] 
281. Wang M et al. Identification of different oxygen species in oxide nanostructures with (17)O solidstate NMR spectroscopy. Sci. Adv. 1, e1400133 (2015). [PubMed: 26601133]

282. Berruyer P, Lelli M, Conley MP, Silverio DL, Widdifield CM, Siddiqi G, Gajan D, Lesage A, Coperet C \& Emsley L Three-Dimensional Structure Determination of Surface Sites. J. Am. Chem. Soc. 139, 849-855 (2017). [PubMed: 27997167]

283. Kobayashi T, Perras FA, Slowing II, Sadow AD \& Pruski M Dynamic Nuclear Polarization SolidState NMR in Heterogeneous Catalysis Research. Acs Catalysis 5, 7055-7062 (2015).

284. Perras FA, Wang ZR, Naik P, Slowing II \& Pruski M Natural Abundance O-17 DNP NMR Provides Precise O-H Distances and Insights into the Bronsted Acidity of Heterogeneous Catalysts. Angew. Chem. Int. Ed. 56, 9165-9169 (2017).

285. Tošner Z, Sarkar R, Becker-Baldus J, Glaubitz C, Wegner S, Engelke F, Glaser SJ \& Reif B Overcoming Volume Selectivity of Dipolar Recoupling in Biological Solid-State NMR Spectroscopy. Angew. Chem. Int. Ed. Engl. 57, 14514-14518 (2018). [PubMed: 29989288]

286. Lewandowski JR, De Paëpe G \& Griffin RG Proton assisted insensitive nuclei cross polarization. J. Am. Chem. Soc. 129, 728-9 (2007). [PubMed: 17243786]

287. Samoson AH-MAS J. Magn. Res. 306, 167-172 (2019).

288. Wang Z, Hanrahan MP, Kobayashi T, Perras FA, Chen Y, Engelke F, Reiter C, Purea A, Rossini AJ \& Pruski M Combining fast magic angle spinning dynamic nuclear polarization with indirect detection to further enhance the sensitivity of solid-state NMR spectroscopy. Solid State Nucl. Magn. Reson. 109, 101685 (2020). [PubMed: 32932182]

289. Tycko R \& Hu KN A Monte Carlo/simulated annealing algorithm for sequential resonance assignment in solid state NMR of uniformly labeled proteins with magic-angle spinning. J. Magn. Reson. 205, 304-314 (2010). [PubMed: 20547467]

290. Fritzsching KJ, Yang Y, Schmidt-Rohr K \& Hong M Practical use of chemical shift databases for protein solid-state NMR: 2D chemical shift maps and amino-acid assignment with secondarystructure information. J. Biomol. NMR 56, 155-167 (2013). [PubMed: 23625364]

291. Fritzsching KJ, Hong M \& Schmidt-Rohr K Conformationally selective multidimensional chemical shift ranges in proteins from a PACSY database purged using intrinsic quality criteria. J. Biomol. NMR 64, 115-130 (2016). [PubMed: 26787537]

292. Yang Y, Fritzsching KJ \& Hong M Resonance Assignment of Disordered Proteins Using a MultiObjective Non-Dominated Sorting Genetic Algorithm. J. Biomol. NMR 57, 281-296 (2013). [PubMed: 24132778]

293. Bartok AP \& Yates JR Regularized SCAN functional. J. Chem. Phys. 150(2019).

294. Hartman JD, Kudla RA, Day GM, Mueller LJ \& Beran GJ Benchmark fragment-based (1)H, (13) C, (15)N and (17)O chemical shift predictions in molecular crystals. Phys. Chem. Chem. Phys. 18, 21686-709 (2016). [PubMed: 27431490]

295. Paruzzo FM, Hofstetter A, Musil F, De S, Ceriotti M \& Emsley L Chemical shifts in molecular solids by machine learning. Nat. Commun. 9, 4501 (2018). [PubMed: 30374021]

296. Iwasa Y, Bascunán J, Hahn S, Voccio J, Kim Y, Lécrevisse T, Song J \& Kajikawa K A HighResolution 1.3-GHz/54-mm LTS/HTS NMR Magnet. IEEE Trans. Appl. Supercond. 25(2015).

297. Gan Z et al. NMR spectroscopy up to $35.2 \mathrm{~T}$ using a series-connected hybrid magnet. J. Magn. Reson. 284, 125-136 (2017). [PubMed: 28890288]

298. Xue K, Sarkar R, Lalli D, Koch B, Pintacuda G, Tosner Z \& Reif B Impact of Magnetic field strength on Resolution and Sensitivity of Proton Resonances in Biological Solids. J. Biomol. NMR submitted(2020).

299. Keeler EG, Michaelis VK, Colvin MT, Hung I, Gor'kov PL, Cross TA, Gan Z \& Griffin RG (17)O MAS NMR Correlation Spectroscopy at High Magnetic Fields. J. Am. Chem. Soc. 139, 17953-17963 (2017). [PubMed: 29111706]

300. Chen PH, Albert BJ, Gao CK, Alaniva N, Price LE, Scott FJ, Saliba EP, Sesti EL, Judge PT, Fisher EW \& Barnes AB Magic angle spinning spheres. Sci. Adv. 4(2018).

301. Agarwal V, Penzel S, Szekely K, Cadalbert R, Testori E, Oss A, Past J, Samoson A, Ernst M, Bockmann A \& Meier BH De Novo 3D Structure Determination from Sub-milligram Protein Samples by Solid-State 100 kHz MAS NMR Spectroscopy. Angew. Chem. Int. Ed. 53, 1225312256 (2014). 
302. Xue K, Sarkar R, Motz C, Asami S, Decker V, Wegner S, Tošner Z \& Reif B Magic Angle spinning frequencies beyond $300 \mathrm{kHz}$ are necessary to yield Maximum Sensitivity in Selectively Methyl Protonated protein samples in solid state NMR. J. Phys. Chem. C 122, 16437-16442 (2018).

303. Gao C, Judge PT, Sesti EL, Price LE, Alaniva N, Saliba EP, Albert BJ, Soper NJ, Chen PH \& Barnes AB Four millimeter spherical rotors spinning at $28 \mathrm{kHz}$ with double-saddle coils for cross polarization NMR. J. Magn. Reson. 303, 1-6 (2019). [PubMed: 30978570]

304. Berruyer P, Björgvinsdóttir S, Bertarello A, Stevanato G, Rao Y, Karthikeyan G, Casano G, Ouari O, Lelli M, Reiter C, Engelke F \& Emsley L Dynamic Nuclear Polarization Enhancement of 200 at 21.15 T Enabled by $65 \mathrm{kHz}$ Magic Angle Spinning. J. Phys. Chem. Lett. 11, 8386-8391 (2020). [PubMed: 32960059]

305. Can TV, Walish JJ, Swager TM \& Griffin RG Time domain DNP with the NOVEL sequence. J. Chem. Phys. 143, 054201 (2015). [PubMed: 26254646]

306. Jaudzems K et al. Dynamic Nuclear Polarization-Enhanced Biomolecular NMR Spectroscopy at High Magnetic Field with Fast Magic-Angle Spinning. Angew. Chem. Int. Ed. 57, 7458-7462 (2018).

307. Tosner Z, Vosegaard T, Kehlet C, Khaneja N, Glaser SJ \& Nielsen NC Optimal control in NMR spectroscopy: Numerical implementation in SIMPSON. J. Magn. Res. 197, 120-134 (2009).

308. Concistrè M, Johannessen OG, Carignani E, Geppi M \& Levitt MH Magic-angle spinning NMR of cold samples. Acc. Chem. Res. 46, 1914-22 (2013). [PubMed: 23488538]

309. Jeon J, Thurber KR, Ghirlando R, Yau WM \& Tycko R Application of millisecond time-resolved solid state NMR to the kinetics and mechanism of melittin self-assembly. Proc. Natl. Acad. Sci. U. S. A. 116, 16717-16722 (2019). [PubMed: 31387974]

310. Freedberg DI \& Selenko P Live cell NMR. Annu. Rev. Biophys. 43, 171-92 (2014). [PubMed: 24895852]

311. Chow WY et al. NMR spectroscopy of native and in vitro tissues implicates polyADP ribose in biomineralization. Science 344, 742-6 (2014). [PubMed: 24833391]

312. Narasimhan S, Scherpe S, Lucini Paioni A, van der Zwan J, Folkers GE, Ovaa H \& Baldus M DNP-Supported Solid-State NMR Spectroscopy of Proteins Inside Mammalian Cells. Angew. Chem. Int. Ed. 58, 12969-12973 (2019).

313. Jacso T, Franks WT, Rose H, Fink U, Broecker J, Keller S, Oschkinat H \& Reif B Characterization of membrane proteins in isolated native cellular membranes by dynamic nuclear polarization solid-state NMR spectroscopy without purification and reconstitution. Angew. Chem. Int. Ed. 51, 432-435 (2012).

314. Kaplan M et al. EGFR Dynamics Change during Activation in Native Membranes as Revealed by NMR. Cell 167, 1241-+ (2016). [PubMed: 27839865]

315. Yusa G, Muraki K, Takashina K, Hashimoto K \& Hirayama Y Controlled multiple quantum coherences of nuclear spins in a nanometre-scale device. Nature 434, 1001-5 (2005). [PubMed: 15846341]

316. Meriles CA, Sakellariou D, Moulé A, Goldman M, Budinger TF \& Pines A High-resolution NMR of static samples by rotation of the magnetic field. J. Magn. Reson. 169, 13-8 (2004). [PubMed: 15183351]

317. Sakellariou D, Hugon C, Guiga A, Aubert G, Cazaux S \& Hardy P Permanent magnet assembly producing a strong tilted homogeneous magnetic field: towards magic angle field spinning NMR and MRI. Magn. Reson. Chem. 48, 903-8 (2010). [PubMed: 20891027]

318. Niu Z, Sarkar R, Aichler M, Wester H-J, Yousefi BH \& Reif B Mapping of the binding interface of PET tracer molecules and Alzheimer Disease A $\beta$ fibrils using MAS solid-state NMR. ChemBioChem in press, 10.1002/cbic.202000143(2020).

319. Reichert D \& Krushelnitsky A CODEX-based Methods for Studying Slow Dynamics. in Modern Methods in Solid-state NMR: A Practitioner's Guide (ed. Hodgkinson P) (RSC Publishing 2018).

320. Haw JF, Song W, Marcus DM \& Nicholas JB The mechanism of methanol to hydrocarbon catalysis. Acc. Chem. Res. 36, 317-26 (2003). [PubMed: 12755641]

321. Alanazi AQ et al. Atomic-Level Microstructure of Efficient Formamidinium-Based Perovskite Solar Cells Stabilized by 5-Ammonium Valeric Acid Iodide Revealed by Multinuclear and Two- 
Dimensional Solid-State NMR. J. Am. Chem. Soc. 141, 17659-17669 (2019). [PubMed: 31593456]

322. Martins V, Xu J, Wang X, Chen K, Hung I, Gan Z, Gervais C, Bonhomme C, Jiang S, Zheng A, Lucier BEG \& Huang Y Higher Magnetic Fields, Finer MOF Structural Information: (17)O Solid-State NMR at 35.2 T. J. Am. Chem. Soc. 142, 14877-14889 (2020). [PubMed: 32786791] 
Box 1.

\section{Coupling terms and methods}

\section{through-bond $J$ coupling}

The $\mathrm{J}$ coupling is the coupling between nuclear spins that is mediated by the electrons in the chemical bonds. In solution-state NMR spectroscopy J coupling is responsible for the complex splitting of resonance lines. In solids, these splittings are usually not resolved in the spectra, but the $\mathrm{J}$ coupling can be used to transfer magnetisation between nuclear spins. The J coupling has both isotropic and anisotropic components.

\section{through-space dipolar coupling}

The dipolar coupling results from the direct through-space interaction of one nuclear spin with the magnetic field generated by a proximal spin. The coupling falls off rapidly with internuclear distance (proportional to $\mathrm{r}^{-3}$ ) and so provides information on spatial proximity. Unlike the $\mathbf{J}$ coupling, the dipolar coupling is purely anisotropic and so is averaged to zero in a rapidly tumbling isotropic solution.

Decoupling is the application of either continuous or pulsed RF irradiation on a nuclear spin channel in order to remove the scalar and/or dipolar couplings between that nuclear spin and other nuclei. Both heteronuclear and homonuclear decoupling can be conducted. Decoupling is critical for enhancing the resolution and sensitivity of the observed spin.

Dipolar recoupling is the application of RF pulses that selectively reintroduce heteronuclear or homonuclear dipolar interactions under MAS of the sample. In this way, dipolar couplings can be used to transfer spin polarization from one nucleus to another, or to measure internuclear distances to restrain three-dimensional structures. 


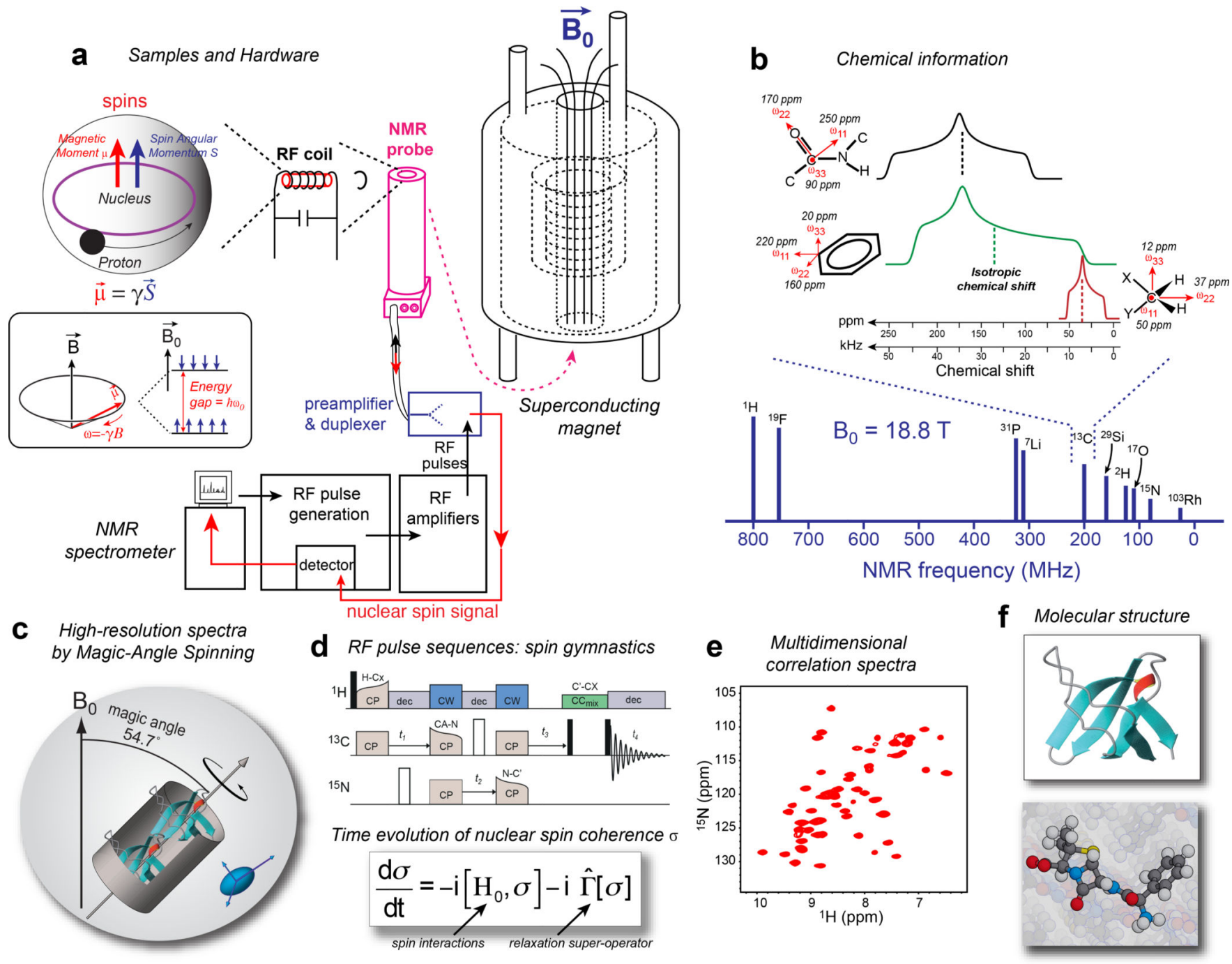

FIG. 1. Basics of solid-state NMR for structural analysis of biomolecules and materials.

a. Nuclear spin magnetic dipole moments $(\mu)$ precess around a static magnetic field $\left(\mathrm{B}_{0}\right)$ at a frequency that is identical to the transition frequency between the energy levels of the spins $\left(\Delta \mathrm{E}=\hbar \mathrm{v}_{0}\right)$ A radiofrequency $(\mathrm{RF})$ coil wrapped around the sample at the top of an NMR probe that is inserted into the center of the magnet allows irradiation of the RF pulses as well as detection of the transition frequency of the nuclear magnetic moment. Angular velocity, $\omega=-\gamma B$. (b) The NMR frequencies of different nuclear isotopes depend on their gyromagnetic ratios $(\gamma)$ and the magnetic field $\left(\mathrm{B}_{0}=18.8 \mathrm{~T}\right.$, in this example). In addition, for spins of the same isotope, the frequency depends sensitively on the electronic environment of the individual nuclei. Schematic NMR spectra of a static powder containing three ${ }^{13} \mathrm{C}$ nuclei relate to the chemical structure of attached functional groups. The broad powder pattern reflects chemical shift anisotropy (CSA), whose geometric average corresponds to the isotropic chemical shifts, which are detected when the sample undergoes magic-angle spinning (MAS). (c) MAS of the sample in the rotor yields high-resolution NMR spectra of solids by averaging the anisotropic part of the interaction to zero. 
a ${ }^{1 D}{ }^{13} \mathrm{C} \mathrm{CP}$

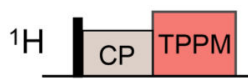

${ }^{13} \mathrm{C}$

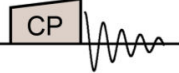

d $2 \mathrm{D}{ }^{1} \mathrm{H}-{ }^{13} \mathrm{C}$ HETCOR

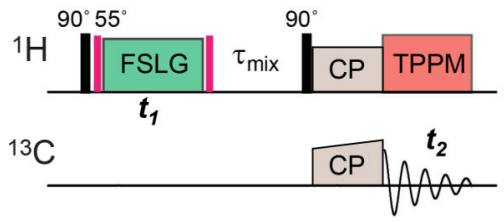

b $2 \mathrm{D}{ }^{13} \mathrm{C}-{ }^{13} \mathrm{C}$ DARR

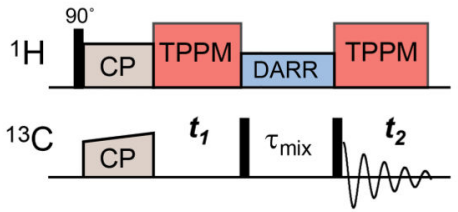

e $2 \mathrm{D}{ }^{13} \mathrm{C}-{ }^{-1} \mathrm{H}$ DIPSHIFT

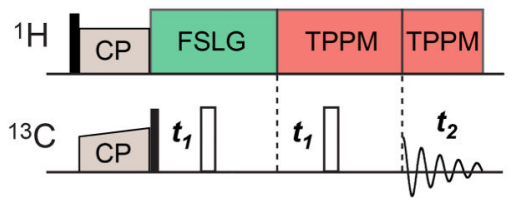

c $2 \mathrm{D}{ }^{13} \mathrm{C}-{ }^{13} \mathrm{C}$ refocused-INADEQUATE

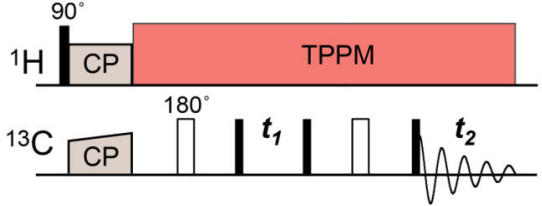

f $1 \mathrm{D} X-Y$ REDOR

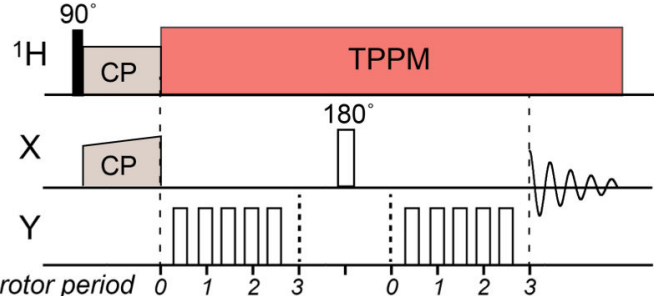

g $3 \mathrm{D} \mathrm{NCaCx}$

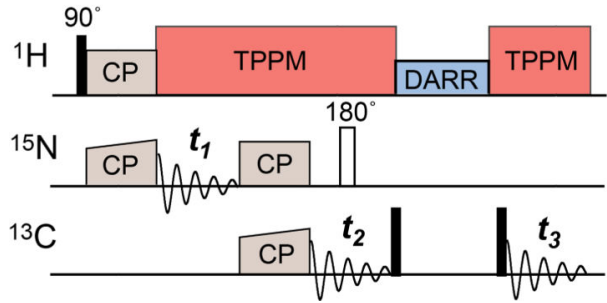

h $2 \mathrm{D} \mathrm{hNH}$

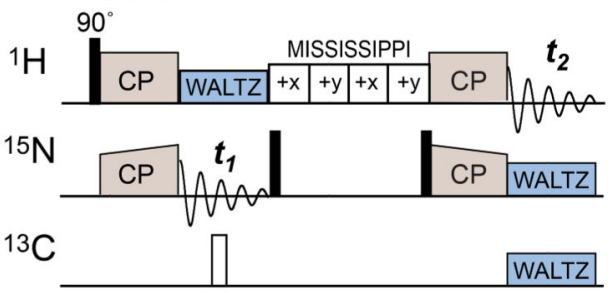

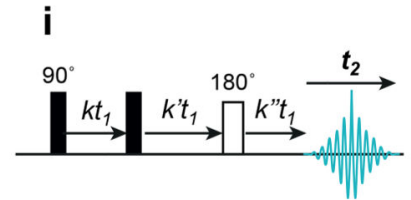

FIG. 2. Some common solid-state NMR pulse sequences.

${ }^{13} \mathrm{C}$ is used as an example of a heteronuclear (X) spin. (a) Cross polarization (CP). (b) 2D

${ }^{1} \mathrm{H}_{-}{ }^{13} \mathrm{C}$ heteronuclear chemical shift correlation (HETCOR) with ${ }^{1} \mathrm{H}$ homonuclear decoupling. (c) $2 \mathrm{D}^{13} \mathrm{C}-{ }^{13} \mathrm{C}$ correlation through dipolar spin diffusion. (d) $2 \mathrm{D}^{13} \mathrm{C}-{ }^{13} \mathrm{C} \mathrm{J}$ based refocused-incredible natural abundance double quantum transfer experiment (INADEQUATE). (e) The multiple-quantum MAS (MQMAS) experiment for quadrupolar nuclei. (f) X-Y rotational echo double resonance (REDOR) for heteronuclear distance measurement. (g) $2 \mathrm{D}^{13} \mathrm{C}_{-}{ }^{1} \mathrm{H}$ dipolar shift correlation (DIPSHIFT). (h) Centerband-only detection of exchange (CODEX) pulse sequence for studying slow motion. (i) $2 \mathrm{D}{ }^{1} \mathrm{H}-$ detected hNH correlation under fast MAS. WALTZ is applied to yield heteronuclear scalar decoupling. In these pulse sequences, the heteronuclear decoupling scheme can be TPPM, SPINAL and other sequences, while the homonuclear decoupling scheme can be FSLG, DUMBO, and other sequences. The symbols $\mathrm{t}_{1}, \mathrm{t}_{2}$ and $\mathrm{t}_{3}$ refer to time domain increments for $2 \mathrm{D}$ and $3 \mathrm{D}$ experiments, and $90^{\circ}$ and $180^{\circ}$ pulses are shown as filled and open narrow rectangles, respectively. DARR: dipolar-assisted rotational resonance. FSLG: frequencyswitched Lee-Goldburg. TPPM: two-pulse phase modulation. 


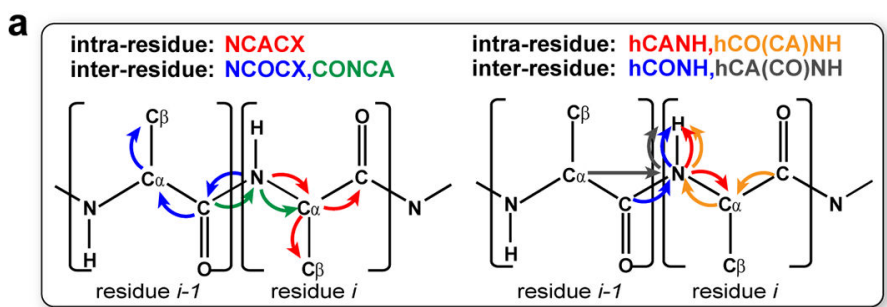

b

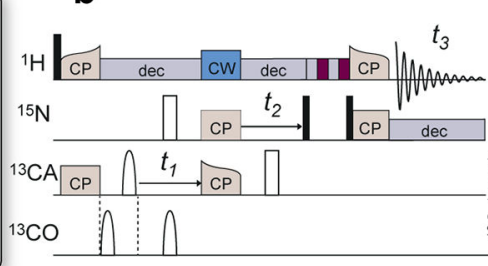

${ }^{13} \mathrm{CO}$

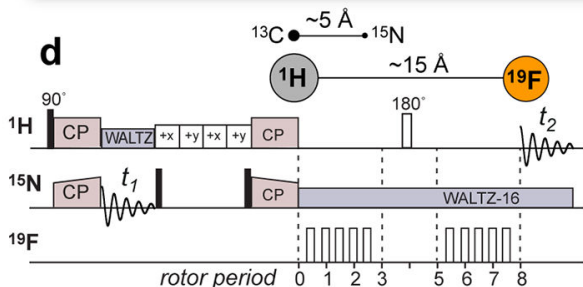

e
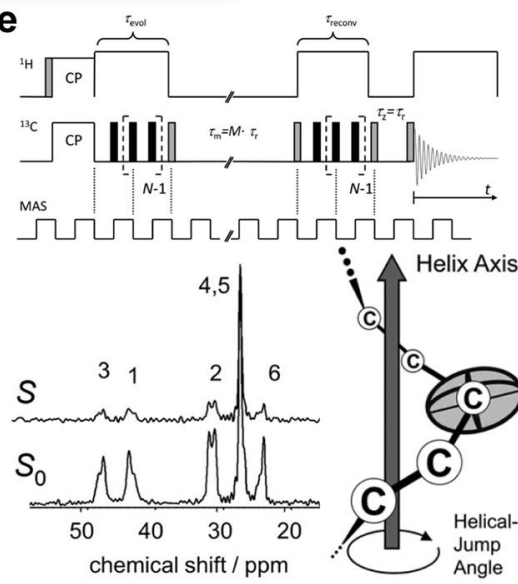
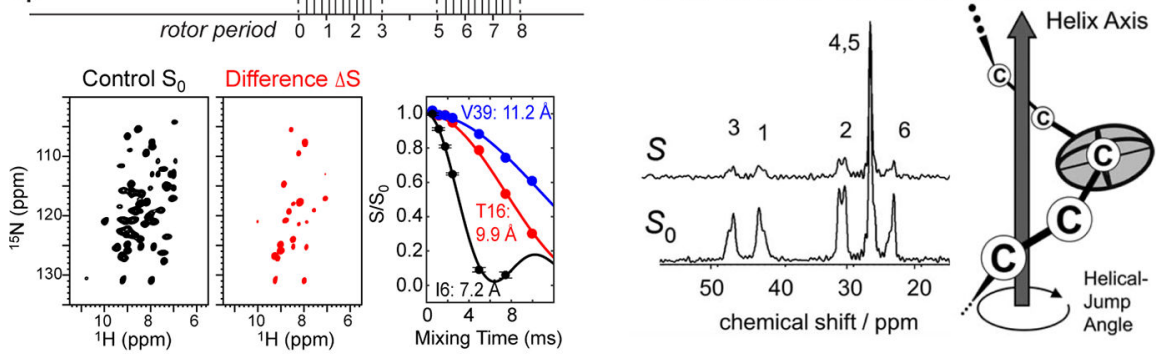

Fig. 3. Representative solid-state NMR results and experiments.

(a) Resonance assignment experiments. The chemical shifts of ${ }^{13} \mathrm{C},{ }^{15} \mathrm{~N}$, and ${ }^{1} \mathrm{H}$ are correlated to obtain sequence-specific assignment of all chemical shifts. (b) Intra-residue hCANH and inter-residue $\mathrm{hCA}(\mathrm{CO}) \mathrm{NH}$ correlation spectra of $\mathrm{A} \beta$ fibrils ${ }^{318}$. (c) ${ }^{1} \mathrm{H}^{-}{ }^{19} \mathrm{~F}$ REDOR to measure internuclear distances to $1.5 \mathrm{~nm}$. The spectra shown is for the model protein $\mathrm{GB} 1$, where amide protons that are close to the ${ }^{19} \mathrm{~F}$ spins manifest intensities in the difference spectrum $\Delta S^{68}$. The REDOR dephasing for the cross peaks is fit to give the ${ }^{1} \mathrm{H}-{ }^{19} \mathrm{~F}$ distances. (d) Centerband-only detection of exchange (CODEX) to study slow motion as shown with an experiment used to determine the rates of helical jumps in isotactic-poly(4-methyl-1-pentene) as shown with helix axis model (right) ${ }^{319}$. (e) ${ }^{17} \mathrm{O}$ magic angle spinning (MAS, left) and multiple-quantum MAS (MQMAS, right) spectra of $\mathrm{MgSiO}_{3}$, showing resolution of six distinct $\mathrm{O}$ species. Lineshapes simulated using density functional theory (DFT) calculated values are also shown (red), enabling assignment of all signals ${ }^{143}$.
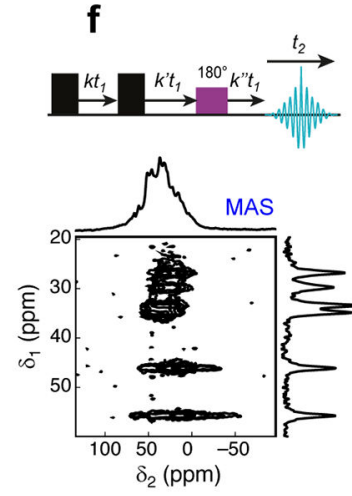

$A B(1-40)$ fibril hCANH 15N: 109.7 ppm $15 \mathrm{~N}: 111.1$ ppm $15 \mathrm{~N}: 123.5 \mathrm{pp}$

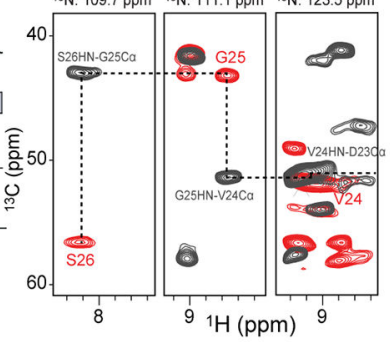

${ }_{1}(\mathrm{ppm})$

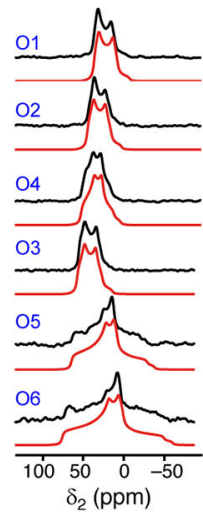




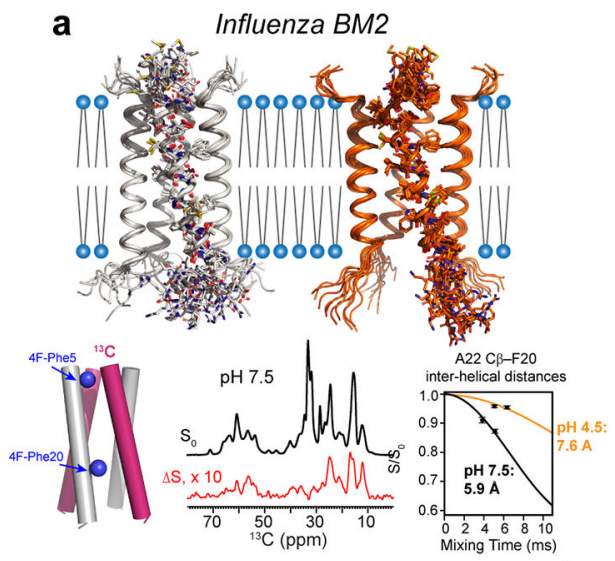

b Proteorhodopsin

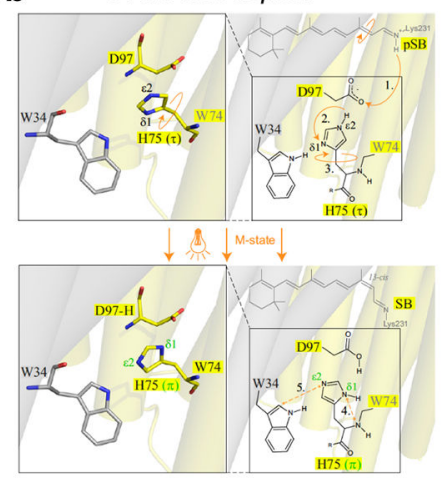

C AB fibrils with bound ligand

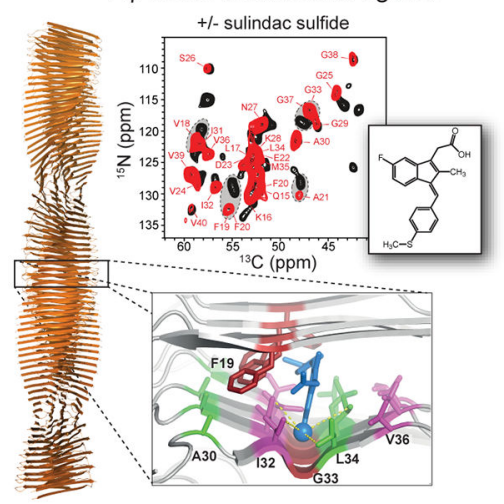

e Protein-protein interactions $\alpha B$ crystallin
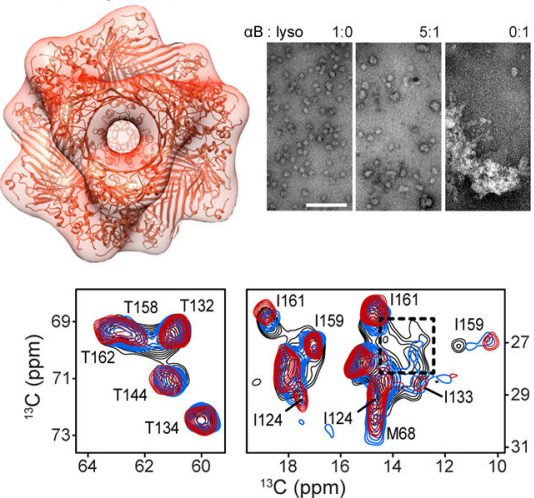

d

Glucagon fibrils
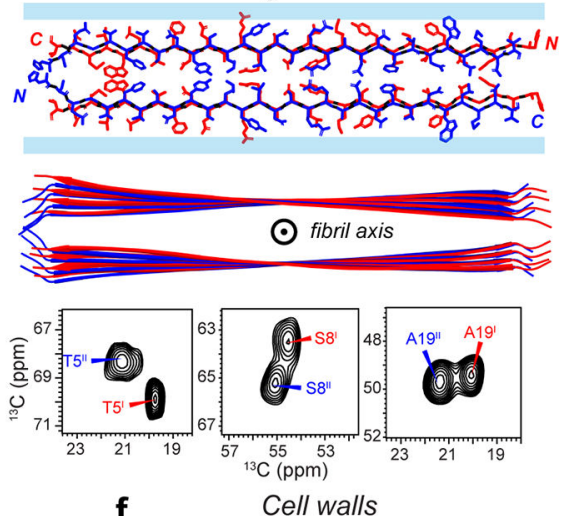

f

Cell walls

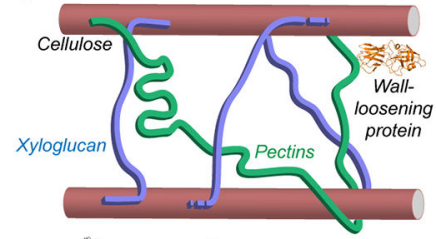

is

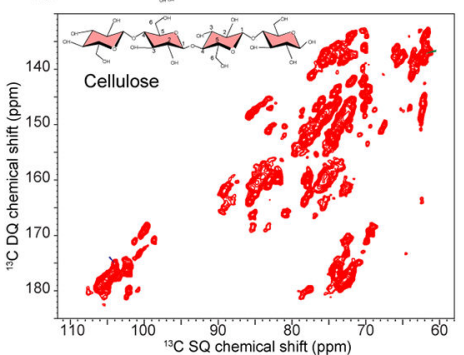

Fig. 4. Applications of solid-state NMR to biological chemistry.

(a, b) Examples of membrane protein studies. (a) Atomic-resolution structures of the influenza B M2 proton channel in its closed and open states ${ }^{128}$. The structures, determined using interhelical distance experiments such as ${ }^{13} \mathrm{C}-{ }^{19} \mathrm{~F}$ REDOR and orientation experiments, reveal a distinct activation mechanism of the channel compared to influenza $\mathrm{A}$ M2 protein. (b) Structural changes of a Asp-His-Trp triad in the pentameric light-driven proton pump, green proteorhodopsin (GPR) ${ }^{170}$. DNP NMR experiments revealed tautomeric and rotameric structural changes of His75 to mediate proton transfer. (c, d) 
Examples of amyloid fibril studies. (c) The binding site of sulindac sulfide to the Alzheimer's disease A $\beta$ peptide is determined by $2 \mathrm{D}$ experiments and chemical shift perturbation ${ }^{186}$. Structure on left generated using PDB: 2LMN. (d) Atomic-resolution structure of the glucagon amyloid fibril. The peptide assembles as an antiparallel cross- $\beta$ fibril that contains two coexisting molecular conformations. These two conformations manifest as two sets of chemical shifts for each atom in the spectra ${ }^{195}$. (e) The

polysaccharide-rich cell walls of plants, bacterial and fungi can be studied using 2D and 3D NMR to understand how macromolecular packing and dynamics explain the properties of these biomaterials. The $2 \mathrm{D}{ }^{13} \mathrm{C}$ refocused-INADEQUATE correlation spectra ${ }^{210}$ resolve the chemical shifts of dynamic matrix polysaccharides in Arabidopsis cell walls. 
a high-pressure minerals
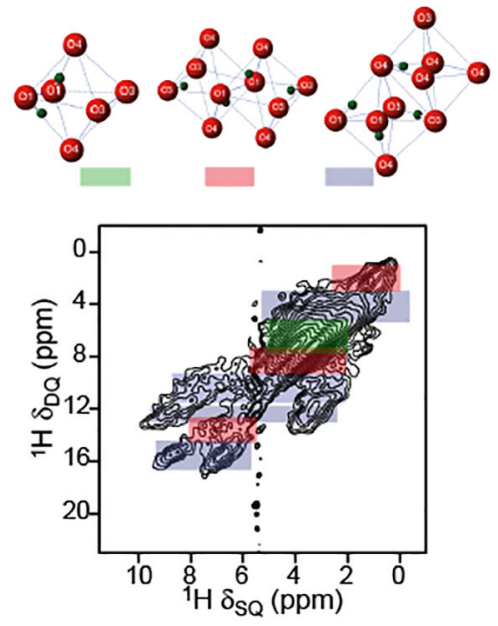

d

ceramics
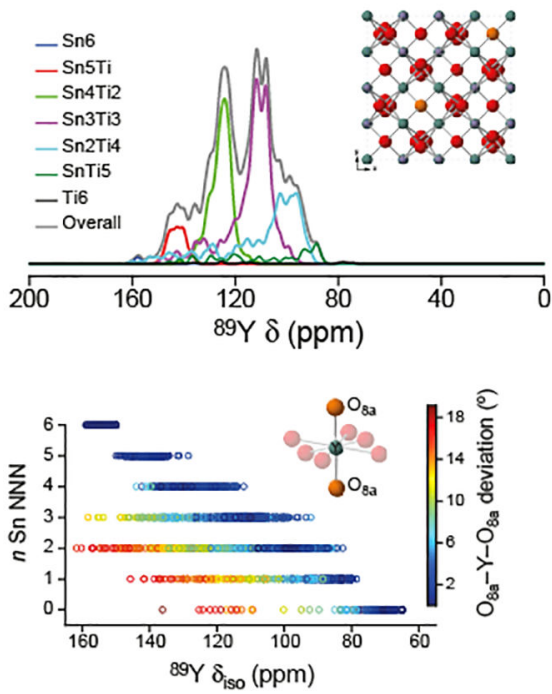

b microporous materials
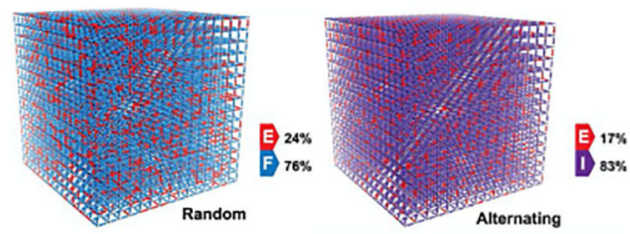

${ }^{13} \mathrm{C}\left\{{ }^{15} \mathrm{~N}\right\}$ REDOR curves
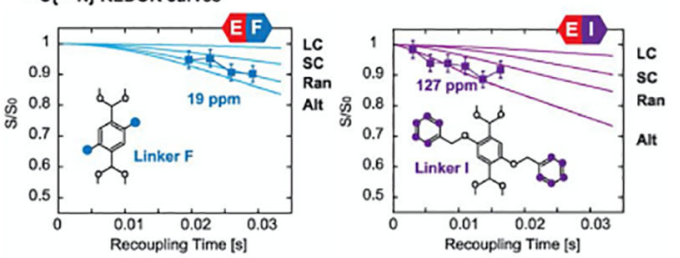

C catalysts
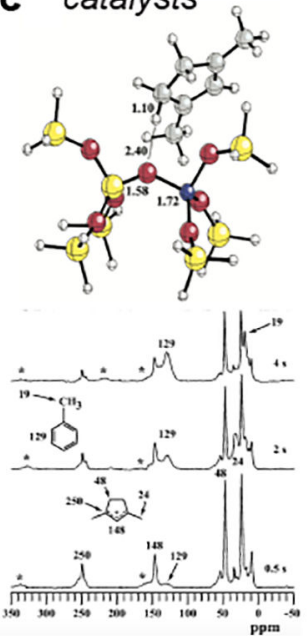

e

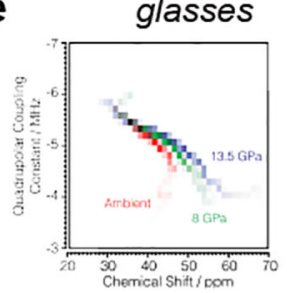

f energy materials
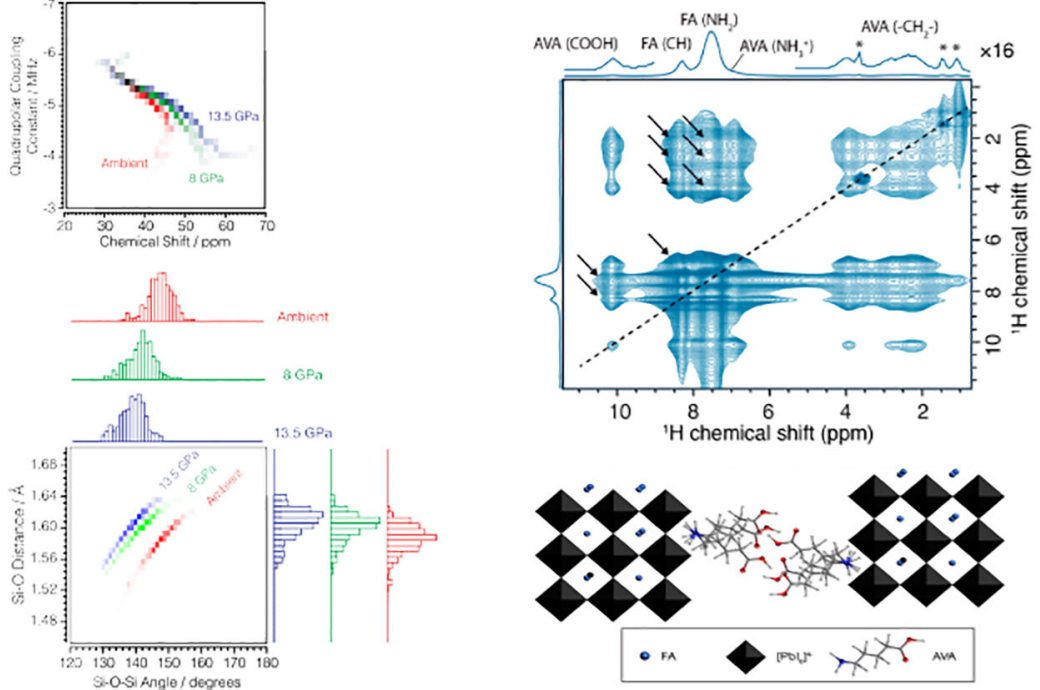

Fig. 5. Applications of solid-state NMR to materials chemistry.

(a) Prediction of the hydrous defects in wadsleyite, an inner Earth mineral found at depths of 400-600 km. Structure searching is used to predict possible structures for which NMR parameters are calculated using density functional theory (DFT), boxes in spectrum represent where structures (colours coordinate) were predicted. ${ }^{261}$. (b) Determination of the mesoscale structure of multivariate molecular organic frameworks (MOFs) containing linkers with different functional groups ${ }^{270} \cdot{ }^{13} \mathrm{C}-{ }^{15} \mathrm{~N}$ REDOR combined with molecular dynamics (MD) simulations allow the distinction of alternating cluster forms from random, small and large cluster forms. (c) ${ }^{13} \mathrm{C}$ CPMAS spectra of high-temperature reaction products of ethylene- ${ }^{13} \mathrm{C} 2$ on zeolite HZSM-5 catalysts beds ${ }^{320}$. The spectra elucidated the mechanism of methanol to hydrocarbon catalysis, establishing that methanol and dimethyl ether react on cyclic organic species contained in the cages or channels of the inorganic host. (d) Prediction of ${ }^{89} \mathrm{Y}$ NMR spectra of pyrochlores using ensemble-based modeling. NMR parameters of all possible cation arrangements are predicted using DFT and their 
Boltzmann-weighted contributions to the spectrum are then determined to obtain detailed information on the local geometry ${ }^{242}$. (e) Pressure induced evolution of the distributions of the $\mathrm{Si}-\mathrm{O}$ distances and $\mathrm{Si}-\mathrm{O}-\mathrm{Si}$ inter-tetrahedra bond angles in vitreous silica quenched from high pressure. 2D dynamic-angle-spinning ${ }^{17} \mathrm{O}$ NMR spectra show that with increasing pressure, the mean $\mathrm{Si}-\mathrm{O}-\mathrm{Si}$ bond angle decreases while the mean $\mathrm{Si}-\mathrm{O}$ distance increases 148. (f) Structure of inorganic-organic hybrid perovskites ${ }^{321}$. 5-ammonium valeric acid iodide was used to stabilize the structure of a-FAPbI3. MAS NMR in combination with DFT was used to determine the atomic-level structure. 

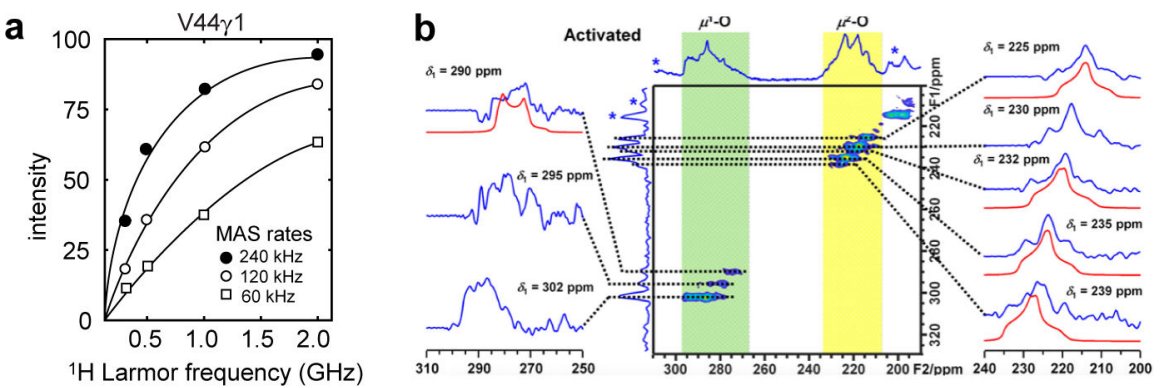

Fig. 6. Outlook for MAS solid-state NMR.

(a) Sensitivities of methyl ${ }^{1} \mathrm{H}$ resonances of a typical selectively methyl protonated protein (V44 $\gamma 1$ from a-spectrin SH3) as a function of magnetic field strength expressed as ${ }^{1} \mathrm{H}$ Larmor frequencies ${ }^{298}$. These sensitivities were measured at different MAS rates. (b) Quadrupolar NMR lineshapes of an ${ }^{17} \mathrm{O}$ enriched metal-organic framework measured using a $35 \mathrm{~T}$ series-connected hybrid magnet illustrate the potential of high magnetic fields ${ }^{322}$. Blue and red solid lines indicate experimental and simulated lineshapes, respectively. Areas on spectrum highlighted in green and yellow correspond to different ${ }^{17} \mathrm{O}$ nuclei. 
Table 1.

Commonly studied nuclei in solid-state NMR.

\begin{tabular}{|l|l|l|l|l|}
\hline Nuclei & $\begin{array}{l}\text { Spin quantum } \\
\text { number }\end{array}$ & $\begin{array}{l}\text { Natural abundance } \\
(\%)\end{array}$ & $\begin{array}{l}\text { NMR transition } \\
\text { frequency at 18.8 } \\
\text { Tesla (MHz) }\end{array}$ & Examples of Applications \\
\hline${ }^{1} \mathrm{H}$ & $1 / 2$ & 99.98 & 800 & Organic materials, proteins, lipids, energy materials \\
\hline${ }^{19} \mathrm{~F}$ & $1 / 2$ & 100 & 753 & $\begin{array}{l}\text { Organic materials, proteins, pharmaceutical compounds, } \\
\text { minerals }\end{array}$ \\
\hline${ }^{31} \mathrm{P}$ & $1 / 2$ & 100 & 324 & Phospholipids, nucleic acids, phosphate frameworks \\
\hline${ }^{7} \mathrm{Li}$ & $3 / 2$ & 92.6 & 311 & Lithium ion batteries \\
\hline${ }^{27} \mathrm{Al}$ & $5 / 2$ & 100 & 208 & $\begin{array}{l}\text { Aluminosilicate zeolites and minerals, phosphate } \\
\text { frameworks }\end{array}$ \\
\hline${ }^{13} \mathrm{C}$ & $1 / 2$ & 1.1 & 200 & $\begin{array}{l}\text { Organic and biological compounds, metal-organic } \\
\text { frameworks }\end{array}$ \\
\hline${ }^{29} \mathrm{Si}$ & $1 / 2$ & 4.7 & 159 & Zeolites, minerals, silica catalysts \\
\hline${ }^{2} \mathrm{H}$ & 1 & 0.015 & 123 & Water, carbohydrates, proteins, medicinal compounds \\
\hline${ }^{17} \mathrm{O}$ & $5 / 2$ & 0.037 & 108 & Water, carbohydrates, proteins, oxides, ceramics, catalysts \\
\hline${ }^{15} \mathrm{~N}$ & $1 / 2$ & 0.37 & 80 & $\begin{array}{l}\text { Proteins, nucleic acids, heterocyclic compounds, nitride } \\
\text { ceramics }\end{array}$ \\
\hline
\end{tabular}


Table 2.

Databases for the deposition of solid-state NMR results

\begin{tabular}{|c|c|c|c|c|}
\hline Database & Utility & Data type & Data Format & Entry requirements \\
\hline $\begin{array}{l}\text { Protein Data Bank (PDB) } \\
\text { (https://www.rcsb.org/) }\end{array}$ & $\begin{array}{l}\text { 3D structures of } \\
\text { molecules }\end{array}$ & $\begin{array}{l}\text { Macromolecular } \\
\text { structure }\end{array}$ & $\begin{array}{l}\text { PDB file format. } \\
\text { Pdb_extract can be } \\
\text { used to extract data } \\
\text { from your data file into } \\
\text { the PDB format. }\end{array}$ & $\begin{array}{l}\text { NMR depositions require one } \\
\text { coordinate file, one chemical shift } \\
\text { file, and at least one restraint file. } \\
\text { Depositors are also encouraged to } \\
\text { upload a peak list file. }\end{array}$ \\
\hline $\begin{array}{l}\text { Biological Magnetic } \\
\text { Resonance Bank (BRMB) } \\
\text { (https://bmrb.io/) }\end{array}$ & $\begin{array}{l}\text { Data from NMR } \\
\text { spectroscopy on } \\
\text { biomolecules }\end{array}$ & $\begin{array}{l}\text { NMR spectral } \\
\text { parameters, } \\
\text { Relaxation data, } \\
\text { kinetic data, } \\
\text { thermodynamic data }\end{array}$ & NMR-STAR & $\begin{array}{l}\text { When preparing a chemical shift } \\
\text { table for NMR structure } \\
\text { deposition, residue and atom } \\
\text { names need to match those in the } \\
\text { coordinates. }\end{array}$ \\
\hline $\begin{array}{l}\text { Inorganic Crystal Structure } \\
\text { Database (ICSD) (https:// } \\
\text { icsd.products.fiz- } \\
\text { karlsruhe.de) }\end{array}$ & $\begin{array}{l}\text { Atomic structure } \\
\text { of inorganic solids }\end{array}$ & $\begin{array}{l}\text { Atomic coordinates } \\
\text { of solids }\end{array}$ & $\begin{array}{l}\text { Crystallographic } \\
\text { information file (CIF) }\end{array}$ & $\begin{array}{l}\text { CIF containing formula, space } \\
\text { group, size and shape of unit cell } \\
\text { and atomic coordinates. } \\
\text { Information usually obtained from } \\
\text { diffraction, but often combination } \\
\text { of diffraction and NMR. }\end{array}$ \\
\hline $\begin{array}{l}\text { Cambridge Structural } \\
\text { Database (CSD) (https:// } \\
\text { www.ccdc.cam.ac.uk/ } \\
\text { solutions/csd-system/ } \\
\text { components/csd/) }\end{array}$ & $\begin{array}{l}\text { Small-molecule } \\
\text { organic and metal- } \\
\text { organic crystal } \\
\text { structures }\end{array}$ & Atomic coordinates & $\begin{array}{l}\text { Crystallographic } \\
\text { information file (CIF) }\end{array}$ & $\begin{array}{l}\text { CIF containing formula, space } \\
\text { group, size and shape of unit cell } \\
\text { and atomic coordinates }\end{array}$ \\
\hline
\end{tabular}

